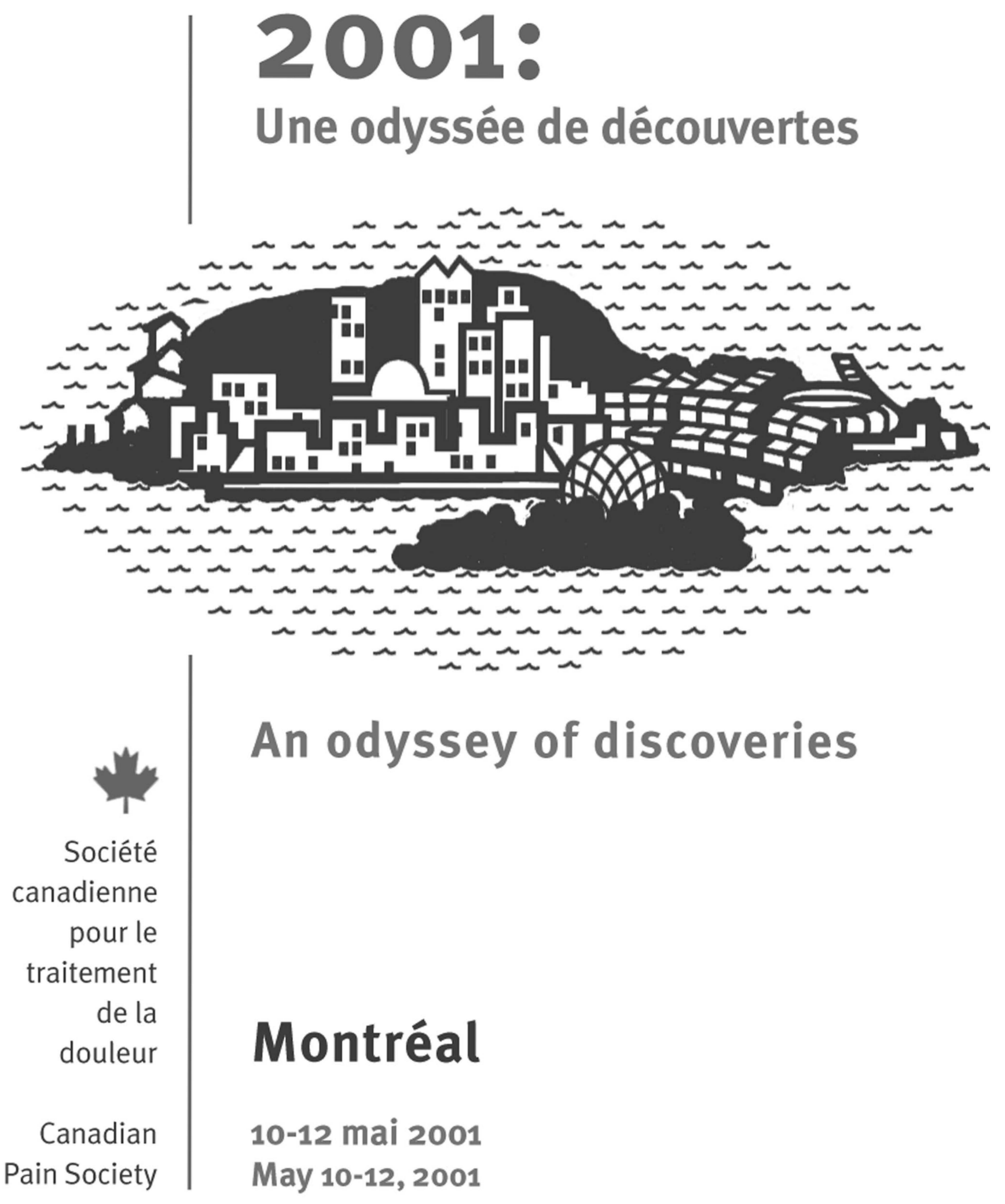




\section{Pain Research \& Management}

Spring 2001

Volume 6 Supplement A

Friday, May 11, 2001

Breakfast Session \#1 - An update on spinal cord stimulation therapy

6A

in chronic pain management

Keynote Address - L'analgésique idéal: espoirs et désillusions

6A

Plenary Session \#1 - Pain and brain imaging

6A

Symposium \& Lunch \#1 - Treatment and prevention of neuropathic pain

$7 \mathrm{~A}$

Concurrent Special Symposia \#1 - Update on pediatric pain

$7 \mathrm{~A}$

Concurrent Special Symposia \#2 - Update on cancer pain/palliative care

Concurrent Special Symposia \#3 - The delta opioid receptor -

A future non-opiate opiate therapy for pain?

Concurrent Workshop \#1 - Cancer pain management -

Results of an intervention study

Concurrent Workshop \#2 - Pain genetics from mouse to man:

$12 \mathrm{~A}$

Research perspectives

Concurrent Workshop \#3 - The sexual pain disorders:

13A

Is the pain sexual or is the sex painful?

Concurrent Workshop \#4 - Assessing pain in the communicatively

impaired elderly: The Parkridge Pain Assessment Tool

\section{Saturday, May 12, 2001}

Breakfast Session \#2 - Learning from our patients with chronic pain:

A doctor's benefit

Keynote Address - Tracing the course of substance $P$ and pain:

From cell to development of drugs

Plenary Session \#2 - Update on opioid therapy

Concurrent Special Research Symposia \#1 - Basic research: Ion channels 


\section{Pain Research \&Management}

Spring 2001

Volume 6 Supplement A

\section{Saturday, May 12, 2001}

Concurrent Special Research Symposia \#2 - Clinical research:

Evidence-based decision making for pain treatment

Lunch - Conference \#2 - The joy of caring

17A

Concurrent Workshop \#5 - The doctor's, family's and patient's

18A

point of view in chronic pain management - An ethical issue

Concurrent Workshop \#6 - Theoretical perspectives on the

psychology of pain

Concurrent Workshop \#7 - Progressive return to work as a

treatment modality in the multidisciplinary treatment of chronic pain

Concurrent Workshop \#8 - Pain in animals:

From the veterinarian's perspective

Concurrent Workshop \#9 - On the psychobiological basis

of "hysterical" anesthesia in chronic pain patients

Concurrent Workshop \#10 - Mechanisms of neuropathic

pain and its treatment

Concurrent Workshop \#11 - Establishing a multidisciplinary

chronic pelvic pain unit that meets the needs of women

Concurrent Workshop \#12 - Élaboration et implantation d'un programme de soulagement de la douleur auprès de personnes atteintes de cancer avancé suivies à domicile

Concurrent Workshop \#13 - Treating the chronic pain patient in an outpatient physiotherapy facility 
FRIDAY, MAY 11, 2001 - 07:00-08:00

BREAKFAST SESSION \#1

An update on spinal cord stimulation therapy in chronic pain management

Speaker: Line Jacques

Montreal Neurological Institute, Montreal, Quebec

Sponsored by Medtronic of Canada Ltd

FRIDAY, MAY 11, 2001 - 09:00-09:45

KEYNOTE ADDRESS

L'analgésique idéal: espoirs et désillusions

Keynote Speaker: Jean-Marie Besson

Unité INSERM 161 de recherches en physiopharmacologie du système nerveux, Paris, France

\section{Sponsored by Purdue Pharma}

\section{Presented by Ronald Melzack}

La découverte des récepteurs opioides et des enképhalines au début des années 70 laissait entrevoir la mise au point rapide de l'analgésique idéal. A la même époque, la substance $\mathrm{P}$ était une voie prometteuse qui s'est révélée très décevante. Les systèmes descendants sérotoninergiques et noradrénergiques ont connu leur heure de gloire. Aujourd'hui la liste des analgésiques "potentiels" est considérable, et les données récentes de la biologie moléculaire amplifient les espoirs de la mise au point de molécules plus efficaces. Cependant, à de rares exceptions près, les cliniciens ne disposent pas de nouvelles molécules très performantes. Les résultats des données expérimentales chez l'animal donnent souvent lieu à de conclusions hâtives, trop optimistes et parfois désarmantes. Il en résulte une certaine anarchie, et il est souvent difficile de s'y retrouver. Cette présentation évoquera rapidement les difficultés rencontrées pour passer de l'animal à l'homme, en tenant principalement compte des évaluations comportementales, des modèles expérimentaux utilisés et des voies d'administration de diverses substances supposées analgésiques. Il est vraisemblable qu'une meilleure compréhension des mécanismes physiopathologiques des différents types de douleur permettra une approche pharmacologique de plus en plus ciblée. Il n'en reste pas moins que les douleurs chroniques sont sous tendues simultanément et-ou progressivement par des mécanismes très variés faisant intervenir des composantes pharmacologiques complexes. Il en ressort que la mise au point de l'analgésique idéal reste très aléatoire et que l'on doit beaucoup plus s'orienter vers l'association de molécules ayant des modalités d'actions différentes, afin de favoriser leurs actions additives ou leurs synergies.

\section{FRIDAY, MAY 11, 2001 - 10:00-11:15 PLENARY SESSION \#1 \\ Pain and brain imaging}

Chairperson: Ronald Melzack

Department of Psychology, McGill University, Montreal, Quebec

FOCUS STATEMENT: Powerful brain imaging methods have evolved during the past decade. This session summarizes the current status of research using these methods to examine brain structures that are active when subjects experience pain that is experimentally induced or associated with chronic pain states. A conceptual framework aimed at integrating the available data is proposed.

EDUCATIONAL OBJECTIVES: This session will provide an understanding of the techniques used in functional brain imaging, the structures in the brain that are active during induced pain and clinical pain states, and will attempt to integrate the available data into a coherent conceptual framework.

ABSTRACT: Functional imaging techniques have revealed that pain experience in human subjects is associated with activity in a widespread network of structures in the brain. Primary and secondary somatosensory cortices, the anterior cingulate cortex, the insular cortex, and the prefrontal cortex are reliably activated when subjects experience pain. All or most of this network is active when pain is induced by widely varying forms of noxious stimulation and is produced by clinical pain states associated with various pathologies. It is commonly agreed that the active structures subserve the sensory, affective, cognitive and motor components of pain experience and aversive drive. Furthermore, this pain-associated activity pattern is modulated by cognitive factors such as attention and distraction. The speakers will describe the relative merits of different approaches in imaging studies, such as different types of noxious stimuli, stimulation of somatic versus visceral systems, and different forms of data analysis in individuals and groups. The consistency and reliability of the active, widespread brain network suggests that each of the multiple dimensions of pain experience is associated with activity in a particular set of brain structures. However, the evidence of parallel activity among the structures reveals a broader unified, overlapping system which underlies the unity of perceptual experience.

Speaker 1

\section{HUMAN BRAIN IMAGING TO STUDY FOREBRAIN MECHANISMS OF NORMAL AND ABERRANT PAIN STATES}

M Catherine Bushnell

Department of Anesthesia, McGill University Hospital Center, Royal Victoria Hospital, Montreal, Quebec

Pain is a complex experience that includes sensory, emotional, autonomic and motoric components, and each of these components can differ among various pain states. Despite the many qualitative differences of clinical and experimental pain states, they all share a common aversive nature, leading us to characterize each as "pain." This talk will present evidence showing a common cortical net- 
work that, when activated, leads to the perception of pain. Activation of this circuit can result from direct stimulation of peripheral nociceptors or from the disruption of endogenous modulatory circuits in the CNS that allows normally nonpainful stimuli to access the cortical pain system. Using positron emission tomography (PET) and functional magnetic resonance imaging (fMRI), we find that a network of cortical regions is reliably activated by experimental pain and chronic clinical pain states, including the primary and secondary somatosensory cortices (S1 and S2), the anterior cingulate cortex (ACC) and the insular cortex (IC). This network is activated during pain produced by stimuli as divergent as cutaneous heat, visceral pain produced by esophageal distension, or tactile allodynia produced by capsaicin application. Our imaging data show that allodynia related to peripheral or CNS damage activates the same cortical pain system as that activated during acute pain states. Other experiments suggest that these various cortical regions have a differential role in processing the sensory and affective dimensions of pain. Experimental manipulations that selectively alter the affective component of pain predominantly modulate activity in ACC, whereas those that alter the sensory component of pain modulate activity in the other cortical regions, particularly S1 cortex. Finally, whether the cortical areas are activated by experimental pain or by aberrant clinical pain states, the pain-evoked activation can be modulated by cognitive factors, such as direction of attention.

\section{Speaker 2}

\section{THE DETERMINANTS OF PAIN REVISITED: ANALYSIS THROUGH FUNCTIONAL IMAGING}

\section{Kenneth L Casey}

Neurology Service, Veterans Administration Medical Centre, Ann Arbor, Michigan

Functional brain imaging provides an opportunity to identify and analyze the neurophysiological mechanisms that mediate pain. In response to an invitation (Fields, 1999) to reconsider a conceptual framework for pain research (Melzack and Casey, 1968), we identify three critical psychological dimensions of sensory experience that define pain and related sensory experiences: sensory salience, affect, and motivational dominance. We show that each of these dimensions can be measured and is mediated by a specific neurophysiological mechanism. We propose that pain emerges from the conjoint action of these neurophysiological systems and falls within specific coordinates of a three dimensional sensory surface that they form. We present evidence that these mechanisms can be identified in functional imaging studies. Thus, one set of brain structures encodes salient physical features of noxious stimuli. A second set, active primarily during inflammation, mediates affective tone and has relatively little effect on perceived pain intensity. A third set of structures mediates the behavioral response by interacting with these two systems and providing a contextually dependent modulation of each of them. Functional brain imaging studies have yet to provide an unchallenged identification of each of these neurophysiological sets, in part because it is likely that some individual components of each are shared. However, this goal can be achieved through functional imaging (broadly defined) and within the current, slightly revised, conceptual framework pre- sented here. Our understanding of pain mechanisms would benefit by studying the physiology of these fundamental sensory dimensions in pain and other sensations.

\section{Speaker 3}

\section{FMRI OF PAIN: AN UPDATE}

Karen D Davis

Department of Neurosurgery, Toronto Western Hospital, University Health Network, Toronto, Ontario

Evidence from electrophysiological, anatomical, behavioral, and other imaging technologies (PET, MEG) support a role for several cortical areas in the various aspects of pain. These areas include the primary and secondary somatosensory cortex (S1, S2), insula, anterior cingulate cortex (ACC) and prefrontal cortex (PFC). However, the role of these areas in various types of painful experiences (hot, cold, aching, etc.,) are not completely understood. Modern brain imaging technologies have been adopted for the study of such pain mechanisms. In particular, functional magnetic resonance imaging (fMRI) has rapidly developed into a valuable tool for the study of cortical mechanisms underlying both acute and chronic pain. fMRI has the capability to examine brain responses in individual subjects, with good spatial and temporal resolution. This presentation will review the special technical issues related to fMRI pain studies and data from fMRI studies of different types of pain. Several approaches will be discussed including 1) the use of different types of noxious stimuli, 2) stimulation of somatic versus visceral systems, 3) analysis in individual subjects versus group responses, 4) correlations to subject pain ratings, and 5) time course analysis. These data will illustrate the importance of combining studies of common (i.e. group) versus unique (i.e. individual) aspects of the pain experience.

\section{FRIDAY, MAY 11, 2001 - 11:45-12:45 SYMPOSIUM \& LUNCH \#1 Treatment and prevention of neuropathic pain}

Robert Dworkin

Department of Anesthesiology, University of Rochester School of Medicine and Dentistry, Rochester, New York

\section{Sponsored by Pfizer Canada}

\section{FRIDAY, MAY 11, 2001 - 13:15-14:45 CONCURRENT SPECIAL SYMPOSIA \#1 Update on pediatric pain}

\author{
Chairperson: C Celeste Johnston \\ School of Nursing, McGill University, Montreal, Quebec
}

\section{Sponsored in part by Elsevier}

Current unresolved issues in pain in children are many, but of pressing concern is how to assess pain in special populations of 
children and infants as well as how to appreciate the consequences of pain in infants and young patients who cannot self-report.

At the conclusion of the session participants will:

1) Have an algorithm to determine best means of assessing pain in infants

2) Have an understanding of ways of assessing pain in cognitively impaired children

3) Have an appreciation of the consequences of untreated pain in infants and understand the possible underlying mechanisms for these consequences

Making decisions about clinical care of pain in nonverbal children can be challenging. For infants who are non-verbal due to their early developmental stage, there is an overwhelming number of measures to choose from and selecting the most appropriate one is challenging. Dr. Stevens will begin the session by reviewing the best assessment tools for pain in infants in terms of psychometric properties followed by the presentation of an algorithm to assist in the selection of the best measure.

Not all children who are non-verbal are infants. Many children who are hospitalized are cognitively impaired and their communication of pain is difficult to interpret. Dr. McGrath will present the challenges and the most recent research on this topic.

Clinicians are only beginning to appreciate the consequences of not treating pain adequately in non-verbal pediatric patients. Dr. Anand will present empirical evidence of long-term sequellae to non-treated or poorly treated pain as well as discuss the mechanisms underlying the consequences. Finally, he will present possible new treatment approaches that are a result of basic research in pain in the developing human.

\section{Speaker 1}

\section{THE EFFECTS OF UNTREATED PAIN IN THE DEVELOPING HUMAN: UNDERLYING MECHANISMS AND POTENTIAL TREATMENTS}

\section{Kanwalijeet $S$ Anand \\ Department of Critical Care Medicine, Arkansas Children's Hospital, Little Rock, Arkansas}

There is mounting evidence of the long term effects of untreated pain in the developing human. From earlier studies it was observed that inadequately treated pain following major thoracic surgery lead to increased morbidity and even mortality. More recent research has used observational data from human neonates during their NICU stay. Based on those correlational studies, it can be hypothesized that there may be important developmental sequellae to untreated pain these infants endure. This hypothesis can be tested using animal models in which manipulation of pain can be controlled. Furthermore, studies of the mechanisms underlying the long term effects of pain can be determined. The understanding of these basic mechanisms may lead to specific interventions that can be tested for efficacy and safety. Recent results and projected studies will be presented.
Speaker 2

\section{ACUTE PAIN IN INFANTS - BEST ASSESSMENT AND MANAGEMENT PRACTICES}

\author{
Bonnie J Stevens \\ Faculty of Nursing, University of Toronto, Toronto, \\ Ontario
}

Assessment is the cornerstone of optimal pain management. Over the past decade, approximately two dozen pain assessment measures have been developed for the assessment of acute procedural and post-operative pain in term and preterm neonates and infants. Of these, several measures have been well established as valid and reliable for use in research. However, the challenge facing practitioners is to find a pain measure that is, not only psychometrically sound, but also feasible and clinically useful. To assist with this dilemma, a decision-making algorithm for infant pain assessment is proposed. This algorithm is based on the intended purpose for the pain assessment which can be delineated in terms of clinical, research or a combination of clinical and research activities.

Once pain is adequately assessed, a multidimensional approach is required to either eliminate pain or to achieve optimal pain management. Nonpharmacologic strategies (more appropriately labeled as behavioral, environmental, cognitive, physical and nutriceutical) should form the basis for all pain management. In addition, appropriate pharmacologic interventions administered systemically or peripherally should be considered for all painful events. A summary of the most recent research incorporating these modalities will be addressed and evidence-based guidelines will be presented.

\section{Speaker 3}

\section{PAIN IN COGNITIVELY IMPAIRED CHILDREN}

Patrick J McGrath

Department of Psychology, Dalhousie University, Halifax, Nova Scotia

Children who have significant cognitive impairment have been ignored in the pain literature. These children are at high risk for poorly managed pain because of their underlying problems, behavior that may be misunderstood, and beliefs that these children are insensitive to pain.

Recent data on attitudes to pain in this population by professionals and caregivers reveal that caregivers believe that cognitively impaired children do not differ in their sensation of pain but do have major differences in behavior and communication of pain. The picture with professionals is less clear.

In the last 5 years, several groups have begun to develop pain measures for this population. The reliability, validity and useability of measures of pain in this population have been evaluated in studies of everyday pain, procedure pain and postoperative pain. Different measures and supporting data will be reviewed.

The correlates of chronic pain in cognitively impaired children may provide us with a better understanding of their pain. However, our knowledge base is limited.

Finally, an algorithm for pain management in this population that 
is being developed by a national, cross-disciplinary group will be discussed.

EDUCATIONAL OBJECTIVE: To develop an understanding of the measurement and assessment of pain in children who have severe cognitive and physical impairment

\section{FRIDAY, MAY 11, 2001 - 13:15-14:45 CONCURRENT SPECIAL SYMPOSIA \#2 Update on cancer pain/palliative care}

\author{
Chairperson: S Robin Cohen \\ Department of Oncology, McGill University Health Center, \\ Royal Victoria Hospital, Montreal, Quebec
}

\section{Sponsored by Purdue Pharma}

This symposium will cover topics that are critical to the treatment of cancer pain but which are not typically the focus of presentations on cancer pain. The presentations will describe how to do a thorough multi-dimensional assessment of cancer pain, management of opioid side effects, and evaluation of pain services created to serve minority and medically underserved communities.

At the conclusion of this symposium, participants will better understand how to:

- Take a history and perform a physical exam that will lead to proper diagnosis and treatment of cancer pain

- Control cancer pain with opioids while minimizing side effects

- Evaluate pain services created for populations that are traditionally more difficult to reach

It is estimated that over 132,000 Canadians were diagnosed with cancer in the year 2000, and the number of new diagnoses continues to grow each year. Pain related to cancer or its treatment affects $50-90 \%$ of people with a cancer diagnosis. For those whose cancer cannot be cured, the fear of cancer pain is often greater than the fear of death itself, and can lead to despair and requests for euthanasia or physician-assisted suicide if the pain is not properly controlled. For cancer pain to be properly controlled, the patients must have access to and be comfortable with a health care service that is knowledgeable about diagnosing and assessing cancer pain, as well as management of opioid side effects. Without attention to access, even in developed countries part of the population suffers unnecessarily from cancer pain. Without an understanding of the complexities of cancer pain and how to thoroughly assess contributing factors, pain management will not be optimal, also resulting in unnecessary suffering. Opioid side effects can be a source of suffering on their own. Without proper management, side effects can result in patients losing their ability to live their lives as fully as possible. Others will choose to suffer from the cancer pain rather than endure the opioid side effects. Each of these aspects of providing optimal care for cancer pain is complex, and the speakers will define the problems encountered as well as various solutions.
Speaker 1

Richard Payne

Department of Neurology, Memorial Sloan-Kettering Cancer

Center, New York, New York

(Abstract not provided)

Speaker 2

THE ASSESSMENT AND MANAGEMENT OF OPIOID SIDE EFFECTS

Eduardo Bruera

Department of Symptom Control \& Palliative Care UT/MD

Anderson Cancer Center, Houston, Texas

Opioid analgesics are the most effective agents for the treatment of severe pain. In recent years increased education of health care professionals has resulted in earlier use of opioids and higher dosages than ever before. This increased opioid use has considerably improved pain control in a number of populations, including cancer patients. On the other hand, it poses, for health care professionals, the challenge of appropriately diagnosing and managing the main side effects. Among the traditional side effects of opioids nausea, sedation, and constipation are common. Sedation and nausea usually disappear within a few days of continued opioid exposure. In a minority of cases chronic use of anti-emetics or psycho-stimulants such as methylphenidate may be required for persistent sedation. Constipation requires continued attention to frequency and size of bowel movements and chronic laxative therapy. Recent evidence suggests that the frequency of side effects is different according to the type of opioid and sometimes also the route of administration. Opioid rotation may be an effective way of controlling serious side effects. In recent years emerging side effects include opioid induced neurotoxicity including delirium, hallucinations, generalized myoclonus and hyperalgesia. These side effects are observed more frequently in patients exposed to high dosages for prolonged periods of time, with renal failure, previous borderline cognitive function, dehydration, or those receiving other psycho-active drugs. These side effects are probably related to both parent compounds as well as active metabolites and are caused by a combination of opioid receptor plus non-opioid effects. Effective management strategies include opioid rotation, hydration, discontinuation of other drugs, and the use of opioids with reduced cross-tolerance such as methadone. Perhaps the main advance has been the increased ability of clinicians to diagnose these neuro-toxicities as opioid related, and therefore potentially reversible, instead of being interpreted as a manifestation of the underlying malignancy. 


\section{Speaker 3}

\section{PAIN DIAGNOSIS IN PALLIATIVE CARE}

\author{
Neil A Hagen \\ Department of Clinical Neuroscience, University of Calgary, \\ Calgary, Alberta
}

Palliative care patients with pain need comprehensive assessment in order for the clinician to construct an effective analgesic strategy. A great deal is known about validated methods to obtain a pain history, past medical history, psychosocial evaluation and other aspects of a palliative patient's current and past experience. While various aspects of the pain physical examination have been validated, the value of screening maneuvers that reproduce a palliative patient's pain on physical examination have been less well defined. Once a detailed history and physical examination have been performed, a hypothesis about the mechanisms of the underlying experience of pain can be developed, and efforts undertaken to identify the pain sensitive structure. Comprehensive patient assessment can reveal insight as to whether the pain is due to the patient's underlying disease processes, due to side-effects of medical treatment the patient has received, or due neither to the disease nor to the treatment. Commonly, palliative care patients have pain that is best characterized using a multidimensional model rather than a strict biomedical model.

In this presentation, details of how to take pain history, perform a pain physical examination and construct a multidimensional pain diagnosis will be reviewed. Practical approaches to difficult to diagnose pain situations will be presented.

\section{FRIDAY, MAY 11, 2001 - 13:15-14:45 CONCURRENT SPECIAL SYMPOSIA \#3 The delta opioid receptor - A future non-opiate opiate therapy for pain?}

\author{
Chairperson: Martin Perkins \\ AstraZeneca Research and Development Montreal, \\ Montreal, Quebec
}

\section{Sponsored by AstraZeneca R\&D Montreal}

FOCUS STATEMENT: This symposium will focus on the delta opiate receptor as a target for the development of novel analgesics. The presentations will cover basic mechanistic studies using mu and delta receptor 'knock-out' mice aimed at understanding the physiological role of these two receptors as well as pharmacological studies in primates evaluating the effectiveness of delta receptor agonists as anti-nociceptive agents. In addition, there will be presentations from pharmaceutical companies with a major interest in delta opiate receptors describing recent progress in developing highly selective, non-peptide delta opiate receptor agonists as potential therapeutic agents.

EDUCATIONAL OBJECTIVES: In this symposium, participants will learn about:

- Delta opiate receptor mechanisms in nociception.

- How genetically modified animals and pharmacological and physiological studies in primates have helped clarify the role of the mu and delta opiate receptor.

- Recent advances in the development of non-peptide delta agonists as potential novel analgesics.

ABSTRACT: The clinical use of strong analgesics have long been dominated by the opiate morphine and its related compounds. When administered acutely, opiates produce powerful analgesia, however, their chronic use is often severely limited by significant side-effects such as constipation, respiratory depression, confusion and the risk of physical dependency. Such narcotic analgesics all share the same basic mechanism, namely, activation of the mu opioid receptor. Recent studies, however, have suggested that the delta opioid receptor may also have a role in modulating nociception. Genetic studies in mice lacking the mu, delta or kappa opioid receptor have clearly demonstrated that morphine produces analgesia via the mu opioid receptor, confirming pharmacological studies. These genetic studies have also demonstrated that the adverse side-effects seen with morphine are also mediated through the mu opioid receptor. The availability of selective, potent peptide and non-peptide ligands for the delta opioid receptor has also allowed a pharmacological dissection of the relative roles of the opioid receptors in nociception. In addition to several studies in rodents, recent studies in the primate have shown that selective delta receptor agonists reduce capsaicin-induced thermal hypersensitivity, a model which involves mechanisms of peripheral and central sensitisation of nociceptors believed to exist in man. Studies such as these have helped establish a rationale for pharmaceutical companies to explore the possibility of developing selective delta receptor agonists as potential analgesics comparable to morphine in efficacy but devoid of the limiting side-effects. Two approaches will be presented in this symposium from two major pharmaceutical companies working in this field. Significant advances have been made in developing highly potent, selective non-peptide delta receptor agonists increasing the prospect of a novel therapeutic analgesic being available in the clinic within a few years.

\section{Speaker 1}

\section{GENETIC APPROACH TO REVISIT MU AND DELTA OPIOID RECEPTORS AS THERAPEUTIC TARGETS FOR PAIN TREATMENT}

Brigitte Kieffer

Professor at University Louis Pasteur, Strasbourg, France

Despite tremendous efforts in the search for safe, efficacious and non-addictive opioids for pain treatment, morphine remains the most valuable pain killer in contemporary medicine. Opioids exert their pharmacological actions through three opioid receptor classes, mu, delta and kappa (1) whose genes have been cloned recently (1). Genetic approaches are now available to redefine the molecular targets of classical opiate drugs in vivo and to delineate the contribution of each receptor in opioid physiology. We have produced mice lacking the MOR, KOR and DOR genes by homologous recombination. Our results indicate that lack of mu-receptors causes abolition of morphine-induced analgesia, place preference and physical dependence, as well as morphine respiratory depression and immunosuppression. These results demon- 
strate that the MOR gene product is the major molecular target for morphine activity in vivo and demonstrate that mu receptors are essential in mediating both desired and adverse effects of the prototypal opiate (rev. in (2)). Pharmacological studies using delta opioids suggests low in vivo selectivity for prototypal compounds under classical experimental conditions. Finally, we have compared behavioral responses of mutant mice in several models of anxiety and depression (3). Our data show opposing phenotypes in MOR-/- and DOR-/- mutants, which contrasts with the classical notion of alike activities of mu- and delta receptors. They also show consistent anxiogenic- and depressive-like responses in DOR-/mice, indicating that delta receptor activity contributes to improve mood states. Altogether, the data from knockout mice suggest that more selective delta compounds need to be developed and some aspects of delta receptor activity deserve further exploration.

1. B. L. Kieffer (1995) Cell. Mol. Neurobiol. 15, 615-635.

2. Kieffer B. L. (1999) Trends Pharmacol. Sci. 20, 537-544.

3. Filliol D., et al. (2000) Nature Genetics 25, 195-199

\section{Speaker 2}

\section{TWO SERIES OF POTENT AND EXCEPTIONALLY SELECTIVE, NONPEPTIDIC $\delta$ OPIOID RECEPTOR AGONISTS DEMONSTRATE POTENTIAL AS CANDIDATE DRUGS FOR PAIN}

$C$ Walpole, N Plobeck, Z-Y Wei, D Delorme, W Brown, B Takasaki, $H$ Yang, P Jones, L Gawell, R Schmidt, S-Y Yue, P Schwarz, K Payza, S St-Onge*, M Labarre*, J Butterworth*, J Ducharme*; P-E Morin*, D Projean*,

T-M Tu*, Daniel Menard*, Martin Perkins*, E Roberts* Department of Chemistry, AstraZeneca R\&D Montreal, SaintLaurent, Quebec, and *Department of Pharmacology, AstraZeneca R \& D Montreal, Montreal, Quebec

Non-peptide $\delta$ opioid agonists have potential as novel analgesics with an improved side-effect and abuse liability profile, compared to classical opioids. Simplification of the NIH non-peptide lead SNC-80, by removal of substituents not predicted to contribute to binding, led to ARM250 which had lower molecular weight and had fewer metabolically labile groups, but retained full biological activity. From this lead, key pharmacophores for delta receptor affinity and activation were defined by SAR and mutagenesis studies. SAR of two chemical classes of delta agonists which resulted from optimisation of this lead, the piperazine and olefinic piperidine classes, will be described. An example of the former class, the piperazine AR-M575, shows delta receptor-mediated anti-allodynia in a number of rodent pain models. Activity of this compound in a monkey model will be presented by Steve Negus. One example of the second class, the olefin ARM 390, is the most selective delta agonist known to us and so demonstrates that truly selective agonists are indeed effective anti-allodynic agents. In addition, AR-M390 has excellent DMPK attributes as a candidate oral drug and orally is active in chronic pain models.
Speaker 3

\section{EFFECTS OF DELTA OPIOID AGONISTS ON CHEMICALLY-INDUCED THERMAL HYPERSENSITIVITY IN RHESUS MONKEYS}

\author{
S Stevens Negus \\ McLean Hospital, Harvard Medical School, \\ Belmont, Massachusetts
}

The effects of SNC80 and other structurally related delta opioid receptor agonists were assessed under conditions of chemicallyinduced hypersensitivity to thermal stimuli in rhesus monkeys. The shaved tail of each monkey was exposed to warm water (38, 42,46 and $50^{\circ} \mathrm{C}$ ), and the tail-withdrawal latency from each temperature was recorded. The effects of drugs on the temperature that produced a 10 -sec tail-withdrawal latency (the $T_{10}$ value) were examined. Capsaicin (0.01-0.32 mg) injected into the tail of monkeys dose-dependently decreased the $\mathrm{T}_{10}$, indicating that capsaicin increased sensitivity to thermal stimuli. A dose of $0.1 \mathrm{mg}$ of capsaicin decreased the $\mathrm{T}_{10}$ from $48.0^{\circ} \mathrm{C}$ to $42.1^{\circ} \mathrm{C}$ (a $-5.9^{\circ} \mathrm{C}$ change) 15 -min after injection. SNC80 (1.0-10.0 mg/kg s.c.) dose-dependently blocked the capsaicin-induced decrease in the $\mathrm{T}_{10}$, and $10.0 \mathrm{mg} / \mathrm{kg}$ SNC80 fully blocked the effects of capsaicin. The delta-selective antagonist naltrindole $(0.1-1.0 \mathrm{mg} / \mathrm{kg})$ dosedependently antagonized the effects of SNC80, whereas a muselective dose of the opioid antagonist quadazocine $(0.1 \mathrm{mg} / \mathrm{kg})$ did not. Two other delta-selective agonists, SNC162 (1.0$10.0 \mathrm{mg} / \mathrm{kg}$ ) and SNC243A (1.0-10.0 mg/kg), also dose-dependently blocked capsaicin-induced thermal hypersensitivity. In contrast, SNC67 (10.0 mg/kg), the (-)-enantiomer of SNC80, and the non-steroidal anti-inflammatory drug (NSAID) ketorolac (1.0$10.0 \mathrm{mg} / \mathrm{kg}$ ) did not modify the effects of capsaicin. SNC80 was also effective in reversing thermal hypersensitivity induced by prostaglandin $\mathrm{E}_{2}(0.0158 \mathrm{mg})$ and Freund's complete adjuvant (10\% FCA concentration). These findings suggest that delta-agonists have antinociceptive effects in primates under conditions of chemically-induced thermal hypersensitivity and might be effective under a broader range of conditions than clinically available NSAIDs.

\section{Speaker 4}

\section{THE DELTA-OPIOID RECEPTOR IN HYPERALGESIC CONDITIONS: IDENTIFICATION AND PRE-CLINICAL EVALUATION OF NOVEL PYRROLOMORPHINANS}

\section{Giulio M Dondio, Department of Medicinal Chemistry Smithkline Beecham SpA, Milan, Italy}

The modulation of the opioidergic system has represented for centuries one of the most powerful pharmacological treatment for pain relief. However, drugs like morphine which activate the mu-opioid receptor, elicit a plethora of side effects including respiratory depression, constipation and physical dependence. On the other hand, also the brain penetrant kappa-opioid agonists did not show a suitable therapeutic window in view of their strong dysphoric, psycotomimetic and diuretic effects. Animal models indicated that selective delta-opioid receptor agonists have antinociceptive properties without any of the major 'narcotic' side effects, therefore 
representing a valid therapeutic target for the development of safe pain relief agents.

The rational design, SAR and pharmacological profile of compounds belonging to a novel and promising class of potent and selective delta-opioid agonists, the pyrrolomorphinans, will be disussed. SB 235863 emerged as a tool for proof-of-concept studies in animal models being a potent and selective delta-opioid agonist (Ki $\delta=6 \mathrm{nM}$; with $\mu / \delta$ and $\kappa / \delta$ selectivity greater than 200 -fold). In the rat carrageenan-induced hyperalgesia model, SB 235863 given orally increased latencies to the thermal stimulus in a doserelated fashion with a potency comparable to that of morphine. Similarly, in a rat model of established neuropathic pain (Seltzer test), SB 235863 also showed dose-related antihyperalgesic activity. Furthermore, SB 235863 did not show propensity to induce tolerance, withdrawal symptoms and abuse potential after chronic administration. The pharmacological profile of other representative compoundscongeners will be discussed to reinforce the potential of the delta-opioid agonist as safe and effective antihyperalgesic agents in inflammatory and neuropathic pain conditions.

\section{FRIDAY, MAY 11, 2001 - 16:00-17:15 CONCURRENT WORKSHOP \#1 Cancer pain management - Results of an intervention study}

\section{Speaker 1}

Christine Miaskowski

Department of Physiological Nursing, University of California, San Francisco, California

(Abstract not provided)

\section{FRIDAY, MAY 11, 2001 - 16:00-17:15 CONCURRENT WORKSHOP \#2 Pain genetics from mouse to man: Research perspectives}

\author{
Chairperson: William R Larivière \\ Genetics of Pain Lab, Department of Psychology, University of \\ Illinois, Champaign, Illinois
}

FOCUS STATEMENT: The workshop will present several key findings from animal and human studies of the genetics of pain, and introduce pain researchers to the methods used in the studies.

EDUCATIONAL OBJECTIVES: Attendents will become familiar with the type of evidence derived from genetic studies of pain phenomena, and will obtain some notion of how the animal studies relate to the human studies, and the basic research to the understanding and management of patients' pain.

It has long been recognized that individual differences exist in pain responses to identical laboratory stimuli or to similar injuries in the clinic. However, only recently has the role of genetic factors in this variability been studied systematically. In this workshop, the speakers will present key findings from studies of the genetics of pain sensitivity, analgesic mechanisms, and the heritability of chronic pain syndromes.

Dr. Greg Elmer will present data from inbred mouse strain surveys that demonstrate the heritability of sensitivity to painful stimuli and to opiate analgesia. Using the method of genetic correlation analysis, he will examine the correlations among pain sensitivity, the potency of opiate analgesia, and the efficacy of morphine analgesia against stimuli of increasing intensities. He will also present evidence that opiate analgesia is mediated by different subtypes of opiate receptor in different strains of mice, and will show how this receptor selectivity is related to the potency and efficacy of morphine.

Dr. Bernard Brais will review data from human studies of hereditary sensory and autonomic neuropathies. He will present evidence for specific gene mutations underlying a subtype of these pain syndromes, and will present linkage analysis mapping studies which have shown inheritance of these pain syndromes to be linked to specific chromosomal loci. In addition, his presentation will demonstrate that the genetic methods provide knowledge that is not restricted to the particular syndromes, further elucidating the basic mechanisms of the peripheral sensory nervous system.

The implications of these findings for pain management and the direction of future research will be discussed.

\section{Speaker 1}

\section{THE ROLE OF GENOTYPE IN PAIN SENSITIVITY AND IN THE EFFICACY AND RECEPTOR SELECTIVITY OF OPIOID ANALGESIA}

Gregory I Elmer

Maryland Psychiatric Research Center, University of Maryland School of Medicine, Baltimore, Maryland

Individual differences exist in pain sensitivity, the potency of morphine to produce a given degree of pain relief and the efficacy of morphine to relieve severe pain. Heritable factors play a significant role in all three endpoints: nociception, potency and efficacy. These conclusions are based upon the following experimental paradigms.

NOCICEPTION: The relative sensitivity of eight inbred mouse strains to a range of thermal stimulus intensities was determined. Linear interpolation of stimulus-effect curves revealed large genotype-dependent differences in the temperature resulting in similar latencies on the hot-plate.

POTENCY: Morphine dose-response curves at a fixed stimulus intensity were determined. Linear interpolation of the dose-effect curves revealed large genotype-dependent differences in the dose of morphine resulting in an equivalent degree of analgesia.

EFFICACY: Morphine's analgesic efficacy was determined by assessing the effectiveness of equi-analgesic doses of morphine to maintain antinociceptive efficacy against increasing stimulus intensities. Linear interpolation of the stimulus-response curve revealed large genotype-dependent differences in the efficacy to which morphine maintained its antinociceptive effect. Genetic correlations across these endpoints suggest that there is an inverse correlation between innate nociception and potency while there is no correlation between the potency and efficacy of morphine as an analgesic. Antagonist studies with $\mu, \delta$ and $\kappa$ antagonists reveal 
genotype-dependent differences in agonist selectivity. Genetic correlations with antagonist dose-ratios suggest that $\mu$-selectivity may be more involved with potency while $\delta$-selectivity may be more involved with efficacy. Overall, these studies highlight the significant role that genotype may play in pain sensitivity and pain management.

\section{Speaker 2}

\section{THE GENETICS OF HEREDITARY SENSORY AND AUTONOMIC NEUROPATHIES}

\section{Bernard Brais}

Institut interuniversitaire de recherches sur les populations, Centre de recherche du Centre hospitalier de l'Université de Montréal, Montréal, Quebéc

Hereditary sensory neuropathies are a genetically heterogenous group of diseases. They were longer to yield to positional cloning strategies than mixed motor and sensory neuropathies. The scarcity of families was largely responsible for this delay. However, during the past seven years, the loci for Hereditary Sensory and Autonomic Neuropathies (HSAN) type I and III were mapped and the mutated gene in type IV was identified. The 9q31-q33 chromosomal locus for recessive HSAN-III (MIM 223900, Familial dysautonomia or Riley-Day syndrome) was identified using linkage analysis. In this disease, it is the autonomic system dysfunction that predominates. This condition is only observed in children of Ashkenazi Jewish descent. In 1996, the locus for dominant HSANI was mapped to chromosome 9p22.1-q22.3 (MIM 162400). The same year the mutated gene for HSAN-IV (MIM 256800, Congenital insensitivity to pain with anhidrosis, CIPA) was identified. Mutations were found in the human homologue of the neurotrophic tyrosine kinase receptor type 1 (NTRPK1) gene (1q21q22) deleted in mice insensitive to pain with anhidrosis. These observations suggest that the Nerve Growth Factor-TRPK system plays a crucial role in the development and function of the nociceptive sensory system and in the establishment of temperature regulation via sweating. HSAN type II and V have yet to have their chromosomal loci identified. In this lecture we will review the classification of the HSAN and in which way the molecular genetics of these rare disorders is shedding light on the biology of the peripheral sensory nervous system.

\section{FRIDAY, MAY 11, 2001 - 16:00-17:15 CONCURRENT WORKSHOP \# 3 The sexual pain disorders: Is the pain sexual or is the sex painful?}

\section{Chairperson: Yitzchak M Binik}

Department of Psychology, McGill University and McGill

University Health Center, Montreal, Quebec

The main Sexual Pain Disorders in pre-menopausal women are Vulvar Vestibulitis Syndrome (VVS) and Vaginismus. VVS is probably the most common cause of female dyspareunia (i.e., pain during intercourse), affecting up to $15 \%$ of women in general gynecological practice. It has long been viewed as a sexual dysfunction despite the fact that women with VVS experience pain during intercourse. This workshop will emphasize the importance of examining the Sexual Pain Disorders from a pain perspective. There will be 2 presentations on VVS. The first presents data concerning tactile and pain thresholds in genital and non-genital regions of women who suffer from VVS and matched controls. It also discusses potential peripheral and central mechanisms that may be involved in the development and maintenance of VVS. The second talk focuses on the results of a 2.5-year follow-up of a randomized comparison of group cognitive-behavioral therapy, surface electromyographic biofeedback, and vestibulectomy in the treatment of VVS. The general pattern of findings suggests that current surgical and behavioral interventions are effective in reducing pain due to VVS. The third presentation focuses on the main diagnostic criterion for Vaginismus, muscle spasm. Based on empirical data that have been recently collected, a re-conceptualization of the muscle spasm criterion is presented. This workshop will reflect the multidisciplinary (psychology, gynecology, physical therapy) research and clinical approach that we have adopted.

\section{Speaker 1}

\section{A LONG-TERM FOLLOW-UP OF A RANDOMIZED COMPARISON OF GROUP COGNITIVE-BEHAVIORAL THERAPY, SURFACE ELECTROMYOGRAPHIC BIOFEEDBACK, AND VESTIBULECTOMY IN THE TREATMENT OF VULVAR VESTIBULITIS}

Sophie Bergeron, Yitzchak M Binik, Samir Khalifé, Kelly Pedigas, Howard I Glazer

Département de sexologie, Université du Québec à Montréal, Montréal, Québec

The present study is a long-term treatment follow-up of women with vulvar vestibulitis syndrome. Seventy-eight participants were randomly assigned to one of three treatment conditions: group cognitive-behavioral therapy (CGBT), surface electromyographic biofeedback, and vestibulectomy. They were initially assessed at pretreatment, posttreatment, and 6-month follow-up; a 2.5-year follow-up was recently completed. Measures included gynecological examinations, structured interviews and standard questionnaires pertaining to pain (Pain Rating Index and Sensory scale of the McGill Pain Questionnaire, vestibular pain index, pain during intercourse), and sexual function (Sexual History Form, frequency of intercourse, Information subscale of the Derogatis Sexual Functioning Inventory). Study completers of all treatment groups reported significant reductions on pain measures at posttreatment and 6-month follow-up, although the vestibulectomy group was significantly more successful than the two other groups. All three groups significantly improved on measures of sexual function from pretreatment to 6-month follow-up. However, frequency of intercourse remained markedly below community sample norms for this age group. Results of the 2.5-year follow-up showed significant reductions on most pain measures in comparison to the 6-month follow-up, suggesting that participants continued to improve over time. Findings of the long-term follow-up generally continued to support the superiority of vestibulectomy, although in terms of self-reported pain during intercourse, vestibulectomy was 
not superior to GCBT. As for sexual function, participants remained unchanged between 6-month and 2.5-year follow-up. The general pattern of findings suggests that current surgical and behavioral interventions are effective in reducing pain due to vulvar vestibulitis, but not in significantly altering the associated sexual impairment.

\section{Speaker 2}

\section{VULVAR VESTIBULITIS SYNDROME: TACTILE AND PAIN THRESHOLDS IN AFFECTED AND NON-AFFECTED WOMEN}

Caroline Pukall, Yitzchak M Binik, Frances A Abbott, Samir Khalifé, Kimberley Payne

Department of Psychology, McGill University, Montreal, Quebec

INTRODUCTION: Little is known about the sensitivity of the vulvar vestibule. Despite its description as an important source of sexual sensation, this region causes pain during intercourse in women with Vulvar Vestibulitis Syndrome (VVS). VVS is probably the most common cause of dyspareunia in pre-menopausal women. The primary objective of our study was to investigate punctate tactile and pain sensitivity of the vestibule in affected and non-affected women.

METHODS: Tactile and pain thresholds were measured with modified von Frey stimuli around the vulvar vestibule of 13 women with VVS and 13 matched controls. Thresholds were also measured in non-vestibular areas. General pain sensitivity was measured with a pressure-pain meter on the deltoid and tibia.

RESULTS: Women with VVS had significantly lower vestibular tactile and pain thresholds than control women. Women with VVS also had lower deltoid pressure-pain thresholds than controls, suggesting that their pain problem may be more generalized than previously believed. Therefore, we systematically tested non-vestibular tactile and pain thresholds in the same women. We found that women with VVS had lower tactile thresholds on the labium minus and deltoid and lower pain thresholds on the labium minus, deltoid, and forearm than controls. Vestibular tactile and pain thresholds were re-tested and were found to be reliable.

CONCLUSIONS: VVS appears to be associated with abnormal tactile and pain sensation in the affected region, and a tendency towards generalized hyperalgesia. These results support the classification of VVS as a pain disorder as opposed to its traditional classification as a sexual dysfunction.

\section{Speaker 3}

\section{CHARACTERISTICS OF VAGINISMUS: AN EMPIRICAL INVESTIGATION}

Elke Reissing, Yitzchak M Binik, Deborah Cohen, Samir Khalifé Department of Psychology, McGill University,

Montreal, Quebec

INTRODUCTION: Vaginal spasms that interfere with intercourse have been uncritically accepted as the main diagnostic criterion for vaginismus. This assumption has rarely been challenged and the validity of the vaginal spasm as the defining criterion of vaginismus, as well as the reliability of the diagnosis based on this criterion, remains untested.
METHODS: Two gynecologists and 2 physiotherapists examined 29 women with vaginismus and their matched controls (29 women with Vulvar Vestibulitis Syndrome and 29 women with no intercourse problems). Women also completed a series of questionnaires, participated in a structured interview, and underwent vaginal surface EMG testing. Two psychologists independently reviewed the interview data and provided a diagnosis.

RESULTS: The reliability of a diagnosis of vaginismus was moderate despite the low rate of observed or self-reported spasm and the lack of reliability on the report of spasm by health professionals. Presence of spasm did not differentiate diagnostic categories. However, women with vaginismus demonstrated higher levels of chronic vaginal tension. The degree of interference with intercourse regardless of the presence of spasm differentiated diagnostic groups.

CONCLUSIONS: A re-conceptualization of the current diagnostic criteria and the utility of differential diagnoses of the sexual pain disorders are discussed.

FRIDAY, MAY 11, 2001 - 16:00-17:15 CONCURRENT WORKSHOP \#4 Assessing pain in the communicatively impaired elderly: The Parkridge Pain Assessment Tool

Chairperson and Speakers: Joan Middleton, Sandy Knezacek, Christie Ife, Norma Stewart

Parkridge Centre, Saskatoon District Health, Saskatoon, Saskatchewan

FOCUS STATEMENT: A behavioural observational method will be presented to assist caregivers in identifying pain in the communicatively impaired.

EDUCATIONAL OBJECTIVES: Participants will learn how to assess pain using the Parkridge Pain Assessment Tool

ABSTRACT: This workshop will present a clinical tool for assessment of pain in persons with communication impairment. The tool was developed by a multidisciplinary team including nursing, pharmacy, speech language pathology, and psychology. Workshop participants will be instructed in the use of the assessment tool using a training video developed by the research team. Participants will then be given an opportunity to practice these learned skills through observation of vignettes of potentially painful events. Discussion will occur regarding the research process undertaken in the development of the tool. Reliability and validity results will be shared. Clincal applications and further research development of the tool will also be discussed. 
SATURDAY, MAY 12, 2001 - 07:00-08:00 BREAKFAST SESSION \#2

Learning from our patients with chronic pain: A doctor's benefit

Helen Hays

Edmonton, Alberta

Sponsored by Purdue Pharma

SATURDAY, MAY 12, 2001 - 08:30-09:15 KEYNOTE ADDRESS

Tracing the course of substance $P$ and pain: From cell to development of drugs

James L Henry - Recipient of the Distinguished Career Award of the CPS (2000)

Department of Physiology, McGill University, Montreal, Quebec

Sponsored by Pharmacia Canada

(Abstract not provided)

SATURDAY, MAY 12, 2001 - 09:15-10:15 PLENARY SESSION \#2 Update on opioid therapy

Chairperson: Andre Dray

AstraZeneca Research and Development Montreal, Montreal, Quebec

\section{Speaker 1}

\section{TARGETING OF DELTA OPIOID RECEPTORS FOR IMPROVED ANALGESIC THERAPY}

\author{
A Beaudet, A Morinville, C Hoffert, D Hubatsch, \\ D O'Donnell, CM Cahill \\ Montreal Neurological Institute, Montreal, Quebec
}

Activation of delta opioid receptors ( $\delta \mathrm{OR}$ ) has been shown to elicit antinociception in a variety of phasic and persistent pain models. Given that $\delta \mathrm{OR}$ are reportedly very sparse on neuronal plasma membranes, we propose that increased membrane targeting of $\delta \mathrm{OR}$ may be required for these analgesic effects to occur. We recently demonstrated that $\delta \mathrm{OR}$ membrane targeting could be pharmacologically enhanced and this increase was correlated with an augmented $\delta \mathrm{OR}$-induced response. Thus, cellular imaging studies on primary neurons in culture revealed that prolonged treatment with the $\mu \mathrm{OR}$ agonist morphine significantly increased $\delta \mathrm{OR}$ cell surface density. No significant change in overall $\delta \mathrm{OR}$ protein levels was detected following such treatment, suggesting that the increase in cell surface $\delta \mathrm{OR}$ was the result of targeting from preexisting receptor pools. In vivo studies carried out in parallel demonstrated that prolonged treatment of rats with morphine similarly augmented targeting of $\delta \mathrm{OR}$ to neuronal plasma membranes in the dorsal spinal cord. Correspondingly, this treatment markedly potentiated intrathecal deltorphin-induced antinociception. A similar increase in the density of cell surface immunoreactive $\delta \mathrm{OR}$ was observed in the ipsilateral dorsal spinal cord of animals subjected to injection of complete Freund's adjuvant (CFA), suggesting that increased targeting of $\delta \mathrm{OR}$ may be responsible for the enhanced antinociceptive effects of $\delta \mathrm{OR}$ agonists in inflammation. However, in this inflammatory model, the increased targeting of $\delta \mathrm{OR}$ was accompanied by an augmentation of $\delta \mathrm{OR}$ mRNA, suggesting that the receptor recruitment mechanism may be different from that elicited by $\mu \mathrm{OR}$ stimulation. We conclude that modulation of membrane targeting may widen the transduction repertoire of $\mathrm{G}$ protein-coupled receptors and offer new avenues of therapeutic strategies.

Speaker 2

\section{MULTIPLE MU OPIOID RECEPTORS AND INCOMPLETE CROSS TOLERANCE: FROM THE BEDSIDE TO THE BENCH}

Gavril W Pasternak

Department of Neurology, Sloan-Kettering Cancer Center,

New York, New York

Clinically, mu opioids share many characteristics, such as analgesia, respiratory depression and tolerance. However, differences among them, including and varying patient sensitivities and incomplete cross tolerance, indicate that their actions cannot be mediated by a single mu opioid receptor, implying mu receptor subtypes. The concept of mu receptor subtypes goes back many years, based upon the actions of selective antagonists such as naloxonazine. In these studies, diverse actions such as respiratory depression and the inhibition of gastrointestinal transit were dissociated from analgesia by mu receptors selective for specific subtypes. More recent work has underscored the importance of morphine-6 $\beta$-gluruconide (M6G). A derivative of morphine, M6G has a distinct and unique pharmacology. With the cloning of a morphine receptor, MOR-1, investigators have been able to examine this system at the molecular level. Although both morphine and M6G analgesia are mediated through receptors encoded by the gene producing MOR-1, differences in their sensitivity to antisense and knockout models imply, at the molecular level, that these agents act through distinct receptors. These observations implied the existence of mu receptor subtypes based upon alternative splicing. Although many questions remain regarding the receptors responsible for the actions of the various mu analgesics, at least seven mu receptors have been cloned that derive from alternative splicing of a common gene. These variants show distinct distributions within the brain and underscore the complexity of mu opioid systems. 


\section{Speaker 3}

\section{OPIOID THERAPY FOR CHRONIC NON-CANCER PAIN - LESSONS LEARNED FROM CLINICAL TRIALS}

Dwight E Moulin

Department of Clinical Neurological Sciences, Victoria Hospital, London, Ontario

Despite a growing body of literature supporting the use of opioid analgesics for chronic non-cancer pain, considerable controversy still exists in the management of this common clinical problem. There are lingering concerns about the neuropsychological effects of opioids and the risk of psychological dependence or addiction. On the positive side, there are now seven high quality randomized controlled trials showing the efficacy of oral opioids for chronic non-cancer pain - 4 trials in musculoskeletal pain and 3 in neuropathic pain. All of these studies have shown a significant reduction in pain intensity with variable impact on disability. These studies and extensive survey data have also allowed for an emerging consensus that opioid tolerance, physical dependence and psychological dependence seldom cause difficulties.

The extant literature supports the conclusion that sustained-release opioid therapy benefits selected patients with chronic musculoskeletal and neuropathic pain. Significant pain relief can be achieved with a low risk of psychological dependence or addiction in the absence of a history of substance abuse. However, long term opioid therapy may or may not improve functional status and there is some evidence that a treatment program that focuses on analgesics can reinforce pain related behaviour at the expense of functional restoration. Opioid therapy should therefore be part of a comprehensive treatment program that includes a graduated exercise program and psychosocial and behavioural approaches to pain management.

\section{SATURDAY, MAY 12, 2001 - 10:45-12:00 CONCURRENT SPECIAL RESEARCH SYMPOSIA \# 1}

\section{Basic research: Ion channels}

\section{Chairperson: Terence J Coderre}

Department of Anesthesia, McGill University, Montreal, Quebec

OVERVIEW: Ion channels are a diverse assortment of membrane-bound proteins which modulate neuronal activity by regulating ion flux into neurons. They are influenced by various endogenous mediators and physiological stimuli, and provide potential targets for analgesic therapies. Although ion channel modulators have long been used as therapeutic agents, their use has been limited by various undesired side-effects. The recent discovery of several novel classes of ion channels, and subtypes that are selective to primary afferent nociceptors, has provided new targets for the development of ion channel modulators as analgesics. Furthermore, recent evidence suggests that there are changes in the expression of various ion channels in primary afferent neurons following inflammatory or nerve injury, which may contribute to alterations in neuronal excitability. In this symposium, we will review recent evidence on the role of ion channels in nociception, and the potential role of ion channel modulators as therapeutic agents for pain. Philippe Séguéla will review his recent work on acid-sensing cation channels that act within primary sensory neurons as detectors of protons, and which transduce information about tissue acidosis after injury, and thus play a role in chemical nociception. David Ragsdale will address how the molecular structure of sodium channel influences the modulation of neuronal excitability by local anesthetics, and how the binding affinity of sodium channel antagonists can be enhanced with this knowledge. Terrance Snutch will examine the properties of voltage-gated calcium channels, the analgesic potential of a novel N-type calcium channel blocker, and the molecular mechanisms of opioid-dependent modulation of calcium channels on presynaptic nerve terminals.

\section{Speaker 1}

\section{ION CHANNELS ACTIVATED BY ACID IN PAIN PATHWAYS}

Philippe Séguéla

Montreal Neurological Institute, Montreal, Quebec

\section{Supported by the CIHR and Antalium Inc}

Pathological conditions like inflammation, cramps, infarcts and tumors are associated with local acidosis. The pain linked to acidosis involves the activation of specialized detectors of protons located on the peripheral terminals of primary sensory neurons that relay the nociceptive signals to the brain. A set of mammalian genes coding for neuronal acid-sensing cation channels (ASIC) has recently been cloned and functionally characterized. These amiloride-sensitive excitatory receptors are directly activated by extracellular acidification. They belong to a large family of surface proteins including mechanoreceptor subunits from nematodes and epithelial sodium channels. They share with the P2X ATP receptors, expressed also in sensory pathways, an unique transmembrane topology and a large cysteine-rich extracellular sensing domain. In rodents, the ASIC1B and ASIC3 subunits are almost exclusively expressed in primary sensory neurons of the trigeminal, nodose and dorsal root ganglia, confirming the importance of protons in chemical nociception. From their localization and $\mathrm{pH}$ sensitivity, ASIC3 receptors have been proposed as candidates to mediate cardiac pain (angina). In order to evaluate the role of these novel potential therapeutic targets in sensory pathways and brain, data on the properties of rodent and human ASIC receptors, their modulation and the identification of novel subtypes, will be presented.

\section{Speaker 2}

\section{STRUCTURE AND MOLECULAR PHARMACOLOGY OF THE VOLTAGE-GATED SODIUM CHANNEL, AN IMPORTANT TARGET FOR ANALGESIC AGENTS}

David Ragsdale

Montreal Neurological Institute, Montreal, Quebec

Voltage-gated calcium channels play crucial roles in mediating neurotransmission and are strong candidates as therapeutic targets for pain intervention. The talk will briefly summarize the properties of voltage-gated calcium channels and then focus on molecu- 
lar mechanism of opioid-dependent modulation of presynaptic calcium channels. The inhibition of presynaptic N-type calcium channels by opioid receptors was examined by exogenous expression of cloned channels. The inhibitory effects of receptor activation were shown to result from the direct binding of $\mathrm{G}_{\beta \gamma}$ to the calcium channel $\alpha_{1}$ subunit. In vitro mutagenesis identified residues in the domain I-II linker that both alter channel sensitivity to G-proteins and also affect G-protein binding through phosphorylation by protein kinase C. A synthetic cone snail-derived peptide, Ziconotide ${ }^{\circledR}$, that selectively targets the N-type channel, has been shown to be efficacious for the treatment of a variety of opioid-unresponsive neuropathic pain conditions in humans. Ziconotide ${ }^{\circledR}$ must be delivered by intrathecal administration and there remains a significant opportunity to develop small organic molecule blockers of the N-type channel for the treatment of chronic pain conditions. Along these lines, NeuroMed Technologies Inc., has designed, synthesized and tested a novel class of small organic molecules selective as N-type channel blockers. The compounds show affinities of 30 to $60 \mathrm{nM}$ and are active in animals by both intravenous and oral administration. Examining the Chung model, the work has identified several compounds that exhibit strong potential as anti-hyperalgesics and anti-allodynics. The doses compare well with morphine but with the significant advantage of targeting the N-type calcium channel and thus avoiding the addictive and escalating dose requirements of morphine.

\section{Speaker 3}

\section{A NEW CLASS OF N-TYPE CALCIUM CHANNEL BLOCKERS AS PAIN THERAPEUTICS}

Terrance P Snutch

NeuroMed Technologies Inc, Vancouver, British Columbia

Voltage-gated sodium channels are the principle mediators of intrinsic neuronal excitability, and play a central role in transmission of pain signals. Sodium channels are also the molecular targets of a variety of important therapeutic agents, including local anesthetics such as lidocaine. The therapeutic efficacy of these compounds stems from their voltage- and activity-dependent inhibition of ionic currents through sodium channels, resulting in suppression of cell excitability. We have used site-directed mutagenesis to investigate the molecular basis for local anesthetic inhibition of sodium channels. Data from our lab and other labs indicate that the binding site for local anesthetics and related drugs is formed by a ring of amino acid residues that lie within the inner vestibule of the ion-conducting pore. Specific interactions involving aromatic amino acid side chains appear to be particularly important for high affinity drug binding. This information, along with our increasingly accurate overall picture of channel structure, could facilitate the development of subtype-specific sodium channel blockers. Of particular importance for pain management would be the development of compounds that specifically inhibit TTXresistant $\mathrm{Na}_{\mathrm{V}} 1.8$ and $\mathrm{Na}_{\mathrm{V}} 1.9$ sodium channels, which are selectively expressed in primary nociceptive afferents.
SATURDAY, MAY 12, 2001 - 10:45-12:00 CONCURRENT SPECIAL RESEARCH SYMPOSIA \#2 Clinical research: Evidence-based decision making for pain treatment

Chairperson: Sandra M LeFort

School of Nursing, Memorial University of Newfoundland,

St John's, Newfoundland

\section{Speaker 1}

Daniel B Carr

Department of Anesthesia, New England Medical Center, Boston, Massachusetts

(Abstract not provided)

Speaker 2

Jacques LeLorier

Centre de recherche, Centre hospitalier de l'Université de Montréal, Montréal, Québec

(Abstract not provided)

Speaker 3

Patricia A McGrath

Department of Pediatric, Children's Hospital, London, Ontario

(Abstract not provided)

SATURDAY, MAY 12, 2001 - 12:30-14:15

LUNCH - CONFERENCE \#2

The joy of caring

Patch Adams

Gesundheit Institute, Arlington, Virginia

Sponsored by Janssen-Ortho Inc 


\section{SATURDAY, MAY 12, 2001 - 14:15-15:30 CONCURRENT WORKSHOP \# 5 The doctor's, family's and patient's point of view in chronic pain management - An ethical issue}

\author{
Chairperson: Aline Boulanger \\ Clinique Anti-Douleur, Hôtel-Dieu du Centre hospitalier de \\ l'Université de Montréal, Montréal, Québec
}

Sponsored by Janssen-Ortho Inc

Speaker 1

\section{THE DOCTOR'S POINT OF VIEW}

\section{Aline Boulanger}

Clinique Anti-Douleur, Hôtel-Dieu du Centre hospitalier de

l'Univ de Montréal, Montréal, Quebec

En 1973, Marks et Sacher, publiaient des taux de soulagement inadéquat chez $70 \%$ des patients d'une population chirurgicale. Depuis, les campagnes de sensibilisation auprès des bénéficiaires, les guides thérapeutiques et les formations médicales continues concernant le traitement de la douleur se sont multipliés. Il est navrant de constater 28 ans plus tard, que malgré tous ces efforts environ $50 \%$ des patients souffrants chroniques présentent des douleurs modérées à sévères.

La douleur a un impact majeur sur la qualité de vie des individus et se répercute sur toute la dynamique familiale. Elle conduit à l'arrêt de travail, aux pertes financières, au retrait social, à l'éclatement des familles et à la dépression. Pour obtenir un soulagement efficace, les patients font face à des préjugés. Dans une étude épidémiologique conduite par 1'American Pain Society en 2000, les patients reconnaissent que les médecins savent peu de chose concernant la douleur, qu'ils ne la prennent pas au sérieux et qu'ils ne sont pas près à la traiter agressivement. Il n'est pas surprenant que les patients aillent chercher des solutions auprès de traitement alternatif, souvent coûteux et dont les bienfaits n'ont pas été évalués scientifiquement.

Le traitement de la douleur est un droit pour le patient et pour le médecin, traiter la douleur est une obligation. Le médecin doit reprendre de lui-même le leadership dans le soulagement des douleurs et ne pas attendre que les pressions externes (gouvernementales, judiciaires et des Collèges des médecins) nous l'imposent.

\section{Speaker 2}

\section{THE FAMILY'S POINT OF VIEW}

\section{Michael R Thomas, Ranjan Roy \\ Department of Psychology, University of Manitoba, Winnipeg, Manitoba}

Our recent research has investigated three generational pain in a group of college students, their parents and grandparents. The data leaves little doubt that pain problems tend to be intergenerational. Pain sites are often shared by parents and their children and on occasions between grandchildren and grandparents. While we are interested in the mechanisms that might explain intergenerational pain, in this workshop we simply want to draw attention to the ubiquitous nature of pain complaints and how they are commonly shared between generations.

The other focus of the workshop will highlight some of the problems associated with chronic pain and family research. In our estimation, the degree of family problems reported in the research literature is overly pessimistic and often exaggerated. A key problem in measuring family function. The existing instruments were rarely normed on clinical populations. Therefore, what is normal functioning for a family with a chronically sick parent remains an elusive question.

On the other hand clinical experience shows over and over again that chronic pain in a family member creates difficulties. Those difficulties are generally in the following areas: 1) Issues of intimacy; 2) changes in family roles; and 3) children. We hope to address these three issues in some detail.

\section{Speaker 3}

\section{THE PATIENT'S POINT OF VIEW}

Jean-Luc Lavoie

Montreal, Quebec

Elle était seule, triste, isolée, et pleurait. Au début des années '50, certains disaient qu'elle était sans colonne vertébrale et probablement paresseuse. D'autres, pensaient qu'elle n'avait aucune motivation et qu'elle n'était pas intéressante. Puis, un jour ses comportements sont devenus des symptômes dénudés de tout préjugé. Un diagnostic fût reconnu... elle était en dépression. La marche entre les préjugés et celle du traitement et de la reconnaissance de la dépression venait d'être montée.

Il était démotivé, épuisé, tanné de son travail. Au début des années '70, on disait de lui qu'il était un employé sans ambition, sans envergure et qu'il tuait le temps au travail. De nos jours, ces attitudes sont devenues un symptôme. Un diagnostic de "burn out" peut être posé. La marche entre les préjugés et celle du traitement était, encore une fois, gravie.

Il était souffrant, fatigué, et se sentait incompris. Il présentait une douleur chronique qui s'incrustait dans son quotidien. En milieu de travail tout comme en famille les répercussions se faisaient ressentir négativement. Malgré cela, il se devait d'être un père fort, solide et puissant. Assez puissant pour pleurer...quelque fois. Un père qui, malgré la douleur chronique, devait permettre d'offrir un modèle d'identification positif à ses enfants. Pas évident...Etait-il narcomane, était-il déprimé, était-il manipulateur, était-il réellement souffrant. Cette persistance de la douleur était-elle réelle ou camouflait-elle quelque chose d'autre?

$\mathrm{Au}$ début des années 2000, certains de ces préjugés demeurent concernant la douleur chronique. En ce qui a trait au traitement de cette dernière, à son acceptation sociale et à ses répercussions familiales...la marche à monter apparaît encore bien haute. La douleur chronique, ses effets sur la famille, la personne, le milieu de travail, les préjugés, les résistances, tels seront les sujets abordés lors de ce bref exposé. De plus, la nécessité d'une équipe experte et multidisciplinaire de même que l'importance de la médication constitueront aussi des termes d'intérêt. Et si en plus, on parlait du "savoir être" du médecin et des autres professionnels de l'équipe...par rapport au phénomène de la douleur chronique. 


\section{SATURDAY, MAY 12, 2001 - 14:15-15:30 CONCURRENT WORKSHOP \# 6 Theoretical perspectives on the psychology of pain}

Chairperson: Michael JL Sullivan

Department of Psychology, Dalhousie University, Halifax, Nova Scotia

FOCUS STATEMENT: The primary objective of this research workshop is to address the strengths and limitations of different conceptual models of how psychological and physiological factors interact to give rise to the pain experience.

EDUCATIONAL OBJECTIVES: At the conclusion of this session, participants will have a greater understanding of the current status of research examining psychological predictors of pain, including anxiety, fear of pain and catastrophizing. Participants will also be introduced to theoretical models that might explain interactions between psychological and physiological mechanisms involved in pain experience.

ABSTRACT: The past two decades has seen a proliferation of research on the psychology pain. Anxiety, fear and catastrophizing are three constructs that have received considerable attention. However, little is known about the mediational relations among these variables, or the contextual factors that determine how they impact on pain experience. Even less is known about the links between the psychological and physiological mechanisms that underlie the pain experience. The primary objective of this research workshop is to address the strengths and limitations of different conceptual models of how psychological and physiological factors interact to give rise to the pain experience. At the conclusion of this session, participants will have a greater understanding of the current status of research examining psychological predictors of pain, including anxiety, fear of pain and catastrophizing. Participants will also be introduced to theoretical models that might explain interactions between psychological and physiological mechanisms involved in pain experience. The first presentation (Dr. MJL Sullivan) will address mediational relations between fear of pain and catastrophizing in response to experimental and clinical painful procedures. The second presentation (Dr. JG Asmundson) will address relations among anxiety sensitivity, trait anxiety, fear of pain, and the prediction of functional limitations following musculoskeletal injury. The third presentation (Dr. J. Katz) will address mechanisms through which psychological variables may interact with physiological variables during pain experience.

\section{Speaker 1}

\section{FEAR, CATASTROPHIZING AND PAIN EXPERIENCE: EXPERIMENTAL AND CLINICAL FINDINGS}

\author{
Michael JL Sullivan \\ Department of Psychology, Dalhousie University, Halifax, \\ Nova Scotia
}

The studies reported below are part of a research program examining inter-relations among psychological predictors of pain. Two studies are described addressing the hypothesis that components of catastrophizing (i.e., rumination, magnification, helplessness) mediate the relation between fear of pain and pain experience. In Study 1, 60 undergraduates (30 men, 30 women) completed measures of catastrophizing and fear of pain prior to participating in a cold pressor procedure. Results of regression analyses revealed that rumination, but not helplessness or magnification, mediated the relation between fear of pain and pain experience. In Study 2, 60 undergraduates (30 men, 30 women) participated in a mild to moderately aversive dental hygiene procedure referred to as scaling, which involved removing hard and soft deposits from the tooth surface with a metal instrument. Results of regression analyses revealed that both rumination and helplessness mediated the relation between fear of pain and pain experience. Implications of these findings for theoretical models of the psychology of pain are discussed. Attention is drawn to the importance of considering hierarchical levels of analysis in understanding the inter-relations among psychological predictors of pain. Discussion also addresses the potential contextual determinants of pain where specific psychological variables may impact on pain in some circumstances but not others.

\section{Speaker 2}

\section{IS ANXIETY SENSITIVITY A BETTER PREDICTOR OF PAIN-SPECIFIC FEAR, AVOIDANCE, AND FUNCTIONAL LIMITATIONS THAN NEGATIVE AFFECTIVITY?}

Gordon JG Admundson

Clinical Research and Development Program, Regina Health

District, Regina, Saskatchewan

Several investigators have shown that anxiety sensitivity (AS), a disposition to respond with fear to a variety of stimuli, influences pain-specific fear and, thereby, impacts on avoidance behavior and functional limitations. It remains to be determined (a) whether the relationship of AS is unique from that of general negative affectivity (NA; the disposition to appraise the world and oneself within the world negatively) to fear of pain, and (b) if AS provides unique information in the prediction of pain-specific avoidance and functional limitations when fear of pain and NA are accounted for. A sample of 227 first time referrals to a community-based physiotherapy clinic who had pain stemming from musculoskeletal injury completed a battery of questionnaires designed to measure these constructs. A series of hierarchical multiple regressions indicated that AS explained unique variance, relative to NA, in the prediction of fear of pain. On the other hand, only fear of pain explained unique variance in the prediction of avoidance behavior and functional limitations. These results indicate that AS, relative to NA, contributes uniquely to fear of pain. The results also support the notion that AS influences avoidance and functional limitations indirectly through its unique contribution to fear of pain. The importance of these findings to conceptualizing psychological variables important to chronic pain, to fear models of chronic pain, and for future clinical and research applications will be discussed. 


\section{Speaker 3}

\section{LINKING PSYCHOLOGICAL AND PHYSIOLOGICAL MECHANISMS OF PAIN PERCEPTION}

\author{
Joel Katz \\ Acute Pain Research Unit, Department of Anesthesia, Toronto \\ General Hospital, University Health Network, Toronto, Ontario
}

This presentation will focus on linking physiological mechanisms of nociception and psychological-affective aspects of pain in neuropathic pain conditions. In particular, I will outline a model that describes how the joint influence of peripheral neurophysiological factors and higher-order cognitive and affective processes combine to trigger or modulate awareness of phantom limb sensations and pain. A model of sympathetic-sensory coupling is presented to explain fluctuations in the intensity of sensations and pains referred to the phantom limb. The sympathetic-efferent somaticafferent cycle may be triggered by activity in pre-frontal and limbic brain regions associated with specific thoughts and feelings via a descending excitatory pathway to the hypothalamus and lateral horn of the spinal cord. Alternatively, spontaneous neural discharge of post-ganglionic sympathetic fibres located in amputation stump neuromas may provide the trigger to excite somatic afferents in close proximity leading to the experience of abnormal sensations or pain referred to the phantom limb. This model explains the otherwise puzzling finding that only after amputation are thoughts and feelings capable of evoking referred sensations to the (phantom) limb and might also explain psychologically-triggered pain experience in other neuropathic pain conditions. In the case of amputation, phantom pains and other sensations frequently are triggered by thoughts and feelings. Throughout the presentation it is emphasized that the psychological or emotional triggering of pain is a normal consequence of amputation. There is no evidence that the painful or painless phantom limb is a symptom of a psychological disorder.

\section{SATURDAY, MAY 12, 2001 - 14:15-15:30 CONCURRENT WORKSHOP \# 7 Progressive return to work as a treatment modality in the multidisciplinary treatment of chronic pain}

\section{Chairperson: Richard Catchlove}

Montreal Pain Clinic, Montreal, Quebec

FOCUS STATEMENT: Progressive return to work as a treatment modalities. Its integration into a treatment approach

EDUCATIONAL OBJECTIVES: Understand the role of work return in pain treatment. Details of its application. Understand its effect on outcome.

ABSTRACT: Occupational rehabilitation is often a part of multidisciplinary pain management programs and many programs include occupational rehabilitation as a treatment goal. 20 years ago, we used the progressive return to work, PRW, as a kind of treatment goal, based upon our awareness of the early work histories and the extreme importance of work to our patients, who were unable to return to work because of their chronic pain. Since then, we have developed this aspect to the point that we now consider PRW as a treatment modality, rather than a goal, and it is now a permanent part of our pain management program. However, when used in this way it must be clearly differentiated from the goal of returning patients to work. Since we have been using PRW purely as a treatment modality, we have learnt much about its application and usefulness. We wish to share this with our colleagues who are faced with these very challenging patients with chronic pain.

\section{Speaker 1}

\section{PROGRESSIVE RETURN TO WORK IN A MULTIDISCIPLINARY PAIN TREATMENT PROGRAM: AN OVERVIEW}

\author{
Christina Anston \\ Montreal Pain Clinic, Montreal, Quebec
}

Treating chronic pain patients, particularly those who are on workers' compensation, is a challenging task. Approximately $80 \%$ of the patients seen at our center, the Montreal Pain Clinic, suffer from a musculoskeletal disorder of the spine or upper extremities and are receiving workers' compensation. Our pain treatment program is integrated, comprehensive, multidisciplinary and multimodal. Treatment consists of nerve blocks, narcotic adjustment, anti-depressant medication, physiotherapy, occupational therapy, cognitive-behavioral group therapy, physical conditioning and a progressive return to work (PRW). The PRW begins at approximately the halfway point of the treatment program. During the PRW, patients are gradually re-integrated into their jobs. They usually start with 2 half work days per week and this is slowly increased over a 10-12 week period until they are working full time. Patients attend the clinic on the days they are not working and continue to receive the full set of multidisciplinary treatments. We see the PRW as a therapeutic tool in which patients have the opportunity to confront and learn to manage issues related to chronic pain, work and the self with the assistance of the multidisciplinary team. The PRW facilitates the development of a sense of independence and mastery in patients. It helps them shed the sick role, learn healthy work habits and attitudes, and build self-esteem.

\section{Speaker 2}

\section{ON-SITE WORK ANALYSIS AND WORK HARDENING: INTEGRAL COMPONENTS OF A SUCCESSFUL PROGRESSIVE RETURN TO WORK}

\author{
Carole Chiang \\ Montreal Pain Clinic, Montreal, Quebec
}

For patients who have been off work for a substantial amount of time, the thought of returning to work, even as a part of treatment, can create much anxiety. The progressive return to work facilitates the chronic pain patient's transition to the work place. Work conditioning and work hardening programs, on-site work visits, implementation of a return to work schedule and close liaison with the CSST (the provincial workers' compensation board) are essential elements of a progressive return to work. Work conditioning and work hardening programs are conducted at the clinic approxi- 
mately 4 weeks before the first day of work. These are important since they allow the patient to practice healthy work habits within a supervised setting prior to returning to work. On-site work visits facilitate the return to work by extending the presence of the clinic into the workplace. The goals of the visits are to 1) emphasize the progressive return to work as a treatment modality; 2) allow the therapist to obtain a better understanding of the patient's job demands, working conditions and types of work stress; 3 ) ensure that the principles taught in the first 6 weeks of occupational therapy treatment are being applied in the work environment and 4) provide emotional support. The return to work schedule is established in consultation with the patient. Thus, the patient becomes a more active participant in the treatment process. Throughout the program, contact with the CSST is vital for overall treatment success.

\section{Speaker 3}

\section{RETURN TO WORK THERAPY GROUP: AN APPROACH FOR DEALING WITH WORK RELATED STRESS}

Aurelio Sita

Montreal Pain Clinic, Montreal, Quebec

We have observed that the weeks immediately preceding and following the start of the progressive return to work are exceptionally stressful for patients. Regardless of the progress they have made in the initial weeks of treatment, many patients complain of increased pain before the start of their return to work. They also demonstrate increased anxiety and irritability. A return to work therapy group led by a clinical psychologist was implemented to provide specific support for patients throughout the duration of their progressive return to work. Unlike typical psychological therapy groups for chronic pain patients which are broad in scope, the group specifically focuses on application of cognitive-behavioral and psychodynamic principles to work related problems. The issues addressed include: 1) managing job-related stress and maintaining healthy work habits 2) dealing with fear of work activities/fear of reinjury; 3) coping with pain flare-ups and relapse and 4) managing relationships with superiors and co-workers. The progressive return to work gives the patient and the therapist the opportunity to address these work-related issues when they are most intense and most accessible.

\section{SATURDAY, MAY 12, $2001-14: 15-15: 30$ CONCURRENT WORKSHOP \#8 Pain in animals: From the veterinarian's perspective}

\section{Chairperson: Manon Choinière}

Animal Care Committee, Centre de recherche du Centre hospitalier de l'Université de Montréal, Montréal, Québec

FOCUS STATEMENT: The primary objective of this workshop is to provide veterinarians working in the field of laboratory animal research the opportunity to expose and discuss their point of view regarding pain research and assessment of suffering in animals.

\section{EDUCATIONAL OBJECTIVES:}

1. To provide basic scientists with a better knowledge and comprehension of the various concerns veterinarians have when reviewing and evaluating pain research protocols that involve laboratory animals

2. To provide basic scientists with a better knowledge of the methods and signs veterinarians use to assess pain in animals.

Evaluation of pain research protocols and assessment of suffering in animals are two important aspects of the veterinarian's work in research laboratory settings. In principle, basic scientists and veterinarians involved in laboratory animal research should have the same ethical and scientific concerns regarding pain research in animals. However, their point of view may not be necessarily the same due to their different background. In the first part of this workshop, Dr Ménard will present the specific concerns veterinarians have when evaluating pain research protocols that involve the use of laboratory animals. In the second part of the workshop, Dr Héon will address the issue of pain assessment in animals from the veterinarian's perspective. She will review clinical and behavioral signs veterinarians use to evaluate suffering in animals and discuss the difficulties they encounter. The period of questions and discussion will provide a unique opportunity to basic scientists and veterinarians to share their view about pain research and assessment in animals.

\section{Speaker 1}

\section{PAIN RESEARCH IN ANIMALS: THE VETERINARIAN'S POINT OF VIEW}

\section{Stéphane Ménard}

Division des animaleries, Université de Montréal, Montréal, Québec

Evaluation of experimental protocols is an important part of the duties of any veterinarian working in the field of laboratory animal research. These evaluations are based on one of the fundamental principles of veterinary medical care - i.e., prevention and alleviation of pain. In most experimental protocols submitted to veterinarian's review, this principle is readily applied as pain is not, in itself, the object of the study. Things get more complicated when experimental protocols involve infliction of pain to laboratory animals. To be comfortable with the approval of pain research in animals, the veterinarian must take into consideration several aspects when assessing a protocol. According to Animal Care Committee principles, any proposal of pain research in animals should contain clear and convincing statements of justification and soundness of the research. The relevance of the study must be clearly stated in terms of practical benefits and/or important gains in theoretical knowledge. The research and animal care personnel should demonstrate their competence and ability to monitor and minimize animal pain. Due to his background, the veterinarian will, in addition, pay close attention to the description of the type of pain under study (nature of the expected pain, its duration and potential effects on animal behavior and physical integrity), the animal monitoring procedures, the choice of humane end points, and the appropriateness of euthanasia method. All these aspects should be carefully described in the protocol. Answering these questions might make ethically acceptable a pain research protocol in animals but we 
must always bear in mind that it does not matter to an animal if its pain or distress is part of a study aimed at getting a better understanding of the mechanisms and treatment of pain. We, thus, owe them to approach the ethics of pain research as seriously as we approach the science and try to minimize the impact it can have on them.

\section{Speaker 2}

\section{ASSESSMENT OF PAIN IN ANIMALS: THE VETERINARIAN'S POINT OF VIEW}

\section{Hélène Héon}

Centre de recherche du Centre hospitalier de l'Université de Montréal, Montréal, Québec

Any person who has been confronted with the difficulty of determining whether or not an animal is suffering, knows how pain assessment in animals constitutes a real challenge. In the veterinarian's practice, this can translate into the type of situation where the owner of a nice waging, foolish dog describes his pet as being "not the same". The task can be even more difficult with laboratory animals when the investigator is asking the veterinarian "Do you think this rat is in pain?" The recognition of "obvious" clinical signs of pain in animals is, of course, not difficult, and treatment is usually effective. However, determination of mild or moderate pain can be truly challenging as the clinical signs or behavioral changes can be very subtle in animals. Although pain behaviors in humans and in animals share some common characteristics, animals express their pain in many different ways. The situation is further complicated by the fact that a variety of factors can affect the animal response and mask its pain-related behaviors. Pain assessment in animals remains purely subjective and its adequacy depends largely on the experience of the observer. This presentation will provide an overview of the clinical and behavioral signs of pain in animals, based on the veterinary research literature. Factors that contribute to accurate pain estimation in animals will also be emphasized. Some of the available scoring systems will be presented and the need to develop finer pain graduation methods will be stressed.

\section{SATURDAY, MAY 12, 2001 - 15:45-17:00 CONCURRENT WORKSHOP \# 9 On the psychobiological basis of "hysterical" anesthesia in chronic pain patients}

\author{
Chairperson: Angela Mailis \\ Comprehensive Pain Program, Toronto Western Hospital, \\ University Health Network, Toronto, Ontario
}

FOCUS STATEMENT: Non Dermatomal Somatosensory Deficits (NDSDs) have been traditionally considered "hysterical" or "nonorganic" in origin. The symposium will present a scientific framework relating these deficits to CNS maladaptive neuroplasticity.

EDUCATIONAL OBJECTIVES: 1. Review current status of knowledge regarding NDSDs in humans; 2. Examine recent data re: prevalence/characteristics of NDSDs; 3. Present novel fMRI data; 4. Attempt to shed light into the neurocircuits and psychobiology of NDSD.

ABSTRACT: The Symposium will explore the characteristics and nature of Non Dermatomal Somatosensory Deficits (NDSDs) that have puzzled clinicians for many years. Since NDSDS do not confine to peripheral nerve or dermatomal distribution, they are considered "non organic". Dr. Mailis will a) present illustrative case reports, b) review current literature regarding the prevalence and dynamic nature of NDSDs, c) visit the concept of "hysteria" and its evolution since antiquity and d) present novel research into the epidemiology and temporal, spatial and qualitative characteristics of NDSDs. Dr. Davis will report functional imaging data on several representative cases. Dr. Magnusson will produce a scientific framework related to the psychobiology of NDSDs, approaching the subject from a "total person's perspective". At the conclusion of the symposium the 3 presenters will support the positions that: a) NDSDs maybe viewed as the result of CNS maladaptive neuroplasticity, b) potentially occuring in the context of certain personality organizations and/or psychosocial stressors, and c) appearing in the presence or even the absence of peripheral physical pathology. Directions for future research relating to the generation, maintenance, evolution and resolution of NDSDs, their relationship to perceived pain and implications for clinical practice will be discussed.

\section{Speaker 1}

\section{PREVALENCE AND SPATIAL, TEMPORAL AND QUALITATIVE CHARACTERISTICS OF NON-DERMATOMAL SOMATOSENSORY DEFICITS (NDSDS) IN CHRONIC PAIN PATIENTS}

\author{
Angela Mailis \\ Comprehensive Pain Program, Toronto Western Hospital, \\ University Health Network, Toronto, Ontario
}

The symposium will explore the characteristics and nature of Non Dermatomal Somatosensory Deficits (NDSDs) that have puzzled clinicians for many years and are traditionally considered to be the product of "hysteria" or "non organic disorders". I will a) present illustrative case reports, b) review current literature regarding the prevalence and dynamic nature of NDSDs, c) visit the concept of "hysteria"; and its evolution since antiquity, and d) present novel research into the epidemiology and temporal, spatial and qualitative characteristics of NDSDs. My position, based on research conducted in my institution plus the existing literature, is that a) NDSDS may be viewed as the result of CNS maladaptive neuroplasticity, b) potentially occur in the context of certain personality organizations and/or psychosocial stressors, and c) happen in the presence or even absence of peripheral physical pathology. Directions for future research relating to the generation, maintenance, evolution and resolution of NDSDs, as well as implications for clinical practice, will be discussed in conjunction with my copresenters. 


\section{Speaker 2}

\section{FUNCTIONAL IMAGING OF "HYSTERICAL" ANESTHESIA}

\author{
Karen D Davies, Jane E Magnusson, Angela Mailis \\ Department of Neurosurgery, Toronto Western Hospital, \\ University Health Network, Toronto, Ontario
}

The hallmark of "non-organic" pain disorders is considered to be non-dermatomal sensory deficits (NDSD) to various cutaneous sensory modalities (touch, pin prick, cold), ranging from hypaesthesia to complete anaesthesia in the absence of substantial pathology. The prevalence of NDSDs in chronic pain populations may be more than $40 \%$. The DSM-IV classification of Somatoform Disorders includes the subtype of "Conversion Disorder with unexplained motor and/or sensory symptoms in the absence of pathology". Psychological factors are judged to be associated with the symptoms or deficits. However, psychological and other nonorganic factors do not account for all aspects of NDSD. Consequently, chronic pain patients with NDSD pose a great challenge for both diagnosis and management. We hypothesized that if an organic factor contributed to reduced sensation in non-malingerers with NDSD, then functional imaging would reveal an altered sensory-evoked response in the primary somatosensory cortex (S1). To test this hypothesis, we investigated 3 chronic pain patients with NDSD. We describe lack of activation of the primary somatosensory cortex with fMRI in three patients with intractable pain in anaesthetic limbs in the absence of detectable pathology. The findings support a neurophysiological substrate underlying "conversion" disorders.

\section{Speaker 3}

\section{THE BIOPSYCHOLOGY OF CHRONIC PAIN DISORDERS: THE NEUROPLASTICITY OF NON-DERMATOMAL SENSORY DEFICITS}

\author{
Jane E Magnusson \\ Department of Clinical Neurosciences, University of Calgary, \\ Calgary, Alberta
}

Pain involves the perception of an aversive sensation and thus serves a vital role in the maintenance of an organism. However, once pain persists beyond this adaptive role it becomes chronic and maladaptive. What causes this adaptive response to become maladaptive remains unclear. The nature of chronic pain is made even more puzzling by the existence of such "non-organic" pain disorders as non-dermatomal sensory deficits (NDSDs). NDSDs are characterized by the patient's abnormal reaction to various cutaneous stimuli. Using the modalities of touch, pin prick, vibration or cold, patients report a range of responses from hyperaesthesia to complete analgesia despite the fact that they do not have significant pathology. As pain is a multidimensional experience involving physiological, affective and attentional mechanisms, it is likely that these factors contribute to the experience of pain and to chronic pain disorders such as NDSD. For example, peripheral tissue and nerve damage often leads to pathological pain syndromes such as phantom limb pain, spontaneous pain, hyperalgesia, and allodynia which occur due to long-lasting changes in central nerv- ous system function such that the injury itself is no longer the primary source of pain. Similarly, in "non-organic" pain disorders such as NDSD, central nervous system plasticity is likely a critical component. However, in contrast to other pain disorders, the plasticity mechanisms of patients with NDSD may have more to do with the attentional and affective components of pain as opposed to the physiological as the sensory phenomena occur in the absence of substantial pathology. It is therefore essential that psychological variables be considered in these chronic pain disorders as they likely play an important and interactive role in mediating mechanisms of nociception and tonic inhibition.

\section{SATURDAY, MAY 12, 2001 - 15:45-17:00 CONCURRENT WORKSHOP \#10 Mechanisms of neuropathic pain and its treatment}

\author{
Chairperson: Terence J Coderre \\ Department of Anesthesia, McGill University, \\ Montreal, Quebec
}

OVERVIEW: Neuropathic pain is defined as pain in which the predominating mechanism is a site of aberrant somatosensory processing in the peripheral or central nervous system. Peripheral neuropathic pain occurs when the lesion or dysfunction affects the peripheral nervous system. Central pain occurs when the lesion or dysfunction affects the central nervous system. Pains of neuropathic origin are highly resistant to many therapeutic interventions, and due to their intractable nature, represent a significant proportion of types of pain that are seen in clinical practice. The recent introduction of various animal models has greatly expanded our knowledge concerning neuropathic pain mechanisms and its treatment. Our speakers will discuss recent advances in the understanding of the neurochemical mediators and neuroimmune contributions to neuropathic pain, as well as pharmacological treatments for neuropathic pain in preclinical animal models. Dr. Loomis will examine the role of spinal prostaglandins and glutamate in the development of tactile allodynia in a nerve ligation model, and the ability of COX inhibitors and a prostaglandin (EP1) receptor antagonist to alleviate it. Dr. Bennett will present evidence that cytokines contribute to neuropathic pain in an animal model of neuritis, and that neuropathic pain in this model is alleviated by immunosuppressant, as well as anti-inflammatory agents. Dr. Sawynok will discuss the nature of the therapeutic actions of amitriptyline in both the formalin test and the spinal nerve ligation model, comparing the effects of systemic, spinal and local peripheral administration of the agent. 


\section{Speaker 1}

\section{SPINAL PROSTAGLANDINS IN TACTILE ALLODYNIA: EVIDENCE FROM THE SPINAL NERVE LIGATION MODEL}

\author{
Christopher W Loomis \\ School of Pharmacy, Memorial University of Newfoundland, \\ St John's, Newfoundland
}

Spinal prostaglandins (PGs) have a documented role in normal nociception. Sustained C-fiber activity induces the expression of cyclooxygenase (COX) in the spinal cord, and an increase in spinal PG synthesis. PGs evoke glutamate release from the spinal cord and sensitize spinal neurons to nociceptive input. These observations have raised questions about the putative role of spinal PGs in abnormal (neuropathic) pain states. In fact, there is growing evidence that products of the arachidonic acid cascade, generated in the spinal cord by low threshold afferent, contribute to the development and early maintenance of allodynia. In the spinal nerve ligation model of neuropathic pain, light brushing of the allodynic hind paw significantly increased the concentration of $\mathrm{PGE}_{2}$ in spinal microdialysate samples collected from conscious, unrestrained rats. Brushing of the ipsilateral hind paw in sham-operated rats was without effect. Tactile allodynia in this model was significantly attenuated by the intrathecal (i.t.) delivery of COX inhibitors, or the PG (EP1)-receptor antagonist, SC-51322. All inhibitory effects were stereo-selective and/or dose-dependent. Subsequent pharmacological studies revealed a marked increase in the PG-evoked release of glutamate from the spinal cords of allodynic versus sham-operated rats. These results suggest an increased sensitivity to PGs in the spinal cord of nerve injured animals, and are consistent with reports that i.t. PGs induce hyperalgesia and allodynia in conscious rats and mice. The implications of these results, and the contribution of spinal PGs in tactile allodynia will be discussed.

\section{Speaker 2}

\section{NEUROIMMUNE INTERACTIONS AND THE GENESIS OF PAINFUL PERIPHERAL NEUROPATHY}

\section{Gary J Bennett}

Faculty of Dentistry and Department of Anesthesia

McGill University, Montreal, Quebec

Painful peripheral neuropathies occur when nerves are damaged by trauma or disease. In most of these cases, structural damage to axons and their ensheathing glia occurs together with an inflammatory response that mobilizes the immune system. Immune system involvement obviously occurs when the nerve damage is due to an infection or an autoimmune reaction, but the immune system is also mobilized in the absence of infection, because cellular debris is an immune stimulus. A model of sciatic nerve inflammation in the absence of significant structural damage (the neuritis model of Eliav et al. 1999) has been shown to produce neuropathic pain in the hind paw, and it has been hypothesized that this pain is the result of a neuroimmune interaction.

Using the neuritis model, it has been shown that there is an endoneurial inflammatory response (even though the immune stimulus is applied to the outside of the nerve) that consists of the rapid appearance of neutrophils, followed by an invasion of mast cells, macrophages, T-lymphocytes, and the activation of microglia cells. Immunocytochemical analyses show a massive increase in the presence of pro-inflammatory cytokines, including tumor necrosis factor-alpha (TNF $\alpha$ ) and interleukin-1-beta (IL-1 $\beta$ ). Schwann cells are seen to be a major source of TNF $\alpha$ and IL-1 $\beta$, with staining originally concentrated in the perinuclear cytoplasm and subsequently spreading along the internode, either within the outermost lamellae or extracellularly beneath the basement membrane. The effects of immunosuppressant drugs have been tested in both the neuritis model and in the chronic constriction injury (CCI) model of Bennett and Xie (1988) where there is both an inflammatory response and massive structural injury to the nerve. Thalidomide, which inhibits the release of TNF $\alpha$, partially but significantly decreased the abnormal pain sensations seen in CCI rats but had no effect at all in the neuritis model. Cyclosporin A, which is widely used to prevent organ transplant rejection, blocked the neuropathic pains in both CCI and neuritis models in a dosedependent manner. Methylprednisolone, a potent anti-inflammatory corticosteroid, blocks the pain in both models, and in the neuritis model it significantly decreases the number of TNF $\alpha$-positive mast cells in the endoneurial compartment. Taken together, these data and recent work from other laboratories indicate that one or more neuroimmune interactions play a major role in the genesis of painful peripheral neuropathy. For comparison, we have also tested the effects of these drugs in animals with the chronic constriction injury (CCI) model of Bennett and Xie (1988). In CCI rats, the sciatic nerve has considerable structural damage in addition to an inflammatory process. We report here that cyclosporin A reduces neuropathic pain in a dose-related manner in both the neuritis and CCI models. However, thalidomide has no more than a minor effect in the neuritis model, while producing a significant (but partial) reduction in the CCI pain syndrome.

\section{Speaker 3}

\section{ANTIDEPRESSANTS AS ANALGESICS IN PRECLINICAL MODELS OF CHRONIC PAIN}

Jana Sawynok, Michael I Esser, Allison R Reid

Department of Pharmacology, Dalhousie University, Halifax, Nova Scotia

Amitriptyline is widely used in the treatment of neuropathic and chronic pain states in humans. In this study, we have evaluated the effects of amitriptyline in the formalin test (a model of central sensitization) and the spinal nerve ligation model (a peripheral nerve injury model). In the formalin test, systemic administration of amitriptyline enhances flinching and, at the same time, suppresses biting/licking behaviours. Spinal administration reproduces these effects, but local peripheral administration into the hindpaw suppresses both behaviours. In the spinal nerve ligation model, systemic, spinal and local peripheral administration of amitriptyline all inhibit thermal hyperalgesia, but have no effect on static mechanical allodynia in the paw ipsilateral to the nerve ligation. However, both systemic and spinal amitriptyline produce a hyperaesthesia in the contralateral paw. Chronic administration of 
amitriptyline in the drinking water for 3 weeks reproduces the effects observed with acute administration of amitriptyline. These observations lead us to conclude: (a) amitriptyline actions against biting/licking but not flinching behaviours in the formalin test reflect analgesic properties reported in humans, (b) local peripheral application of amitriptyline may be a useful route by which to administer amitriptyline, (c) amitriptyline (acute/chronic) produces complex effects on the expression of pain behaviours following spinal nerve ligation, and (d) optimal pain control in humans may require combinations of agents that target different components of pain. (Supported by CIHR/Regional Partnership Program).

\section{SATURDAY, MAY 12, 2001 - 15:45-17:00 CONCURRENT WORKSHOP \#11 Establishing a multidisciplinary chronic pelvic pain unit that meets the needs of women}

\section{Chairperson: Allan Gordon}

Wasser Pain Management Centre, Mount Sinai Hospital, Toronto, Ontario

FOCUS STATEMENT: The workshop will highlight the biopsychosocial factors involved, provide an overview of empirical and clinical literature and present a multidisciplinary treatment approach through case examples and discussion.

\section{EDUCATIONAL OBJECTIVES:}

At the conclusion of this workshop, participants will be able to:

a) recognize conditions producing CPRP

b) identify the expertise and factors required in order to assess CPRP

c) approach the treatment of CPRP from a multi-disciplinary pain perspective

d) identify potential barriers to effective treatment for CPRP

e) identify strategies that address potential challenges and barriers in managing $\mathrm{CPRP}$

f) become familiar with some of the literature in this area and identify gaps requiring further research

Chronic Pelvic Region Pain (CPRP) is very common among women. It is estimated to comprise up to $15 \%$ of outpatient gynecological referrals, and $12-39 \%$ prevalence rates have been reported. It is associated with high economic and social costs. Recent studies suggest that $50-75 \%$ of women experience significant pain with sexual activity during their lifetime. The aim at the Wasser Pain Management Centre has been to develop a comprehensive interdisciplinary approach to the evaluation, diagnosis and treatment of these patients and to include CPRP into the mainstream of pain management and research. An emerging perspective in women's health proposes that the biological, psychological and social factors interact to influence both the onset and course of illness and treatment behaviour, suggesting a biopsychosocial approach. For example, symptoms may be generated from physiological disturbances which are connected to the nervous system activity. The symptom-reporting, health care seeking and illness behaviour may interact with potentially detrimental factors, such as lack of social support, decreased validation, the promotion of self-silencing, increased stress and ineffective coping strategies that can play a role in both the onset and the perpetuation of CPRP. The biopsychosocial model proposes a multi-disciplinary team approach from the initial stage of assessment throughout the course of treatment, promoting optimal care.

\section{Speaker 1}

\section{WHAT IS CPRP?}

Allan Gordon

Wasser Pain Management Centre, Mount Sinai Hospital, Toronto, Ontario

Chronic pelvic region pain is the name applied to those non-malignant disorders producing pain in the pelvis, vulva and other genital regions for a period of 6 months or more. The author will describe vulvar vestibulitis, vulvodynia and some of the other genital pain syndromes as well as endometriosis and muscle pain syndromes. Pain specialists need to become familiar with these syndromes as they are often seen in women referred to pain clinics or who should be referred. Women with these conditions often have other pain syndromes as well. More trials needed to determine what is the most effective treatment. An illustrative case will be presented.

\section{Speaker 2}

\section{PSYCHOSOCIAL FACTORS IN CHRONIC PELVIC PAIN IN WOMEN - THE CASE FOR VALIDATION}

\section{Mary Jane Esplen \\ Department of Psychiatry, University of Toronto, Toronto, Ontario}

Chronic pelvic pain is a common gynecological problem which is poorly understood. A physical cause for the pain is often difficult to establish, and consequently it has been challenging to treat successfully. With the difficulty in pinpointing a physical causation for pain, researchers and clinicians have attempted to identify psychopathological causation. Factors studied to date have included personality and mood disturbance, past history of trauma, particularly sexual abuse and relationship, and sexual functioning difficulties. The challenges in determining an etiology for chronic pelvic pain have frequently resulted in women feeling misunderstood, confused and has left them with a sense that that their condition is "psychological", thereby potentially exacerbating feelings of shame, anger and self-blame, which may contribute to increased self-silencing and further stress. Recently, chronic pelvic pain has been identified as being best understood through a biopsychosocial model, both clinically and empirically. Within this conceptualization, symptoms may be generated from physiological disturbances which are connected to the nervous system activity. The symptomreporting, health care seeking and illness behavior interact with potentially detrimental factors, for example, lack of social support, decreased validation, increased stress and self-silencing and ineffective coping strategies, in both the onset and in the perpetuation of chronic pelvic pain. The presentation will include a brief overview of the psychological and social factors involved with application of the biopsychosocial model through case presentations. 


\section{Speaker 3}

\section{CHRONIC PELVIC PAIN: A CASE PRESENTATION}

\author{
Marilyn Galonski \\ Wasser Pain Management Centre, Mount Sinai Hospital, \\ Toronto, Ontario
}

From the viewpoint of many women visiting the Pelvic Pain Unit of the Wasser Pain Management Centre, the healthcare system has largely ignored them or brushed them aside. It is not unusual for this unique group of women to have visited a multitude of healthcare practitioners for a considerable number of years prior to attending our Centre, having acquired many myths and misunderstandings along the way. Living with chronic pelvic pain, treatment for chronic pelvic pain and learning to cope all represent quite a challenge. To meet this challenge the Wasser Pain Management Centre has organized a Team of Healthcare professionals dedicated to the needs of these women. This integrated Team approach does not focus on a specific treatment method but rather a menu of treatment options that is individualized for each patient. This workshop will focus on the patient process, assessment and treatment, which may include acupuncture, surface electromyography, physiotherapy and pharmacotherapy, through a case presentation.

\section{SATURDAY, MAY 12, 2001 - 15:45-17:00 CONCURRENT WORKSHOP \#12 Élaboration et implantation d'un programme de soulagement de la douleur auprès de personnes atteintes de cancer avancé suivies à domicile}

\section{Chairperson: Lise Fillion}

Faculté des sciences infirmières, Université Laval, Québec, Québec

OBJET : Cet atelier de recherche vise à présenter une étude en cours subventionnée par le FRSQ portant sur l'implantation et l'évaluation d'un programme de soulagement de la douleur auprès de personnes atteintes de cancer avancé suivies à domicile. Comme la cueillette de données est en cours, l'atelier portera sur : 1) Un état de question et une justification de la pertinence de développer la recherche clinique dans le domaine , 2) l'élaboration du programme expérimental d'intervention (contenu et matériel), 3) la description du devis de recherche et des variables retenues, et 4) les difficultés rencontrées lors de l'implantation du projet en milieu clinique.

OBJECTIFS ÉDUCATIFS : À la fin de la séance, les participants auront appris à :

- délimiter l'importance et l'impact de la douleur chez les patients atteints de cancer avancé suivis à domicile

- identifier les facteurs qui influencent le soulagement de la douleur à domicile

- reconnaître chez les patients, les proches, les professionnels soignants ainsi qu'au sein des organisations de travail, les principaux obstacles au traitement optimal de la douleur

- reconnaître les principales stratégies thérapeutiques pour améliorer le soulagement de la douleur

- identifier les principales étapes d'implantation et d'évaluation d'un programme d'intervention

- comprendre le processus de recherche permettant l'évaluation de l'efficacité d'un tel programme à optimiser le soulagement de la douleur et à améliorer la qualité de vie du patient et de ses proches

RÉSUMÉ : Le soulagement de la douleur est une condition essentielle au maintien à domicile des personnes atteintes de cancer avancé. Même si la douleur peut être soulagée dans presque $90 \%$ des cas en appliquant des principes thérapeutiques simples, la situation réelle est différente et déplorable. Il devient primordial que les intervenants de première ligne (infirmières et médecins) se dotent d'une stratégie d'intervention cohérente et efficace pour optimiser le soulagement de la douleur chez cette clientèle. L'objectif de cet atelier est de présenter une étude en cours portant sur l'élaboration, l'implantation et l'évaluation d'un programme de soulagement de la douleur auprès de personnes atteintes de cancer avancé suivies à domicile. Comme la cueillette de données est en cours, l'atelier portera sur les thématiques suivantes : 1) Un état de question et une justification de la pertinence de développer la recherche clinique dans le domaine, 2) l'élaboration du programme d'intervention (contenu et matériel), 3) la description du devis de recherche et des variables, et 4) les difficultés rencontrées lors de l'implantation. La première communication abordera les deux premiers thèmes alors que la seconde traitera des suivants. À la fin de l'atelier, le participant aura appris à délimiter l'importance et l'impact de la douleur chez les patients atteints de cancer avancé et suivis à domicile, à identifier les facteurs qui influencent la douleur et les lignes directrices pour son traitement, et à reconnaître les principaux obstacles à son soulagement. De plus, l'atelier permettra de se familiariser avec le processus de recherche évaluative.

\section{Speaker 1}

\section{ÉLABORATION D'UNE INTERVENTION POUR SOULAGER LA DOULEUR AUPRÈS DE PERSONNES ATTEINTES DE CANCER AVANCÉ SUIVIES À DOMICILE}

Lise Fillion, Michèle Aubin, Raymonde Parent, Pierre Allard, Rénald Bergeron, Suzanne Cayer

Faculté des sciences infirmières, Université Laval, Québec, Québec

Dans le cadre d'un projet de recherche en cours portant sur l'implantation et l'évaluation d'un programme de soulagement de la douleur auprès de personnes atteintes de cancer avancé suivies à domicile, une première démarche a été d'effectuer une recension des écrits afin de préciser le concept de douleur, la prévalence, les principaux facteurs associés, les lignes directrices en terme de traitement optimal, les principales barrières au soulagement et les résultats de recherches évaluatives. La première partie de l'atelier de recherche portera sur le résultat de cette recension des écrits. Suite à cette recension, une seconde étape a été d'élaborer un programme d'intervention visant à optimiser le soulagement de la 
douleur chez la clientèle retenue. La seconde partie de cette communication portera sur la présentation des trois volets du programme d'intervention comme tel, soit : 1) le contenu et le format de la formation sur le contrôle de la douleur auprès des infirmières impliquées dans le suivi à domicile des patients atteints de cancer avancé, 2) l'utilisation par les patients d'un carnet de douleur pour documenter de façon régulière l'intensité de leur douleur, 3) la transmission aux patients et à leurs aidants d'un plan d'action à utiliser lors de perte de contrôle de la douleur. Pour chacun de ces volets, le matériel et la démarche standardisée d'application seront présentés. À la fin de cette présentation, le participant aura acquis des connaissances sur les fondements théoriques de l'intervention et le développement d'outils cliniques standardisés pouvant être utilisés dans un contexte de recherche.

\section{Speaker 2}

\section{IMPLANTATION D'UN PROGRAMME POUR SOULAGER LA DOULEUR AUPRÈS DE PERSONNES ATTEINTES DE CANCER AVANCÉS SUIVIES À DOMICILE ET DÉMARCHE ÉVALUATIVE: BARRIÈRES ET AVANTAGES}

\section{Michèle Aubin, Lise Fillion, Raymonde Parent, Pierre Allard, Lucie Vézina, Serge Dumont \\ Université Laval, Québec, Québec}

Un programme d'intervention a été implanté dans le cadre d'un projet de recherche subventionné par le FRSQ afin d'améliorer le soulagement de la douleur de personnes atteintes de cancer avancé suivies à domicile. Puisque l'objectif ultime du projet de recherche est d'évaluer l'efficacité de ce programme, l'implantation s'est effectuée dans un contexte de recherche clinique évaluative. Le premier but de cette communication est de présenter la démarche de recherche comme telle. Le devis quasi expérimental sera d'abord présenté. On y expliquera comment le programme d'intervention a été implanté dans un CLSC de la région de Québec (milieu expérimental) tout en tenant compte de bien l'intégrer dans la routine des soins infirmiers en place. De façon concomitante, un second CLSC de la région de Québec n'ayant pas été exposé au programme a été invité à participer à titre de milieu témoin. Dans les deux groupes, les données sont colligées à trois temps de mesure auprès des patients, de l'aidant principal des malades, et des infirmières impliquées dans le suivi de cette clientèle. S'ajoutant à la variable indépendante (assignation au groupe quasiexpérimental ou au groupe témoin), les variables dépendantes (douleur et qualité de vie) et d'autres variables explicatives seront également présentées (ex., attitudes et croyances, efficacité personnelle). D'autres aspects méthodologiques seront discutés. Les contraintes associées à la démarche scientifique de même que les principaux avantages et inconvénients notés lors de l'implantation termineront cette présentation. Cette communication familiarisera les participants au processus de la recherche évaluative.

\section{SATURDAY, MAY 12, $2001-15: 45-17: 00$ CONCURRENT WORKSHOP \#13 Treating the chronic pain patient in an outpatient physiotherapy facility}

Chairperson and Speakers: D Gloria Gilbert, Sharon Richman, Nicole Paquet

The Downtown Clinic, London, Ontario; Research Centre, Jewish Rehabilitation Hospital, Montreal, Quebec

FOCUS STATEMENT: Only a small percentage of chronic patients are treated in a multi-disciplinary pain clinic environment. Most patients with persistent pain are first seen in an out patient physiotherapy facilities. By expanding the assessment process, the physiotherapist can identify the at-risk patient and more effectively develop treatment protocols.

EDUCATIONAL OBJECTIVES: At the conclusion of the workshop, the health practitioner will be able to develop a more realistic treatment plan for the chronic pain patient and/or the patient who is at high risk for developing persistent pain problems.

ABSTRACT: Assessing and treating patients with chronic nonmalignant soft tissue pain would be a challenge for the physiotherapist (PT) working in an out-patient environment. Many of these patients benefit from a multi-disciplinary approach to treatmentsuch as that which can be offered in a pain clinic. The majority of patients however continue to be followed in a more traditional PT environment, either hospital-based or private practice. By expanding the assessment procedure to include information on psychosocial variables (i.e coping style and general health status) and by implementing realistic rehabilitation goals, the PT can provide more efficient and effective treatment/management programs. The PT must be knowledgeable about the current neurophysiology of pain and the use of pain self-management (mostly electro therapeutic) devices. The PT must also be able to better use community resources, essentially creating a mini out-patient pain management environment.

This workshop will follow a case study approach and address the following areas:

1. The initial PT assessment process....expanding beyond the physical examination.

2. Using staff more effectively by taking the chronic pain patient out of the medical model to one which is self-directed and guided by the PT.

3. Assisting the patient in applying self-management pain methods learned in the Clinic to the home, work and leisure activities.

4. Maintaining an open PT file.....so that if the patient returns for " treatment", re-assessment is brief and focused on previously established rehabilitation goals.

The basic pharmacology of different drugs and the use and theory of electro therapeutic devices for pain management will be an integral component of the discussion. 
FRIDAY, MAY $11-8: 30$

to SATURDAY, MAY 12 - 11:45

POSTER SESSION

P-1

\section{NMDA RECEPTOR AND mGIUR CONTRIBUTIONS TO CAPSAICIN-INDUCED THERMAL AND MECHANICAL HYPERSENSITIVITY}

\section{[CONTRIBUTIONS DES RÉCEPTEURS NMDA ET mGIUR À L'HYPERSENSIBILITÉ THERMIQUE ET MÉCANIQUE INDUITE PAR LA CAPSAÏCINE]}

Alexandra Soliman, Terence J Coderre

Department of Anesthesia, McGill University, Montreal, Quebec

INTRODUCTION: After determining the time of peak thermal and mechanical hypersensitivity caused by sub-dermal injection of capsaicin into the rat hindpaw, the antinociceptive effects of intrathecal pretreatment with various mGluR agonists and antagonists, as well as an NMDA antagonist were assessed.

METHODS: Selective group II ((2R,4R)-APDC) and group III (L-AP4) agonists, as well as selective mGluR1 (RS-AIDA) and mGluR5 (MPEP) subtype antagonists, and selective NMDA antagonist MK-801, were administered intrathecally in male LongEvans rats. Drugs were administered using a lumbar puncture while rats were lightly anaesthetized with halothane, 5 minutes prior to capsaicin injection in the hindpaw. The rats were observed for signs of capsaicin-induced mechanical and thermal hypersensitivity 15 minutes after capsaicin injection. Mechanical hypersensitivity was assessed by determining the $50 \%$ response threshold to stimulation with von Frey hairs. Thermal hypersensitivity was determined by measuring the reduction in paw-withdrawal latency from water at $47^{\circ} \mathrm{C}$.

RESULTS: There was a dose-dependent reduction in capsaicininduced mechanical hypersensitivity for all mGluR and NMDA agents. However, only a weak reduction (non-significant) in thermal hypersensitivity was observed with each of the mGluR agents, though a modest but significant dose dependent reduction in capsaicin induced hypersensitivity was observed with MK-801.

IMPLICATIONS: We conclude that mGluRs contribute to the development of mechanical allodynia, but not thermal hyperalgesia, following capsaicin injury, whereas NMDA agents may contribute to both these types of hyperalgesia.

Supported by Medical Research Council of Canada grant to TJC
P-2

VANILLOID VR-1 RECEPTOR INVOLVEMENT IN PATHOPHYSIOLOGY OF ADJUVANT-INDUCED MONO-ARTHRITIS IN A RAT MODEL

[IMPLICATION DES RÉCEPTEURS VANILLOÏDES VR-1
DANS LA PATHOPHYSIOLOGIE DE LA MONO-
ARTHRITE INDUITE PAR ADJUVANT DANS UN
MODĖLE UTILISANT LE RAT]

Reza Sharif Naeini, Claire Robinson, James L Henry

Department of Psychiatry, McGill University,

Montreal, Quebec

INTRODUCTION: The vanilloid VR-1 receptor is a capsaicinsensitive, ligand-gated cation channel localized in a sub-population of small diameter primary afferent fibers. In situ hybridization and immunohistochemical studies have demonstrated that VR-1 mRNA and VR-1 receptor protein levels are increased in chronic inflammatory states. We examined the contribution of VR-1 receptors to pathophysiological changes seen in the animal model of Complete Freund's Adjuvant (CFA)-induced monoarthritis.

METHODS: CFA was injected intra-articularly in the tibio-tarsal joint of male Sprague-Dawley rats $(25 \mu \mathrm{L})$. The VR-1 antagonist capsazepine (CPZ, $100 \mathrm{nmol}$ ) was administered twice daily for 17 days via a PE-10 tubing located subcutaneously over the injected joint. Ankle circumference, plasma extravasation using Evans Blue dye and spectrophotometric analysis at $620 \mathrm{~nm}$, the degree of movement, subcutaneous $\mathrm{pH}$ and mechanical threshold using Von Frey hair applied to the ankle were quantitated.

RESULTS: Intra-articular injection of CFA produced a significant increase in the ankle circumference, an increase plasma extravasation in the region of the injury, a decrease in the degree of movement of the joint and in the mechanical threshold. CPZ significantly reduced the increase in circumference (days 13 to 17) and in plasma extravasation (day 17) and increased the degree of movement. There was no difference between capsazepine-treated and control animals for subcutaneous $\mathrm{pH}$ (day 17) or mechanical threshold.

CONCLUSION: These results suggest that VR-1 receptors are differentially involved in the pathophysiology of adjuvant-induced monoarthritis and provide evidence that targeting these receptors can be beneficial in the treatment of arthritis.

Supported by CIHR to JLH 
INTRAPLANTAR GLUTAMATE INDUCES THE RELEASE OF ADENOSINE IN THE RAT HIND PAW: INVOLVEMENT OF PERIPHERAL NMDA AND NON-NMDA RECEPTORS

\section{[L'INJECTION INTRAPLANTAIRE DE LA GLUTAMATE INDUIT LA RELÂCHE DE L'ADÉNOSINE DANS LA PATTE POSTÉRIEURE DU RAT : IMPLICATION DES RÉCEPTEURS NMDA ET NON-NMDA AU NIVEAU PÉRIPHÉRIQUE]}

Xue Jun Liu, Thomas D White, Jana Sawynok Department of Pharmacology, Dalhousie University, Halifax, Nova Scotia

INTRODUCTION: Activation of central glutamate receptors can lead to adenosine release in both brain and spinal cord. Recently, peripheral glutamate receptors have been localized on primary sensory afferents and there is accumulating evidence indicating that glutamate also plays an important role in the peripheral transmission of pain. The present study investigated the potential involvement of peripheral glutamate receptors in local adenosine release. METHODS: Microdialysis probes were inserted into the subcutaneous tissue of the plantar surface of the hind paws in anaesthetized rats. Samples were collected every $10 \mathrm{~min}$ at a perfusion rate of $2 \mu \mathrm{l}$ per min, and adenosine levels were determined with high performance liquid chromatography (HPLC). All drugs were injected parallel to the probes in a final volume $50 \mu 1$.

RESULTS: Subcutaneous injection of L-glutamate (0.03, 1, 10, $100 \mu \mathrm{mol})$ induced a dose-related increase of local adenosine levels. The increase of release was observed within the first $10 \mathrm{~min}$ following injection. Co-administration of a N-methyl-D-aspartate receptor antagonist, MK801 $(1,10 \mathrm{nmol})$ and a non-NMDA receptor antagonist, CNQX (10 nmol), significantly inhibited L-glutamate $(1 \mu \mathrm{mol})$ induced release of adenosine.

DISCUSSION: These findings indicate that peripheral activation of glutamate receptors induces an increase in adenosine levels in the rat hind paw. Both NMDA and non-NMDA receptors are involved in this effect. As glutamate is released into the rat hind paw following formalin induced inflammation and nerve stimulation, the present study suggests that part of the increased adenosine levels observed in some inflammatory pain and neuropathic pain models may be secondary to the activation of peripheral NMDA and non-NMDA receptors.

Supported by MRC Canada. XJ Liu is a Killam Scholar.
IN VITRO PHARMACOLOGY OF CLONED HUMAN NPFF RECEPTORS

\section{[PHARMACOLOGIE IN VITRO DES RÉCEPTEURS HUMAINS CLONÉS DE NPFF]}

Mylène Gosselin, Martin Coupal, Jean Labrecque,

Maryse Labarre, Alain Steyaert, Ralph Schmidt, Sultan Ahmad,

Philippe Walker, Kemal Payza

AstraZeneca R\&D Montreal, St-Laurent, Quebec

INTRODUCTION: NPFF is an octapeptide involved in nociception, and recently two NPFF receptor subtypes have been cloned; NPFF1 and NPFF2.

METHOD: In order to study the ability of ligands to bind and activate the NPFF2, we expressed the hNPFF2 receptor in HEK293S/Gaqi5 cells. The binding was studied in competitive displacement experiments with $\left[{ }^{125} \mathrm{I}\right]-\mathrm{Y} 8 \mathrm{~F}-\mathrm{NH}_{2}$. The functional activation of the receptor was studied by recording intracellular calcium responses and by measuring agonist-induced $\left[{ }^{35} \mathrm{~S}\right] \mathrm{GTP} \gamma \mathrm{S}$ binding.

RESULTS: In competitive displacement experiments, the binding SAR correlated with that of rat spinal cord $\left(\mathrm{r}^{2}=0.92\right)$ although there were some differences. The hNPFF2 receptor was activated potently by NPFF, Y8Fa, (1DMe)Y8Fa, and certain other peptides ending in $\mathrm{C}$-terminal Arg-Phe- $\mathrm{NH}_{2}$. The binding and activation assays correlated well $\left(\mathrm{r}^{2}=0.80\right)$.

DISCUSSION: The hNPFF2 receptor is very similar to the predominant NPFF binding site in rat spinal cord. Differences may be due to co-localization of NPFF1 binding sites in the same tissue. The results indicate that further in vitro studies of cloned NPFF receptors may be conducted by the pharmacological techniques described herein.

P-5

\section{IN VITRO PHARMACOLOGY OF NEW HIGHLY SELECTIVE NON-PEPTIDE DELTA RECEPTOR AGONISTS}

\section{[PHARMACOLOGIE IN VITRO DE NOUVEAUX AGONISTES NON-PEPTIDERGIQUES HAUTEMENT SÉLECTIFS POUR LES RÉCEPTEURS DELTA]}

Maryse Labarre, Stéphane St-Onge, ZY Wei, Niklas Plobeck, Fei Zhou, Chantevy Pou, Joanne Butterworth, Martin Coupal, Dominic Salois, Chris Walpole, Paul Jones, Edward Roberts, Andy Dray, Kemal Payza

AstraZeneca R\&D Montreal, Montreal, Quebec

INTRODUCTION: Delta opioid receptors are recognized as important targets for development of analgesics. The objective of this study is to characterize the binding and agonist properties of novel ligands in vitro at cloned human opioid receptors and at endogenous opioid receptors in the brain membranes from rat, mouse and rhesus monkey (commercial sources of membranes).

METHODS: Our methodology involves receptor binding and $\left[{ }^{35} \mathrm{~S}\right] \mathrm{GTP} \gamma \mathrm{S}$ assays to assess affinity and agonist activity of compounds. 
RESULTS: Several compounds showed delta receptor affinity in the nanomolar range and had high selectivity for human delta receptors compared to mu and kappa (>1000-fold). The compounds showed full agonism at the human and monkey brain delta receptors, and had partial agonism in rat and mouse brain membranes. SNC86 was the most potent delta agonist at human delta receptors as well as in the mouse, rat and monkey brain membranes. Certain non-peptide delta agonists from other sources showed lower delta selectivity and weaker agonism than in-house compounds.

DISCUSSION: Our results show that assays utilizing receptors expressed at endogenous levels are critical to correctly evaluate agonist activity that might otherwise be over-estimated in receptor over-expression systems.

P-6

SPINAL PROSTANOID SYSTEMS ARE NECESSARY FOR THE DEVELOPMENT OF TACTILE ALLODYNIA FOLLOWING SPINAL NERVE LIGATION

\section{[LES SYSTÈMES SPINAUX DES PROSTANOÏDES SONT NÉCESSAIRES POUR LE DÉVELOPPEMENT DE L'ALLODYNIE TACTILE À LA SUITE D'UNE LIGATURE DES NERFS DE LA MOËLLE ÉPINIÈRE]}

Michael P Hefferan, Darren O'Reilly, Christopher W Loomis School of Pharmacy and Division of Basic Medical Sciences, Faculty of Medicine, Memorial University of Newfoundland, St John's, Newfoundland

INTRODUCTION: The purpose of this study was to test the hypothesis that spinal prostaglandins mediate the development of allodynia induced by spinal nerve ligation. Specifically, we studied: a) the effect of peri-operative administration of intrathecal (i.t.) NSAIDs on the development of tactile allodynia; and b) $\mathrm{PGE}_{2}$-evoked glutamate release from spinal cord slices harvested from ligated rats.

METHOD: Male, Sprague-Dawley rats were fitted with i.t. catheters 3 days before tight ligation of the left lumber 5/6 spinal nerves. NSAID or vehicle was administered i.t., 20 min before ligation, and every $2 \mathrm{~h}$ after for $4 \mathrm{~h}$ or $8 \mathrm{~h}$. All doses were $100 \mu \mathrm{g}$. Withdrawal thresholds of the affected hind paw were determined for 21 days using von Frey filaments. Spinal cord tissue was harvested on days 3,10 , and 20 post-ligation. Glutamate concentration was determined using the glutamate dehydrogenase/NADPH fluorescence method.

RESULTS: Withdrawal threshold was significantly reduced in the affected hind paw (4 g vs $15 \mathrm{~g}$ control) $24 \mathrm{~h}$ after ligation in vehicle-treated rats. In contrast, rats treated for $8 \mathrm{~h}$ with either $\mathrm{S}(+)$ ibuprofen or SC-560, but not R(-)-ibuprofen, did not develop allodynia. Treatment for $4 \mathrm{~h}$ with any of these drugs had no antiallodynic effect. Based on EC50 values, the glutamate-releasing effect of $\mathrm{PGE}_{2}$ does not appear to be enhanced in NSAID-treated rats as compared to allodynic (vehicle-treated) rats.

CONCLUSION: Spinal PG pathways are activated by spinal nerve ligation and are necessary for the development of allodynia. Pharmacological interruption of these pathways inhibits the development of allodynia in this model.

Supported by the CIHR and RHI
SPINAL NERVE LIGATION ELICITS SPINAL PGE RELEASE IN VIVO AND ENHANCES PGE -EVOKED $^{\text {-EVO }}$ GLUTAMATE RELEASE FROM THE SPINAL CORD OF ALLODYNIC RATS

\section{[LA LIGATURE DES NERFS DE LA MOËLLE ÉPINIÈRE INDUIT LA RELÂCHE SPINALE IN VIVO DE LA PGE ${ }_{2}$ ET AUGMENTE LA RELÂCHE DE LA GLUTAMATE ÉVOQUÉE PAR LA PGE 2 AU NIVEAU SPINAL CHEZ DES RATS ALLODYNIQUES]}

Darren D O'Rielly

School of Pharmacy and Division of Basic Medical Sciences, Faculty of Medicine, Memorial University of Newfoundland, St John's, Newfoundland

INTRODUCTION: Using the spinal nerve ligation model, we investigated: a) the in vivo release of $\mathrm{PGE}_{2}$ into spinal CSF; and b) $\mathrm{PGE}_{2}$-evoked glutamate release from spinal cord slices harvested from ligated and sham-operated animals.

METHOD: Male, Sprague-Dawley rats were fitted with i.t. microdialysis catheters 3 days before tight ligation of the left lumber 5/6 spinal nerves. Spinal microdialysis was performed in conscious, unrestrained animals 1 day before, and on days 1, 2, 5, 10, and 20 after ligation. Samples were collected before, during and after brushing the plantar surface of the affected hind paw with a cottontipped applicator. Spinal slices was harvested on days 3, 10, and 20 post-ligation. $\mathrm{PGE}_{2}$-evoked glutamate release was assayed using the glutamate dehydrogenase/NADPH fluorescence method.

RESULTS: All ligated rats developed tactile allodynia $24 \mathrm{~h}$ after ligation as determined by a decreased withdrawal threshold of the affected hind paw; sham-controls were unaffected. Brushing the affected hind paw evoked a significant increase in $\left[\mathrm{PGE}_{2}\right]$ on days 1 (259+/-59\% - no brushing), 2 (257+/-62\%), and 5 (177+/-46\%) post-ligation. In vitro, $\mathrm{PGE}_{2}$ evoked glutamate release $\left(\mathrm{EC}_{50}=\right.$ $7.2 \times 10^{-15} \mathrm{M}$ ) from control tissue. This effect was significantly enhanced in slices prepared from neuropathic rats on days $3\left(\mathrm{EC}_{50}\right.$ $\left.=1.8 \times 10^{-17} \mathrm{M}\right)$ and $10\left(3.4 \times 10^{-21} \mathrm{M}\right)$ post-ligation.

CONCLUSION: Spinal PG pathways are activated by spinal nerve ligation leading to both increased spinal $\mathrm{PGE}_{2}$ synthesis/release and sensitivity to its glutamate releasing effect. These changes may contribute to the exaggerated response to tactile input in this model of allodynia.

Supported by the CIHR and RHI

P-8

THE EFFECT OF AMITRIPTYLINE ON FOSIMMUNOREACTIVITY IN THE RAT SPINAL CORD

\section{[L'EFFET DE L'AMITRIPTYLINE SUR L'IMMUNORÉACTIVITÉ-FOS DANS LA MOËLLE ÉPINIÈRE CHEZ LE RAT]}

Caroline E Heughan, Gary V Allen, Teena Chase, Jana Sawynok Department of Pharmacology, Dalhousie University, Halifax, Nova Scotia

INTRODUCTION: Subcutaneous injection of formalin into the rat hindpaw produces dense Fos-immunoreactivity (Fos-IR) in the 
superficial layers $\left(\mathrm{LI}-\mathrm{II}_{\mathrm{o}}\right)$ and neck of the dorsal horn (LV-VI) of the lumbar spinal cord. This work compared the effect of amitriptyline (AMI), a tricyclic antidepressant used in the treatment of chronic pain syndromes, on formalin-evoked Fos-IR in the rat dorsal spinal cord following systemic, spinal, and peripheral administration.

METHODS: Male Sprague-Dawley rats were injected with saline or AMI $(15 \mathrm{mg} / \mathrm{kg}$ i.p. $\mathrm{t}=-30$ minutes, $60 \mu \mathrm{g}$ i.th. $\mathrm{t}=-10$ minutes, or $300 \mathrm{nmol}$ coadministered with formalin). Flinching and biting/licking behaviors were recorded for 60 minutes following s.c. injection of formalin $2.5 \%$ into the hindpaw. Animals were perfused at $\mathrm{t}=90$ minutes and spinal cords processed for Fos protein using standard techniques.

RESULTS: Formalin increased expression of Fos-IR in LI-II and LV-VI of the lumbar spinal cord. AMI $15 \mathrm{mg} / \mathrm{kg}$ i.p. and $60 \mu \mathrm{g}$ i.th. increased flinching and decreased biting/licking behaviors, but neither produced any statistically significant change in Fos-IR. In contrast, AMI 300nmol coinjected with formalin 2.5\% decreased both flinching and biting/licking behaviors, and significantly reduced Fos-IR in LI-II and LV-VI.

DISCUSSION: Peripherally administered AMI dramatically decreased Fos-IR in the dorsal spinal cord, while systemic and spinal administration produced no effect. These changes reflect the behavioural profile seen following these routes, as peripheral administration inhibits multiple formalin behaviors, while systemic and spinal administration enhances some and suppresses other behaviors. The exploration of the mechanism of action of peripherally administered AMI is of clinical relevance because of the potential use of antidepressants as topical analgesics.

\section{P-9}

\section{NON-OPIOID ANTINOCICEPTIVE EFFECTS OF SUPRASPINAL HISTOGRANIN AND RELATED PEPTIDES: POSSIBLE INVOLVEMENT OF THE DOPAMINE D2 RECEPTOR}

\section{[EFFETS ANTINOCICEPTIFS NON-OPIACÉS DE L'HISTOGRANINE ET DE PEPTIDES RELIÉS AU NIVEAU SUPRASPINAL : IMPLICATION POSSIBLE DU RÉCEPTEUR D2 DE LA DOPAMINE]}

H Ruan, JA Prasad, S Lemaire

Department of Molecular and Cellular Medicine, University of Ottawa, Ottawa, Ontario

The antinociceptive effects of intracerebroventricular (i.c.v.) administration of histogranin $(\mathrm{HN})$ and related peptides were assessed in the mouse writhing and tail-flick assays. In the writhing test, the peptides displayed dose-dependent analgesic effects with an $\mathrm{AD}_{50}$ of $23.9 \mathrm{nmol} /$ mouse for $\mathrm{HN}$ and the following order of potency for other peptides: HN-(7-15) < histone H4(86-100) ë HN ë HN-(7-10) < [Ser $\left.{ }^{1}\right] \mathrm{HN}<$ OGP ë HN-(1-10). $\mathrm{HN}-(6-9)$ and $\mathrm{HN}-(8-10)$ did not show any significant analgesic activity at $50 \mathrm{nmol} / \mathrm{mouse}$. The importance of the $\mathrm{C}$ - and $\mathrm{N}$-terminal amino acids in the analgesic activity of the peptides was demonstrated by the prolonged effects of $\mathrm{HN}$ and $\left[\operatorname{Ser}^{1}\right] \mathrm{HN}$ (ë $30 \mathrm{~min}$ ) as compared with those of $\mathrm{HN}$ fragments (HN-(7-15), $\mathrm{HN}-(1-10)$ and $\mathrm{HN}-(7-10)$ : 5-10 $\mathrm{min})$. The analgesic activity of
[Ser $\left.{ }^{1}\right] \mathrm{HN}$ (50 nmol/mouse) was not affected by the coadministration of opioid (naloxone, $1 \mathrm{nmol} / \mathrm{mouse}$ ), NMDA (CPP and MK801, $0.3 \mathrm{nmol} / \mathrm{mouse})$ and D1 (SCH-23390, $0.5 \mathrm{nmol} / \mathrm{mouse})$ receptor antagonists, but it was significantly antagonized by the coinjection of the D2 receptor antagonist raclopride $(0.5 \mathrm{nmol} / \mathrm{mouse})$. In the mouse tail-flick assay, $\mathrm{HN}$ and related peptides ( $50 \mathrm{nmol} / \mathrm{mouse}$ ) also showed significant analgesic activity (15\%-35\% MPE). The analgesic effect of $\left[\mathrm{Ser}^{1}\right] \mathrm{HN}$ was dosedependent and, at $75 \mathrm{nmol} /$ mouse, lasted for up to $45 \mathrm{~min}$ and was partially blocked by the coadministration of raclopride ( $1 \mathrm{nmol} / \mathrm{mouse})$, but not naloxone $(2 \mathrm{nmol} / \mathrm{mouse})$. In the mouse rotarod assay, relative high doses $(75 \sim 100 \mathrm{nmol} / \mathrm{mouse})$ of $\mathrm{HN}$ and related peptides did not significantly affect motor coordination. These results indicate that supraspinal administration of $\mathrm{HN}$ and related peptides induce significant non-opioid analgesic effects devoid of motor activity by a mechanism that involves the participation of central dopamine D2 receptors.

Supported by the Canadian Institute for Health Research

P-10

INTRACELLULAR SIGNALING MECHANISMS
CONTRIBUTING TO THE SPONTANEOUS
NOCICEPTIVE BEHAVIOURS (SNBS) INDUCED BY
INTRATHECALLY ADMINISTERED SULPHUR-
CONTAINING AMINO ACIDS (SAAs)

\section{[MÉCANISMES INTRACELLULAIRES DE SIGNALISATION CONTRIBUANT À DES COMPORTEMENTS NOCICEPTIFS SPONTANÉS INDUITS PAR L'ADMINISTRATION INTRATHÉCALE D'ACIDES AMINÉS (SAAs)]}

Michael Osborne, Terence J Coderre

Department of Anesthesia, McGill University, Montreal, Quebec

INTRODUCTION: This study set out to determine the chain of intracellular events responsible for the SNBs observed following the intrathecal administration of four SAAs.

METHODS: Male Wistar rats, under light halothane anaesthesia, were pretreated with specific inhibitors for four intracellular messengers [L-NAME to inhibit nitric oxide synthase (NOS), bisindolylmaleimide to inhibit protein kinase $\mathrm{C}$ (PKC), neomycin to inhibit phospholipase C (PLC), and methylene blue to inhibit soluble guanylate cyclase] via a lumbar puncture. Ten minutes following pretreatment with one of these compounds, each animal was lightly anaesthetized with halothane again and intrathecally administered, via a lumbar puncture, one of the following SAAs: cysteic acid (L-CA), cysteine sulfinic acid (L-CSA), homocysteic acid (L-HCA), and homocysteic sulfinic acid (L-HCSA). For 10 minutes following SAA administration rats were observed for any SNBs. These included: tail elevation, twitching or licking, hindpaw elevation, licking or shaking, and any caudally-directed biting or scratching. The amount of time each rat spent eliciting these behaviours was recorded and a total time (in seconds) spent exhibiting SNBs was recorded.

RESULTS: L-NAME and neomycin significantly reduced the SNBs induced by the administration of all four SAAs tested. 
Bisindolylmaleimide and methylene blue however, significantly reduced the SNBs induced by the administration of only L-CSA and L-CA.

CONCLUSIONS: The SAAs that are aspartate analogs (L-CA and L-CSA) appear to activate all second messengers tested for (NOS, PKC, PLC, and soluble guanylate cyclase), while the SAAs which are glutamate analogs (L-HCA and L-HCSA) appear to only activate NOS and PLC.

This research supported by an MRC grant awarded to TJC

$\mathrm{P}-11$

\section{EFFECTS OF MORPHINE ON IMMUNE FUNCTION IN MICE FOLLOWING A THERMAL INJURY}

\section{[EFFETS DE LA MORPHINE SUR LA FONCTION IMMUNITAIRE CHES DES SOURIS AYANT SUBI UNE LÉSION THERMIQUE]}

Gretchen Summer, Manon Choinière, Michèle Delia, Jacques Bernier

Department of Physiological Nursing, University of California, San Francisco, California

INTRODUCTION: Burn injuries cause severe pain and immunosuppression. Tissue injury stimulates nociceptive stress that is also immunosuppressive. Morphine, the analgesic most frequently administered for severe pain, may also be immunosuppressive. This study assessed the effects of morphine on immune function in animals in pain.

METHODS: After ethical approval from the Animal Care Committee in our institution, 7 week-old female mice $(\mathrm{C} 3 \mathrm{H} \mathrm{HeN})$ were implanted, under general anesthesia with osmotic pumps (Alzet ${ }^{\circledR}$, DURECT Corp., CA) and underwent a thermal injury. Pumps delivered saline (Group 1, N=12) or $2.5 \mathrm{mg} / \mathrm{kg}$ morphine (Group 2, N=12). After 10 days, mice were sacrificed and the following parameters of immune function were examined: T-cell phenotype and proliferation (thymus and spleen), NK activity, splenocytes mitochondrial transmembrane potential, intracellular glutathione (GSH) and level hepathic mRNA of corticobinding protein.

RESULTS: Overall, mice receiving morphine suffered less immunosuppression than controls as shown by T-cell proliferation. Although the percent of splenic $\mathrm{T}$ cells remained unchanged, a decrease of mature thymocytes $(\mathrm{CD} 3+\mathrm{CD} 4+$ and $\mathrm{CD} 3+\mathrm{CD} 8+$ ) associated with an increase of immature thymocytes (CD4+CD8+) occurred in the morphine group. NK activity, GSH, mitochondrial activity, and CBG were comparable in both groups. Our results show that morphine is not detrimental for $\mathrm{T}$ cells activation although thymocyte subpopulations appear somewhat affected.

IMPLICATIONS: Infection is the primary cause of mortality and morbidity in patients with burns. It is critical to determine what the effects of opioid analgesia are on immune function in this patient population.
P-12

THE ANALGESIC PROFILE OF CENTRALLYADMINISTERED NOCICEPTIN IN ACUTE NOCICEPTION

\section{[PROFIL ANALGÉSIQUE DE L'ADMINISTRATION DE NOCICEPTINE AU NIVEAU DU SYSTÈME NERVEUX CENTRAL DANS UN MODÈLE DE DOULEUR AIGUË]}

Patrick Leblanc, Andy Dray, Daniel Ménard AstraZeneca R\&D Montreal, St-Laurent, Quebec

Nociceptin has been identified as the endogenous ligand for ORL-1. A number of diverse physiological roles have been claimed for this peptide including modulation of pain (analgesia and hyperalgesia). Presently we have studied the ability of central nociceptin injections to induce analgesia in the rat, as determined in acute models of pain. Nociceptin was administered centrally, intrathecally (i.t.) or intracerebroventricularly (i.c.v.). The opioid receptor antagonist, naloxone $(10 \mathrm{mg} / \mathrm{kg})$, was injected subcutaneously $10 \mathrm{~min}$ utes prior to drug administration to characterize the behavioral effects. Analgesia was assessed using the paw pressure, the tail flick, and the tail immersion assays. Locomotor activity and signs of catalepsy were evaluated following drug administration. Nociceptin administered i.t. produced potent analgesic effects on the rat tail flick assay ( $\mathrm{ED}_{50}=12.5-25$ nmoles), no signs of catalepsy at doses up to 100 nmoles, and a significant reduction in locomotor activity. Interestingly, nociceptin administered i.c.v. produced hyperalgesia in all three models of acute pain at 50 and 100 nmoles doses. A decrease in locomotor activity was also noted at 12.5, 25, 50 and 100 nmoles doses. The decrease in locomotor activity following central administration and the analgesic and hyperalgesic effects observed following i.t. and i.c.v. administration of nociceptin respectively, were not inhibited by naloxone. These findings confirmed that nociceptin had a potent analgesic effect following spinal injection and a hyperalgesic effect when administered supraspinally. However, there was a narrow window between the analgesic effect of nociceptin and the appearance of side effects following spinal administration. A failure of naloxone to block the analgesic, hyperalgesic and hypoactive effects of nociceptin suggested that its effects may be mediated by a novel mechanism independent of classical opioid receptors.

P-13

\section{STRUCTURE-ACTIVITY RELATIONSHIP STUDY ON THE NEUROPEPTIDE NOCICEPTIN}

\section{[ÉTUDE SUR LA RELATION STRUCTURE-ACTIVITÉ DU NEUROPEPTIDE NOCICEPTINE]}

Joanne Butterworth, Maryse Labarre, Kemal Payza, Ralf Schmidt AstraZeneca R\&D Montreal, St-Laurent, Quebec

INTRODUCTION: Nociceptin (Orphanin FQ), an opioid-like peptide involved in nociception, is the endogenous ligand for the ORL-1 receptor. Although the physiological roles of this peptide remain to be completely elucidated, some similarities exist between the mode of action between nociceptin and the classical opioids. To dissociate these two mechanisms, we characterize the 
pharmacology of a series of nociceptin analogs based on aminoacid substitutions.

METHOD: We used both receptor binding and GTP $\gamma \mathrm{S}$ functional assays. Affinity and agonist activities were compared using mouse brain, cloned human $\delta, \mu, \kappa$ and ORL- 1 receptors.

RESULTS: The peptides for the SAR studies were synthesized with substitution of $\mathrm{Phe}^{4}$ by various proteinogenic and non-proteinogenic aromatic amino acid residues. Substitution at position 4 with $\mathrm{Trp}^{4}, \mathrm{MePhe}^{4}$ and the bulky aromatic amino acids $1 \mathrm{Nal}^{4}$, $2 \mathrm{Nal}^{4}$ and $\mathrm{Bta}^{4}$ was well tolerated, reducing affinity and activation only 5 to 10 times.

Substitution by $\mathrm{His}^{4}$, $\mathrm{Dip}^{4}$, Bip ${ }^{4}$, Ind ${ }^{4}$ and the conformationally restricted Phe analog $\mathrm{Tic}^{4}$ produced analogs with a 1000-fold drop in nociceptin binding and activity as partial agonists.

DISCUSSION: The amino acid in position 4 interacts with a hydrophobic pocket of the receptor in a specific structural arrangement since small changes in this residue have a profound influence on receptor binding and activation. Our study further elucidates the so-called "message-address concept" previously described in the literature.

\section{P-14}

\section{STUDIES ON PERIPHERAL VS CENTRAL EFFECTS OF THE $\mu$-OPIATE RECEPTOR AGONIST, Dmt-DALDA, IN THE RAT FORMALIN TEST}

[ÉTUDES SUR LES EFFETS PÉRIPHÉRIQUES VS CENTRAUX DE L'AGONISTE DU RÉCEPTEUR DES OPIACÉS- $\mu$, LE Dmt-DALDA, DANS LE TEST DE LA FORMALINE CHEZ LE RAT]

Kiran Yashpal, Bruce Ritchie, TMD Nguyen, Peter Schiller, Terence J Coderre

Department of Anesthesia, McGill University,

Montreal, Quebec

INTRODUCTION: Hydrophilic $\mu$-opioid agonists that are unable to cross certain biological barriers may have therapeutic potential for some analgesic applications. We recently reported the analgesic effects of Dmt-DALDA in the formalin test. The present study was directed at identifying its site of action.

METHODS: Nociceptive scores in the formalin test were measured after i.p. administration of $1 \mathrm{mg} / \mathrm{kg}$ Dmt-DALDA. Pharmacological specificity of the antinociceptive effects seen were tested with the $\mu$-opiate receptor antagonists naloxone $\mathrm{HCl}$ $(5 \mathrm{mg} / \mathrm{kg}$, i.p.) and naloxone methiodide $(5 \mathrm{mg} / \mathrm{kg}$ i.p. or $50 \mu \mathrm{g}$ i.th.; this derivative does not cross the blood-brain barrier).

RESULTS: Dmt-DALDA inhibited the second phase when it was given 20 min prior to intraplantar injection of $2.5 \%$ formalin. This inhibition was blocked by preadministration of naloxone $\mathrm{HCl}$ and of naloxone methiodide i.p. However, i.th. administration of naloxone methiodide had no effect on the antinociceptive effect of Dmt-DALDA.

DISCUSSION: The results confirm that Dmt-DALDA expresses its antinociceptive effects via a peripheral action. This compound may be useful therapeutically, as it does not produce central or trans-placental effects.

Supported by CIHR
P-15

EFFETS SPÉCIFIQUES DES HORMONES SEXUELLES
DANS L'EXPRESSION DES COMPORTEMENTS
NOCICEPTIFS LORS DU TEST À LA FORMALINE

\section{[SPECIFIC EFFECTS OF SEXUAL HORMONES ON NOCICEPTIVE BEHAVIORS IN THE FORMALIN TEST]}

Isabelle Gaumond, Nancy Julien, Pierre Arsenault, Serge Marchand

Dépt des Sciences Cliniques, Université du Québec en AbitibiTémiscamingue, Rouyn-Noranda, Québec

INTRODUCTION : Deux comportements principaux caractérisent les réponses nociceptives du test à la formaline : lever et lécher la patte injectée. Ces comportements nociceptifs sont exprimés différemment selon la phase de la réponse, la concentration de formaline et l'utilisation d'analgésiques (Abbott et al., 1995). La présente étude a pour but de déterminer si ces comportements sont modulés par les hormones sexuelles.

MÉTHODOLOGIE : Quatre groupes (mâles normaux, castrés, femelles normales, ovariectomisées) de 8 rats Sprague-Dawley ont reçu une injection sous-cutanée de $50 \mu \mathrm{L}$ de formaline $2.0 \%$. Les rats ont été observés pendant une période de $2 \mathrm{~h} 15$ séparée en 4 phases : phase I= 0-9 min., interphase= 10-21 min., phase II= 22$90 \mathrm{~min}$. et phase III $=91-135 \mathrm{~min}$.

RÉSULTATS : Les femelles normales présentaient plus de douleur (lever + léchage) que les mâles normaux $(p<0.02)$. De plus, les rats gonadectomisés présentaient plus de douleur que les rats normaux $(p<0.03)$. L'hyperalgésie des femelles par rapport aux mâles et des rats gonadectomisés par rapport aux rats sains s'explique uniquement par le lever de patte et non pas par le léchage. DISCUSSION : Les hormones sexuelles joueraient donc indépendamment sur différentes composantes de la douleur. Le lever de la patte pourrait être associé à un comportement de protection tandis que le léchage pourrait être associé à de la détresse ou à une composante plus « émotionelle » de la douleur. Cette interprétation est en accord avec une récente étude chez l'humain qui montre que l'intensité d'une douleur postopératoire est plus élevée chez la femme, mais que l'aspect désagréable est plus élevé chez l'homme (Morin et al., 2000).

P-16

CANNABINOID INVOLVEMENT IN A RAT MODEL OF TONIC PAIN

[RÔLE DES CANNABINOÏDES DANS UN MODÈLE DE DOULEUR CONTINUE CHEZ LE RAT]

\author{
Liliane J Dableh, Kiran Yashpal, James L Henry \\ Department of Psychiatry, McGill University, Montreal, Quebec
}

INTRODUCTION: Increasing evidence suggests that cannabinoids may be useful as analgesics, at least in some types of pain. This study was done to examine the possible role of anandamide, an endogenous ligand of the cannabinoid $\mathrm{CB} 1$ receptor using the formalin test as a model of tonic pain.

METHODS: Two groups were given vehicle or anandamide $(5 \mathrm{mg} / \mathrm{kg}$, i.p., dissolved in $65 \%$ saline, $34.8 \%$ DMSO and $0.2 \%$ 
Tween 80). Two additional groups were run with the $\mathrm{CB} 1$ receptor antagonist, AM281, one alone and the other followed by administration of anandamide.

RESULTS: The control and anandamide treated groups showed the same characteristic two excitatory phases of nociceptive scores separated by the inhibitory phase in the formalin test. In both groups given AM281 there was a potentiation and a prolongation of the second excitatory phase, with no other differences.

DISCUSSION: The potentiation seen in the AM281 treated groups is difficult to explain. It may be that when $\mathrm{CB} 1$ receptors are blocked, the free anandamide has access to pro-nociceptive mechanisms.

Supported by CIHR

P-17

\section{INHIBITION OF NOXIOUS STIMULI-EVOKED RESPONSES OF DORSAL HORN NEURONS BY CANNABINOID CB1 RECEPTOR ACTIVATION IN NEUROPATHIC MOUSE}

\section{[INHIBITION DES RÉPONSES ÉVOQUÉES PAR DES STIMULI NOCIFS DANS LES NEURONES DE LA CORNE POSTÉRIEURE PAR L'ACTIVATION DES RÉCEPTEURS CANNABINOÏDES CB1 CHEZ LA SOURIS ATTEINTE DE NEUROPATHIE]}

Chang Qing Cao, Yanguo Hong, Andy Dray, Martin Perkins AstraZeneca R\&D Montreal, St-Laurent, Quebec

AIM OF INVESTIGATION: To investigate the role of WIN55, 212-2, a cannabinoid receptor agonist, on spinal nociceptive transmission in the adult mouse with a neuropathic lesion of the sciatic nerve.

METHODS: Male mice (CD1, 28-32 g) had their unilateral sciatic nerves crushed 7 days prior to the experiments were deeply anaesthetized with urethane. The descending aorta was cannulated and perfused continuously with aCSF at $32-35^{\circ} \mathrm{C}$. Single wide dynamic range (WDR) neuronal activity was recorded extracellularly from dorsal horn segments L1-3.

RESULTS: The background activity of WDR neurons in nerve injured animals was significantly higher $(28.8 \pm 5.8$ spikes $/ \mathrm{s}$, $\mathrm{n}=78)$ than that of naïve mice $(3.5 \pm 0.8$ spikes/s, $\mathrm{n}=89, \mathrm{P}<0.005)$. Noxious pinch and heat applied to the receptive field elicited a fast initial peak response followed by a slowly decaying afterdischarge. The initial increasing rate of neuropathic neurons (pinch $620 \pm$ $78 \% \mathrm{n}=55$, heat $1107 \pm 136 \% \mathrm{n}=32$ ) was similar to that of naïve animal (pinch $580 \pm 88 \% \mathrm{n}=82$, heat $918 \pm 108 \% \mathrm{n}=52$ ). The evoked afterdischarge, however, lasted much longer in neuropathic neurons (15-110 min) than that of naïve mice ( $<15 \mathrm{~min})$. WIN55, 212-2 dose-dependently $(0.01,0.1,0.2$ and $0.5 \mu \mathrm{M})$ depressed the nociceptive responses in all cells $(\mathrm{P}<0.001, \mathrm{n}=25)$. The respective $\mathrm{IC}_{50}$ values $(\mathrm{nM})$ for depression of initial response were $23.9 \pm 2.5$ $(\mathrm{n}=17)$ for pinch and $29.2 \pm 3.8(\mathrm{n}=8)$ for heat. These $\mathrm{IC}_{50}$ values were about 3 folds lower than that of naïve mice (pinch $45.9 \pm 4.5$ $\mathrm{n}=9$, heat $89.2 \pm 8.9 \mathrm{n}=8$ ). At a dose of $100 \mathrm{nM}$, WIN55, 212-2 almost completely abolished the long duration afterdischarge. SR141716A $(0.5 \mu \mathrm{M}, \mathrm{n}=8)$, a selective CB1 antagonist blocked the depressant action of WIN55, 212-2, indicating a CB1 receptor action.
CONCLUSIONS: Cannabinoid receptors play an important role in mediating nociceptive transmission in neuropathic dorsal horn neurons of the adult mouse.

P-18

\section{A NOVEL ASSAY FOR TESTING ANTI-MIGRAINE DRUGS}

\section{[UN NOUVEAU MODÈLE POUR ÉVALUER DES COMPOSÉS ANTI-MIGRAINEUX]}

Giovanni Martino, Nicole Tremblay, Andy Dray, Martin Perkins AstraZeneca R\&D Montreal, St-Laurent, Quebec

INTRODUCTION: The absence of an animal model of migraine utilising a behavioural indicator of nociception, is an important gap in this research field. We have developed a novel model using ultrasonic vocalisation (USV) as the behavioural indicator of an aversive reaction following the induction of cerebral inflammation by an injection of E.coli lipopolysaccharide (LPS) into the cerebral ventricles of the rat. The pharmacology of this central inflammatory-induced hypersensitivity has been explored using agents known to be active in migraine.

METHODS: Animals were rendered hyperalgesic by the intracerebroventricular (i.c.v.) administration of 2,4 $\mu \mathrm{g}$ of LPS (Walker et al., 1996). Three and half hours following LPS injection, each animal was isolated in a sound attenuated chamber (BRS-LVE Tech Serv) and USV was elicited by the presentation of 10 standardised aversive air-puff stimuli (intensity $=75$ psi; duration $=0.2 \mathrm{~s}$ ). USV was detected with a $1.20 \mathrm{~cm}$ microphone (G.R.A.S. VedBaek)) and the recording period lasted for 10 minutes starting with the first stimulus presentation. A commercial automated signal-detection system (Leuven Measurement System, CADA-X 3.5B) was used to analyse and characterise the recorded USVs.

RESULTS: In naïve rats a baseline level of USV (number of calls) following air-puff stimulation was established (Knapp \& Pohorecky, 1995). LPS treated rats showed an increase in the number of calls emitted and this increase could be modulated by drug administration. Ketorolac (20.0, 40.0, $60.0 \mathrm{mg} / \mathrm{kg}$ ) per os (p.o), Zomig $\left(1.25,2.5,5.0 \mathrm{mg} / \mathrm{kg}\right.$ ) subcutaneous (s.c.), $\operatorname{CGRP}_{(8-37)}$ (12.5, 25.0, $50.0 \mathrm{nM}$ ) i.c.v., L- 733-060 (NK-1 antagonist; 0.01, $0.1,1.0 \mu \mathrm{mol} / \mathrm{kg}$ ) i.c.v. reversed the effect of the LPS treatment while none of these compounds were active in naïve rats.

DISCUSSION: The reversal of a central inflammatory aversive response by anti-migraine drugs suggests that this model may be a useful behavioural model for evaluating novel anti-migraine therapies. 


\section{EXAMINATION OF THE DISSOCIATION OF PAIN AND INFLAMMATION USING GENETIC CORRELATION ANALYSIS}

\section{[ÉVALUATION DE LA DISSOCIATION DES PHÉNOMÈNES DE DOULEUR ET D'INFLAMMATION À L'AIDE D'UNE ANALYSE DE CORRÉLATION GÉNÉTIQUE]}

William R Lariviere, Elissa J Chesler, Sonya G Wilson, Stan Call, Andy L Rankin, Joel Schwarz, Anna Kokayeff, Jeffrey S Mogil Department of Psychology, University of Illinois at UrbanaChampaign, Champaign, Illinois

INTRODUCTION: In the clinic and laboratory, judgments regarding the intensity of pain and hypersensitivity experienced are often made based on the severity of classical overt signs of inflammation. This study examines dissociations between inflammation and pain and hypersensitivity in a new animal model, the bee venom (BV) test, and the commonly used formalin test.

METHODS: Twelve inbred strains of mice received an intraplantar injection of BV $(0.05 \mathrm{mg})$ or formalin $(5 \%)$ in the hind paw, and licking of the injected paw was measured for 60 or $90 \mathrm{~min}$. Two hours after BV injection thermal hyperalgesia was assessed using Hargreaves' test. After testing, edema of the injected paw was measured with precision calipers and Spearman correlations with licking and hyperalgesia were calculated. Quantitative trait locus (QTL) mapping of formalin-induced licking and edema was also performed. RESULTS: BV- or formalin-induced licking, hyperalgesia, and edema differ significantly among strains. Correlations of edema strain means with licking or hyperalgesia are moderate at best ( 0.43 or less for licking; 0.57 or less with hyperalgesia). Instances of strains with similar edema but dissimilar pain measures occurred. The measures are uncorrelated when strain of mouse is not considered in the analysis. QTL mapping results are near completion and will be presented.

DISCUSSION: Although edema is correlated with pain and hyperalgesia in the BV and formalin tests, the latter can not be predicted based solely on overt signs of inflammation, especially when genetic factors are not considered. This suggests that factors other than the peripheral inflammatory response determine the pain experienced following an injury and the assessment and treatment of patients should reflect this.

P-20

\section{CAN MATERNAL GROOMING BLUNT EFFECTS OF REPEATED PAIN IN NEONATES?}

\section{[EST-CE QUE LES SOINS MATERNELS PEUVENT AMOINDRIR LES EFFETS D'UNE DOULEUR RÉPÉTÉE CHEZ DES RATS NOUVEAU-NÉS?]}

\author{
C Celeste Johnston, C Dominique Waller, Kirstin Krudekeis \\ McGill University School of Nursing and Douglas Hospital \\ Research Center, Montreal, Quebec
}

INTRODUCTION: There is evidence that repeated exposure to minor, but noxious, procedures in preterm infants in critical care settings has long term behavioural effects, but the mechanisms of these changes have not been investigated. Using the newborn rat pup as a model, changes in NMDA receptors at supra spinal levels were examined in relationship to exposure to pain.

METHODS: On postnatal days (P) P1-P8, unhandled (UH) rat pups were compared to 4 times, daily handling $(\mathrm{H})$, or handling plus pain from a $25 \mathrm{~g}$ needlestick into hindpaw (HP). Maternal behaviour was observed for 30 minutes following reunion in the $\mathrm{H}$ and HP groups. NMDA receptor levels were measured by autoradiography in the hindlimb area of the cortex, amygdala, and hippocampus at $\mathrm{P} 60$.

RESULTS: RM-ANOVA yielded no group differences, although there was a consistent non-significant trend for the $H$ to have greater NMDA densities across all areas. However, the HP dams groomed pups significantly more at reunion $(\mathrm{p}<.0001)$. When $\mathrm{H}$ and HP were compared, with pup grooming as a covariate $(\mathrm{p}<.08)$, there were still no significant differences, but estimated marginal means reversed so that the HP groups had higher densities than the H group.

CONCLUSIONS: There may be no long term changes in NMDA receptor density at supraspinal levels in response to repeated minor pain in early life. However, it may be that the increased maternal grooming blunted the effect of the pain. A future direction for study will be to inhibit maternal grooming at reunion.

P-21

CONDITIONING AND HYPERALGESIA IN NEWBORN INFANTS EXPOSED TO REPEATED HEEL LANCES

\section{[LE CONDITIONNEMENT ET L'HYPERALGÉSIE CHEZ DES NOUVEAU-NÉS AYANT SUBI DES PONCTIONS RÉPÉTÉES AU TALON]}

Anna Taddio, Vibhuti Shah, Lucia Taddio, Gil Klinger, Joel Katz Department of Pharmacy, Hospital for Sick Children,

Toronto, Ontario

BACKGROUND: Clinical experience suggests that neonates learn to anticipate pain based on past experiences with painful procedures.

AIM: To prospectively evaluate whether infants who undergo repeated painful procedures learn to anticipate pain and exhibit more pain during a painful procedure than control infants.

METHODS: Participants were 42 healthy newborns in a postnatal hospital ward. There were 2 groups: A - infants born to mothers with diabetes; B - infants born to mothers with uneventful pregnancies. Infants in Group A underwent repeated heel lances in the first 24-36 hours of life for blood glucose monitoring. Group B infants were matched to Group A infants on gestational age, sex, type of delivery, and anesthetic. After the first 24 hours of life, all infants underwent a venipuncture on the hand for the newborn screening test. Infant pain responses during venipuncture (baseline, cleansing the hand, puncture) were videotaped and scored by a blinded, trained observer.

RESULTS: Baseline VAS scores did not differ significantly between groups. Pain during skin cleaning and venipuncture were significantly higher in Group A than B (Table). Pain scores during venipuncture correlated with the number of prior heel lances (rho=0.45, $\mathrm{p}=0.003$ ). 


\begin{tabular}{lcc} 
Variables & \multicolumn{2}{c}{ Group } \\
\hline \# of heel lances & $9.6 \pm 2.3$ & B \\
before venipuncture & & $0 \pm 0$ \\
VAS pain score & \\
$(\mathrm{mm})$ during: & \\
$\quad$ Baseline & & \\
$\quad$ Cleansing* & $16.4 \pm 27.9$ & $0 \pm 0$ \\
$\quad$ Venipuncture* & $62.1 \pm 27.0$ & $2.6 \pm 8.8$ \\
\hline${ }^{*}$ & &
\end{tabular}

${ }^{*} p=0.04, A$ vs. B

CONCLUSIONS: Newborns exposed to repeated heel lances in the first 24-36 hours of life learned to anticipate pain and exhibited more pain during venipuncture than control infants.

\section{P-22}

\section{SAFETY AND EFFICACY OF SUCROSE FOR PROCEDURAL PAIN RELIEF IN PRETERM AND TERM NEONATES}

\section{[EFFICACITÉ ET INNOCUITÉ DU SUCROSE DANS LE SOULAGEMENT DE LA DOULEUR RELIÉE AUX PROCÉDURES CHEZ LES NOUVEAU-NÉS PRÉMATURÉS ET NÉS À TERME]}

Sharyn A Gibbins, Bonnie Stevens, Ellen Hodnett, Arne Ohlsson, Janet Pinelli

Faculty of Nursing, University of Toronto, Toronto, Ontario

BACKGROUND: Preterm and acutely ill neonates in Neonatal Intensive Care Units (NICUs) are subjected to multiple painful procedures, such as heel lances. The long-term effects of repeated pain are unclear. While there have been several trials to determine the efficacy of sucrose for managing procedural pain in neonates, these have generally lacked methodological rigor and have not provided clinicians with clear practice guidelines.

OBJECTIVE: To determine (a) the most efficacious dose and method of sucrose administration for heel lances, (b) the safety of sucrose for a variety of gestational age groups and (c) if gestational age has an effect on the safety and efficacy of sucrose.

DESIGN/METHODS: A RCT with prognostic stratification for gestational age was used. After parental consent, neonates were randomized prior to a scheduled heel lance to one of three groups: $0.5 \mathrm{ml}$ of $24 \%$ sucrose with a pacifier (Group A), $0.5 \mathrm{ml} 24 \%$ sucrose without a pacifier (Group B) and $0.5 \mathrm{ml}$ sterile water with a pacifier (Group C). Pain was measured by the Premature Infant Pain Profile (PIPP). Safety was determined by using a priori established criteria. A regression analysis was performed to determine which variables contributed to the PIPP scores. All heel lances were performed within the first week of life.

RESULTS: 190 neonates were randomly assigned to Groups A (n $=64), B(n=62)$ and $C(n=64)$. No differences existed in the groups at randomization. Irrespective of gestational age, sucrose and pacifier was significantly more efficacious than sucrose alone $(\mathrm{p}=0.007)$ or sterile water and pacifier $(\mathrm{p}<0.001)$. Mean PIPP scores were $8.16(\mathrm{SD}=3.2), 9.77(\mathrm{SD}=3.0)$ and $10.19(\mathrm{SD}=2.6)$ in Groups A, B, and C respectively. Few adverse events $(n=6)$ occurred and none of the events occurred in the sucrose and pacifier group. Intervention group and gender contributed to the most variance in PIPP scores.

CONCLUSIONS: Pain responses associated with heel lances in preterm and term neonates are reduced with the administration of sucrose and pacifier. Since sucrose and pacifiers are readily available in NICUs, they may easily be incorporated into practice procedures is required.

$\mathrm{P}-23$

DOES CONSISTENT PROCEDURAL PAIN MANAGEMENT INFLUENCE NEONATAL OUTCOMES?

\section{[UN SOULAGEMENT CONSTANT DE LA DOULEUR RELIÉE AUX PROCÉDURES A-T-IL UNE INFLUENCE CHEZ LES NOUVEAU-NÉS?]}

Bonnie Stevens, Patricia Petryshen, Katherine Henning,

Anne Jack, Janet Narciso

Faculty of Nursing, University of Toronto, Toronto, Ontario

INTRODUCTION: Preterm infants hospitalized in the Neonatal Intensive Care Unit (NICU) undergo multiple painful procedures. Although effective behavioral and nutritive interventions to relieve procedural pain exist, these strategies are used inconsistently in clinical practice. Therefore, the purpose of this study was to determine if consistent management of procedural pain during the neonatal period influenced neonatal outcomes.

METHODS: The study design was a randomized controlled trial. Sixty preterm infants ( $>26$ and $<31$ weeks gestational age; $<72$ hours of life) were randomized to receive (a) standard care (SC) group, (b) pacifier and sterile water (PW), or (c) pacifier and $24 \%$ sucrose (PS) prior to each painful procedure while hospitalized in the NICU. Efficacy (pain) and safety (adverse events) data were collected on Days 7, 14, 21, and 28 of life during a routine heel lance. Clinical and economic outcome data were collected at Day 28 of life or on discharge from the NICU.

RESULTS: The PS and PW interventions were the most efficacious with decreased incidence of adverse events. There was no difference in the clinical outcomes (e.g. days on oxygen, days to full feeds), although there was a significant difference in the economic outcomes (e.g. decreased costs), favouring the two pacifier groups.

DISCUSSION/IMPLICATIONS: Consistent management of procedural pain in neonates is efficacious, associated with fewer adverse events and more economical than standard care. Although no differences in neonatal outcomes were found, further exploration of clinical outcomes using a larger sample is warranted. 
P-24

\section{OBSTETRIC FACTORS AND NEONATAL PAIN: A FIRST LOOK}

\section{[FACTEURS OBSTÉTRIQUES ET DOULEUR NÉONATALE : UNE PREMIÈRE INVESTIGATION]}

Tina C Wang, Christine Korol, Kenneth Craig Department of Psychology, University of British Columbia, Vancouver, British Columbia

INTRODUCTION: Despite recent advances in neonatal pain research, the effect of obstetric factors on neonatal pain remains relatively unexamined. Moreover, studies of obstetric factors on neonatal behavour have mainly focused on feeding, habituation, orientation, etc. Thus, the present study aimed to explore the effect of anesthesia, delivery, and labour on newborns' pain.

METHOD: Participants were 195 full-term infants (103 boys; mean gestational age $=39$ weeks). The following variables were collected from the mother's medical chart: whether an anesthetic was used, delivery method (i.e., vaginal, caesarian, or vacuum), and type of labour (i.e., spontaneous, augmented, or induced). Infants' facial pain activity in response to the heel lance procedure was coded using the Neonatal Facial Coding System (Grunau \& Craig, 1987).

RESULTS: A Welch t' test showed that newborns whose mothers were anesthetized experienced less pain than newborns whose mothers were not anesthetized, $\mathrm{t}^{\prime}(58)=2.02, \mathrm{p}<.025$. However, analyses of variance using the Brown-Forsythe $\mathrm{F}^{*}$ statistic indicated that the main effect of delivery method, $\mathrm{F}^{*}(2,51)=1.90$, $\mathrm{p}>.05$ and type of labour, $\mathrm{F}^{*}(2,136)=1.81, \mathrm{p}>.05$ were not significant.

DISCUSSION: The present finding that neonatal pain may be influenced by obstetric anesthetics is a critical first step to delineate the relationship between types of obstetric medication and neonatal pain. Future research could also benefit from re-examining the effect of delivery and labour on neonatal pain, as the present study was limited by low statistical power. Research efforts in this area could have important implications for clinical practice.

REFERENCE: Grunau, RVE \& Craig, KD (1987). Pain expression in neonates: Facial action and cry. Pain, 28, 395-410.

P-25

\section{IMPACT OF PARENTAL PAIN EXPERIENCE ON ATTRIBUTIONS OF INFANT PAIN}

\section{[IMPACT DES EXPÉRIENCES DOULOUREUSES VÉCUES PAR LES PARENTS SUR LEUR PERCEPTION DE LA DOULEUR CHEZ LE NOURISSON]}

Rebecca RE Pillai, Melanie A Badali, Kenneth D Craig Department of Psychology, University of British Columbia, Vancouver, British Columbia

INTRODUCTION: Given economic necessity and advances in medical technology, hospital stays are being shortened. Parents are being called upon to look after their children at earlier and earlier stages of infancy. A better understanding of factors impacting parental attributions of infant pain will help researchers identify potential barriers to effective pain management
METHOD: Forty-seven parents completed a medical experiences questionnaire (Dahlquist, 1986) regarding the most pain they experienced during six different procedures (throat swabs, medical appointments, dental appointments, hospitalisations, surgery, and bloodwork). Next, they were asked to view ten videoclips of infants receiving a routine immunisation injection. After viewing each clip, parents indicated on a 10 centimetre Visual Analogue Scale (VAS) how much pain they believed the infant was experiencing. An average VAS rating was obtained based on all 10 pain judgements.

RESULTS: Six independent samples t-test were conducted (Bonferroni correction utilised). Each t-test compared the average VAS rating of parents who had experienced clinically significant pain to the average VAS rating of parents who had not experienced clinically significant pain (for each of the aforementioned medical procedures). One significant difference was found. Parents who had experienced clinically significant pain from surgery rated the infants as having more pain $(\mathrm{p}=.014)$.

IMPLICATIONS FOR THE FUTURE: Surgical pain was the only procedural pain queried that significantly related to infant pain attributions. This finding suggests that parents who have significant pain histories (such as from a surgical procedure) will tend to attribute higher levels of pain to infants. An implication of this finding is that parents without significant pain experiences could be at risk for mismanaging their infant's pain due to lower pain attributions. Future research should be done to investigate this relationship.

P-26

\section{EVALUATION OF A COMPREHENSIVE PAIN MANAGEMENT PROGRAM AT CHEO: IMPLEMENTING BEST PRACTICE PAIN MANAGEMENT FOR PEDIATRIC PATIENTS}

\section{[ÉVALUATION D'UN PROGRAMME DE SOULAGEMENT DE LA DOULEUR À L'HÔPITAL DE L'ONTARIO POUR ENFANTS : IMPLANTATION DE MEILLEURES PRATIQUES DE SOINS VISANT LE SOULAGEMENT DE LA DOULEUR DES ENFANTS]}

Jacqueline Ellis, Lynn McCleary, Renee Blouin, Karen Dube, Betty Rowley

School of Nursing, University of Ottawa, Ottawa, Ontario

INTRODUCTION: The Nursing Pain Management Committee was established to develop strategies to improve nurses' pain assessment and management in all patient care areas at the Children's Hospital of Eastern Ontario (CHEO). A multi-faceted program was developed that is based on published guidelines and research evidence about best practice pain management. The Comprehensive Pain Management Program (CPMP) is composed of an education session/workshop, assessment tools, a documentation record, a pain history interview guide, a standard of care and a standardized nursing care plan.

The implementation of the program will be guided by the Ottawa Model of Research Use (OMRU) which is a theoretical framework for policy-makers and clinicians interested in promoting the transfer and use of research findings into clinical practice settings. 
Given the financial and human resource challenges of the current health care system and the extensive literature indicating that organizational change is not simple to achieve, a model that addresses both process and outcome is critical. The proposed study has a twofold purpose, to evaluate the effectiveness of the CPMP and to evaluate the effectiveness of the OMRU for dissemination and uptake of research findings.

METHOD: Multiple methods of qualitative and quantitative data collection include pre-post questionnaires, patient-record audits, process evaluation of implementation, and focus groups to assess barriers and supports to best practice pain management.

RESULTS: Data collection begins in January and should be complete by April 2001. Preliminary data indicate the documentation records are easy to use and well received. Interviews with key stakeholders indicate a broad base of organizational support for the program.

DISCUSSION: Barriers and supports and lessons learned from the implementation will be presented.

P-27

\section{INITIAL DEVELOPMENT OF A PARENT COMFORTING ACTIVITIES CHECKLIST}

\section{[DÉVELOPPEMENT D'UNE ÉCHELLE DE MESURE DES ACTIVITÉS DE CONFORT PARENTAL]}

Colleen Anderson, Sandra LeFort, Andrea Brennan-Hunter School of Nursing, Memorial University of Newfoundland, St John's, Newfoundland

INTRODUCTION: Few studies have investigated how parents treat their child's pain pharmacologically at home and none have examined parents' nonpharmacological management. A checklist of parent comforting activities was developed to examine nonpharmacological management of children's pain. This was part of a larger study investigating parents attitudes, perceptions, and type of pain management used at home following their child's day or short-stay surgery.

METHOD: A preliminary list of nonpharmacological strategies was developed based on the literature and was reviewed by six pediatric nurses, five parents, and a pediatric pain expert to establish face validity. The checklist was revised to incorporate their feedback and was finalized with 39 parent comforting activities. Parents of children undergoing day or short-stay surgery were recruited from a small regional hospital in Atlantic Canada. Parents completed this tool on the evening of postoperative day 1 and identified all activities used to comfort their child as well as the five most effective comforting activities. Parents also completed a diary that included the Parents Postoperative Measure for Pain (PPMP) (Chambers et al., 1996) and medication given.

RESULTS AND DISCUSSION: Children $(\underline{\mathrm{n}}=48)$ ranged in age from 2 to 12 years (mean age of 6 ) with $58 \%$ males and $42 \%$ females. The most common surgeries were tonsillectomy and adenoidectomy and circumcision. Parents used a mean of $20 \pm 8$ activities to comfort their child at home after surgery. The top five comforting activities selected were 1) presence of mother, 2) presence of father, 3) cuddling, 4) holding, and 5) favorite treat. Low but significant correlations were found between number of parent comforting activities and scores on the PPMP $(\mathrm{r}=.34, \mathrm{p} \leq 0.05)$ and parents' pharmacological management on day of surgery $(r=.30$, $\mathrm{p} \leq 0.05$ ). Further research to refine the checklist and establish reliability and validity needs to be conducted.

P-28

\section{THE EFFECTIVENESS OF PARENT AND CHILD BEHAVIOURAL INTERVENTIONS DURING PORT ACCESS IN PEDIATRIC CANCER}

\section{[EFFICACITÉ D'UNE APPROCHE COMPORTEMENTALE PARENTS-ENFANTS VISANT À FACILITER LA PONCTION D'UN CATHÉTER CENTRAL CHEZ DES ENFANTS ATTEINTS DE CANCER]}

\section{Maru Barrera, Susan M Henriques, Sandy Doyle, John Doyle Toronto, Ontario}

OBJECTIVE: The proposed study will investigate the effectiveness of combined psychological intervention (i.e. imagery, relaxation, and distraction) in reducing children's pain and distress responses and parental distress during access to port procedure. A major component of the research is to test the effectiveness of a dual role for parents being actively involved in and being the target of the intervention to reduce their own stress, compared to control parents. METHOD: Newly-diagnosed paediatric oncology patients between the ages of 3 and 6 and one parent per each child will be randomly assigned to one of three groups; a parent/child-coping training group, a child training group, or a 'Typical Intervention' (control) group. Parental and self-reports of children's pain and anxiety, using VAS, standardized instruments and direct observations of children's and parents' behaviours during port access will be obtained prior to intervention (Time 1), following intervention (Time 2) and 3-months post intervention (Time 3).

RESULTS: Data collection is in progress. Currently, data has been obtained from 8 patients. 2 subjects have had complete assessments. 2 subjects have had time 1 and time 2 assessments and are awaiting time 3.4 subjects have only had time 1 assessment. We hope to have 6 subjects in each group by May 2001. This will allow us to present preliminary findings.

FUTURE IMPLICATIONS: Given that some types of pediatric cancer treatments are prolonged and invasive (e.g. acute lymphoblastic leukemia, 2.5 - 3 years of treatment), it is important to develop intervention techniques to reduce the pain and anxiety experienced by these children and their parents in order to improve their quality of life. 
LUMBAR PUNCTURE IN PEDIATRIC ONCOLOGY: CONSCIOUS SEDATION OR GENERAL ANESTHESIA

\section{[LES PONCTIONS LOMBAIRES EN ONCOLOGIE PÉDIATRIQUE: SÉDATION À L'ÉTAT D'ÉVEIL OU ANESTHÉSIE GÉNÉRALE?]}

\author{
Gustaf Ljungman, Torsten Gordh, Stefan Sörensen, \\ Anders Kreuger \\ Unit for Pediatric Hematology/Oncology, Children's University \\ Hospital, Uppsala, Sweden
}

BACKGROUND: Lumbar punctures (LP) were earlier generally performed in conscious sedation (CS), but are increasingly performed under general anesthesia (GA) due to the belief that this is less distressing. The aim of the study was to compare these two methods in LP concerning distress, discomfort, pain, well-being and security after the procedure, and procedure problems.

PROCEDURE: Twenty-five children with cancer participated in this prospective randomized, cross-over study. Children, parents and nurses completed a visual analogue scale questionnaire to evaluate efficacy of CS and GA. In addition, sedation and anesthesia protocols were reviewed.

RESULTS: The two methods seemed to be equivalent concerning distress, discomfort, pain, well-being and security after the procedure, and procedure problems. Most children (80\%), parents (66\%), and nurses (58\%) preferred LP in CS. However, the LP was not performed in CS in five cases because the child did not cooperate. Younger children less often preferred CS.

CONCLUSIONS: Outcome for CS and GA in LP were similar. While there were failures with the CS model, most preferred it to GA. LP in CS also saved time and medical resources. An alternative approach could be to have a pediatric anesthesiologist available at the oncology ward for these elective LPs to provide the sedation or anesthesia required by each individual.

\section{P-30}

\section{COPING IN CHILDREN WITH CHRONIC PAIN}

\section{[DE QUELLE FAÇON LES ENFANTS FONT FACE À LA DOULEUR CHRONIQUE?]}

Debra Konyk, M Thomas, Ranjan Roy, J Whiteley Department of Psychology, University of Manitoba, Winnipeg, Manitoba

INTRODUCTION: The effectiveness of children's mechanisms for coping with painful experiences impacts many important areas in a child's life such as school, social relationships, and in dealing with various medical procedures. The purpose of this study was to investigate the frequency, type, and effectiveness of coping strategies to manage painful episodes in children with recurrent abdominal pain (RAP) and children with headache (tension and migraine). The similarities between child and parent coping styles to pain were also examined.

METHOD: The participants included a subsample of ten children with recurrent abdominal pain and ten children with headache (tension and migraine) and their respective parents. All participants completed a battery of questionnaires including the Pain Coping Questionnaire (PCQ), Waldron/Varni Pediatric Pain Coping Inventory (PPCI), and measures of depression, anxiety, and level of disability.

RESULTS: Preliminary results suggested that Approach and Problem-Focused Avoidance coping in children were related to positive adjustment (e.g., low pain severity, depression, anxiety, and functional disability scores). Emotion-Focused Avoidance coping scores were found to be more related to negative adjustment (e.g., high pain severity, depression, anxiety, and functional disability scores) for each group (RAP and headache). The relationship between child- and parent- self-reports of coping were also found to be related.

IMPLICATIONS: These findings suggest that Approach and Problem-Focused Avoidance coping styles may be more adaptive in dealing with painful episodes among children with recurrent abdominal pain and headache. Factors that may explain the similarities between child and parent coping styles with pain will be discussed.

P-31

\section{PAIN IN CHILDREN WITH CEREBRAL PALSY DURING HOME STRETCHING EXERCISES: FACIAL ACTIONS AND GLOBAL RATINGS}

\section{[DOULEUR RELIÉE AUX EXERCICES D'ÉTIREMENT CHEZ L'ENFANT ATTEINT DE PARALYSIE CÉRÉBRALE : ÉVALUATION DES MOUVEMENTS FACIAUX ET MESURES GLOBALES]}

Kellie L Hadden, Carl L von Baeyer

Department of Psychology, University of Saskatchewan,

Saskatoon, Saskatchewan

INTRODUCTION: In a previous study surveying caregivers of children with cerebral palsy (CP), we found that pain is frequently reported regardless of whether children can communicate their pain verbally, and that stretching exercises are the most frequent source of pain at home. To contribute to development of multidimensional methods for assessment of pain, we videotaped children's faces and bodies during home stretching exercises and assessed their pain using global and molecular observational measures.

METHOD: Participants were 19 children (2 to 21 years of age) diagnosed with CP. Their physical, cognitive and language impairments were assessed using three developmental scales. Children and their caregiver were videotaped in their home before, during, and after stretching exercises. Caregivers were asked to rate their children's expression of pain using the Numerical Rating Scale (NRS) and the Non-Communicating Children's Pain Checklist (NCCPC) following each time segment. Children who were able to pass a training task were also asked to rate their experience of pain using the NRS. Healthcare professionals rated videotaped segments for each of the 3 time periods using the NRS and NCCPC. Raters trained in the Facial Action Coding System (FACS) examined the same videotaped segments.

RESULTS AND DISCUSSION: Preliminary results indicate significant painful reactions to the stretching procedure. Caregivers' NRS ratings showed a significant increase in pain intensity 
between the baseline and stretching procedure. Healthcare professionals' ratings and FACS scores will be described. The results will contribute to multidimensional assessment of pain in children with neurological impairment.

P-32

\section{VALIDATION OF THE FACES PAIN SCALE-REVISED (FPS-R): PAIN INTENSITY IN CLINICAL AND NON-CLINICAL SAMPLES}

\section{[LA VALIDATION DE L'ÉCHELLE DE FACIÈS "FACES PAIN SCALE-REVISED (FPS-R): INTENSITÉ DE LA DOULEUR VÉRIFIÉE AUPRÈS D'ENFANTS DANS DES MILIEUX CLINIQUES ET NON-CLINIQUES]}

Carl L von Baeyer, Pam Spafford, Inez van Korlaar, Carrie L Hicks, Belinda Goodenough

Department of Psychology, University of Saskatchewan, Saskatoon, Saskatchewan, and University of New South Wales, Sydney, Australia

INTRODUCTION: The Faces Pain Scale-Revised (FPS-R) measures self-reported intensity of pain in children. It was adapted from the Faces Pain Scale in order to make it compatible in scoring with other self-rating and observational scales which use a common metric (0 to 10 ) while maintaining the desirable psychometric properties of the original scale. We report data from clinical and non-clinical sources showing that the FPS-R has a strong linear relationship with visual analog (VAS) measures of pain in children from 4 through 12 years of age.

METHOD AND RESULTS: In Study 1, 76 children (5 to 11 years of age) undergoing ear piercing used the FPS-R and a 200-mm paper-and-pencil VAS to rate their pain. Correlations between the two measures in three age groups ranged from .92 to .94. In Study 2, the participants were 90 children ( 4 to 12 years of age) who were in hospital with pain from surgical (75\%) and nonsurgical $(25 \%)$ causes. They rated their current or recalled worst pain using the FPS-R and either the Coloured Analog Scale or a mechanical visual analog scale. The overall correlation between the FPS-R and the analog scales was .87; the correlations exceeded .83 even in the 4-, 5- and 6-year-olds analysed separately. There were no significant mean differences between the FPS-R and the two analog scales. Scatter plots, age effects and analyses of discrepancies between the FPS-R and analog scales will be presented for both studies.

DISCUSSION: The results complement validation data from the original FPS by showing that the FPS-R has good concurrent validity in relation to standard visual analog tools, with the additional advantage that it is scored using a popular common metric (0-10).
P-33

\section{SLEEP PERTUBATIONS INDUCED BY AN EXPERIMENTAL PAINFUL HYPERTONIC SALINE INFUSION INTO MUSCLES OF NORMALS}

\section{[PERTURBATIONS DU SOMMEIL CAUSÉES PAR UNE INFUSION DE SOLUTION SALINE HYPERTONIQUE INDUISANT UNE DOULEUR DANS LES MUSCLES CHEZ DES SUJETS NORMAUX]}

M Brousseau, P Mayer, C Manzini, T Kato, G Lavigne Laboratoire du sommeil, Pneumologie et Stomatologie, Hôtel-Dieu du Centre hospitalier de l'Université de Montréal, Université de Montréal, Montréal, Québec

INTRODUCTION: Poor sleep quality is reported by $50-90 \%$ of chronic musculoskeletal pain patients. The aim of this study was to assess the effect of experimental muscle pain (duration: $>1 \mathrm{~min}$ ), analogous to muscle ache, on sleep of healthy subjects without pain, mood and sleep problems.

METHODS: In 9 subjects (3M, 6F : mean age : 22.9 y), hypertonic $(5.0 \%)$ and isotonic $(0.9 \%$ : control) saline were injected in deltoid muscle during wakefulness and sleep $(0.3 \mathrm{ml}$ over $24 \mathrm{sec})$. Awake pain intensity was rated on a $100-\mathrm{mm}$ VAS. During sleep, saline injections were given during stages 2, 3\&4 and REM, with at least 10-min intervals and arousal and awakening responses (AR+AW) were scored.

RESULTS: During wakefulness, maximum perceived pain intensity $(28.7 \pm 5.4 \mathrm{~mm}$, mean \pm SEM $)$ was obtained at $108 \pm 17 \mathrm{sec}$. Pain was described as cramping, pricking and freezing. Little pain was reported after isotonic saline $(2.3 \pm 0.7 \mathrm{~mm})$. During sleep, $\mathrm{AR}+\mathrm{AW}$ were induced more frequently by hypertonic than isotonic saline in stages 2 and REM $(p<0.05)$. Table shows $\%$ of trials with $\mathrm{AR}+\mathrm{AW}$ :

\begin{tabular}{lcc} 
Sleep stage & Isotonic saline & Hypertonic saline \\
\hline 2 & 20.3 & 75.0 \\
$3 \& 4$ & 11.9 & 29.0 \\
REM & 27.8 & 86.3 \\
\hline
\end{tabular}

In the morning, awake pain intensity to hypertonic saline was similar $(26.0 \pm 6.0 \mathrm{~mm})$.

CONCLUSION: This model suggests that experimental deep muscle pain triggers more $\mathrm{AR}+\mathrm{AW}$ during light and REM sleep. However, delta sleep seems to be more resistant to pain stimuli. This will now be tested in chronic pain patients.

Supported by FRSQ 
POSTOPERATIVE PAIN MANAGEMENT IN QUEBEC: PATTERNS OF PRACTICE AND DETERMINANTS OF PAIN CONTROL

\section{[SOULAGEMENT DE LA DOULEUR POST-OPÉRATOIRE AU QUÉBEC: PROFILS DES PRATIQUES ET DÉTERMINANTS DU CONTRÔLE DE LA DOULEUR]}

Jennifer Cogan, Manon Choinière, Gilbert Blaise, Ana Velly, Chantal Roy, Francesco Carli, Lucie Beauregard, Ann Robinson, Jean-Paul Collet

Research Centre Sir Mortimer B Davis Jewish General Hospital and McGill University Hospital Centre, Royal Victoria Hospital, Department of Anaesthesia, Montreal, Quebec

INTRODUCTION: The current literature on the prevalence of postoperative pain is sparse and there are no data specific to Quebec. We undertook a multicenter epidemiological survey of the practices of pain management in Quebec to identify the determinants of the persistence of pain. This poster describes the structure and implementation of the project in 10 Quebec institutions.

\section{METHODS}

Study design: Cohort follow-up. All patients were administered baseline inclusion questionnaires. Following surgery they were questioned every day during hospitalization; every two days for two weeks, then at 4, 8 and 12 weeks post-surgery.

Population: A total of 600 patients were included: 300 in-patients undergoing total abdominal hysterectomy, total knee or hip replacement and 300 day surgery patients undergoing knee arthroscopy, inguinal hernia and laparoscopic cholecystectomy.

Institutions: Patients were recruited from 5 university affiliated hospitals and 5 regional hospitals.

Baseline assessment: Several questionnaires were administered prior to surgery in order to asses the current level of pain as well as the determinants of pain: the Pain Outcome Questionnaire, the State-Trait anxiety Inventory, the Barriers Questionnaire, the Lazarus coping scale and the Beck Inventory. After surgery follow-up was carried out by telephone to assess the level of pain and its treatment. The consequences of pain on quality of life (SF-36), changes in activities of daily living and the use of health resources was also assessed.

CONCLUSION: The analysis will focus on the determinants and consequences of pain. The consequences of pain will be evaluated in terms of clinical consequences, changes in quality of life, the use of health resources and side effects. Comparison between surgeries will be made.

\section{PRATIQUES ANALGÉSIQUES INADÉQUATES LORS DU TRAITEMENT DE BRÛLURES SUPERFICIELLES EN SALLE D'URGENCE}

\section{[INADEQUATE ANALGESIC PRACTICES IN THE TREATMENT OF SUPERFICIAL BURNS IN THE EMERGENCY DEPARTMENT]}

Édith Filion, Marie-Christine Bournaki, Manon Choinière Centre des Grands Brûlés, Hôtel-Dieu du Centre hospitalier de l'Université de Montréal, Montréal, Québec

INTRODUCTION: La majorité des brûlures (95\%) sont vues en salle d'urgence et traitées sur une base externe. Très peu d'information existe sur la douleur reliée à ce type de blessure et notamment en ce qui a trait aux besoins analgésiques de ces patients. Cette étude multicentrique vise à évaluer la sévérité de la douleur chez des patients qui se présentent à l'urgence pour des brûlures superficielles et la qualité des soins analgésiques qui leur sont prodigués.

MÉTHODOLOGIE: À partir d'un devis prospectif descriptif, 79 patients adultes $(36.5 \pm 13.8$ ans) ayant subi des brûlures récentes ( $<30$ heures) qui ne nécessitaient pas une hospitalisation ont été recrutés dans trois urgences hospitalières. La superficie de leurs brûlures variait de 0.5 à $16.5 \%$ de la surface corporelle, la moyenne étant de $3.5 \pm 3.5 \%$. Un protocole d'entrevue structurée comportant diverses échelles de mesure standardisées et la revue des dossiers médicaux ont permis de colliger des données sur la sévérité des douleurs ressenties et les soins reçus à l'urgence.

RÉSULTATS: Les résultats ont montré que 51\% des patients n'ont reçu aucun médicament contre la douleur lors de leur séjour à l'urgence en dépit du fait que plus du deux tiers (69\%) cotaient leurs douleurs comme étant $\geq 4 / 10$ sur une échelle d'intensité numérique. Seulement un patient sur trois a reçu une médication de type opiacé alors, que pour près de la moitié des patients $(43 \%)$, l'intensité maximale des douleurs ressenties à l'urgence atteignait des valeurs $\geq 7 / 10$. Au moment du congé de l'hôpital, $67 \%$ des patients rapportaient des douleurs modérées à sévères $(\geq 4)$ et seulement $32 \%$ des patients se sont vus remettre une prescription contre la douleur.

CONCLUSION: Cette étude démontre des lacunes importantes dans les pratiques analgésiques en salle d'urgence pour les patients brûlés qui sont traités sur une base externe. Diverses recommandations pour améliorer le contrôle de la douleur chez cette clientèle de patients sont suggérées.

Étude subventionnée par le Fonds de la recherche en santé du Québec 
P-36

\section{PAIN AND ANALGESIC USE AT HOME AFTER CORONARY ARTERY BYPASS GRAFT SURGERY}

\section{[LA DOULEUR ET LA CONSOMMATION D'ANALGÉSIQUES À LA MAISON, À LA SUITE D'UN PONTAGE AORTOCORONARIEN]}

Lesley MacMaster, Judy Watt-Watson, Bonnie Stevens University of Toronto, Toronto, Ontario

INTRODUCTION: Coronary artery bypass graft surgery is a frequent treatment for coronary artery disease. Many patients undergoing CABG surgery have reported considerable unrelieved pain and received inadequate analgesia in hospital following surgery (Watt-Watson et al., 2000). No research has examined analgesic needs of CABG patients at home after surgery. Therefore, the purpose of this study was to describe the pain and analgesic needs of patients in their first week at home following CABG surgery.

METHOD: A convenience sample $(n=71)$ of consenting individuals, part of a larger study, was telephoned at home 5-7 days post discharge. Primary outcomes were pain intensity (0-10) analgesic intake (morphine equivalent/24 hours), interference with activities (Brief Pain Inventory-Interference) and side effects from analgesic use.

RESULTS: The average patient was a 62-year-old male discharged home after 6 days. Ten patients were women. Fifty-two \% had moderate to severe pain in the previous 24 hours. The sites of worst pain were chest (61\%) and leg (11.3\%) incisions. Pain interfered most with sleeping $2.07 \pm 2.55$ and coughing and deep breathing $1.78 \pm(2.44)$ [BPI - 0 to 10]. Patients took $11.03 \pm 13.77 \mathrm{mg}$ morphine equivalents in the previous 24 hours and $44 \%$ were constipated.

IMPLICATIONS: At least half had moderate to severe pain in the first week after discharge most of whom were constipated. Further work needs to be done to prepare patients for analgesic use and related side effects.

Supported by Purdue Pharma

\section{P-37}

\section{PATIENT EDUCATION INTERVENTION AND POSTOPERATIVE PAIN MANAGEMENT}

\section{[PROGRAMME ÉDUCATIF D'INTERVENTION AUPRÈS DE PATIENTS: IMPACT SUR LE SOULAGEMENT DE LA DOULEUR POST-OPÉRATOIRE]}

\author{
J Watt-Watson, Bonnie Stevens, Joel Katz, J Costello, G Reid, \\ T David \\ School of Nursing, University of Toronto, Toronto, Ontario
}

INTRODUCTION: Previously, most patients after coronary artery bypass graft $(\mathrm{CABG})$ surgery $(\mathrm{n}=225)$ reported considerable pain and received inadequate analgesia (Watt-Watson et al., 2000). Therefore, the purpose of this study was to evaluate a preadmission education intervention for reducing moderate to severe pain after CABG surgery.

METHOD: Patients ( $\mathrm{n}=404)$ were randomly assigned to either the 1) generic hospital education (control) or 2) control + pain booklet group. Data were compared from 6 interviews at: the preadmission clinic and days 1 to 5 after surgery. Primary outcomes were pain (McGill Pain Questionnaire-Short Form) and analgesic data. Secondary outcomes were interference, concerns, and satisfaction (APS Patient Outcome Questionnaire).

RESULTS: Analgesic prescription was satisfactory for both groups. Concerns about taking analgesics were significantly less for the intervention group by day 5 [ $\mathrm{t}(324)=1.98 \mathrm{p}<0.05]$. However, inadequate analgesia was given to both groups from day $1\left[\chi^{2}=21 \pm 12 \mathrm{mg}\right]$ to day $5\left[\chi^{2}=20 \pm 16 \mathrm{mg}\right.$ morphine equivalents/ 24h]. Patients received less than half their prescribed dose despite both groups experiencing moderate 24-hour pain from day $2\left[\chi^{2}=\right.$ $6.23 \pm 2.74,0-10$ scale $]$ to day $5\left[\chi^{2}=5.06 \pm 2.5\right]$. On day $4,78 \%$ of both groups identified constipation as an analgesic side effect. Most of the intervention group rated the booklet as very helpful.

P-38

EXAMINATION OF PAIN AND SUFFERING WHILE AWAITING JOINT REPLACEMENT SURGERY

\section{[ANALYSE DE LA DOULEUR ET DE LA SOUFFRANCE CHEZ DES PATIENTS EN ATTENTE D'UNE CHIRURGIE POUR PROTHĖSE TOTALE DE LA HANCHE OU DU GENOU]}

Heather D Hadjistavropoulos

Regina Health District, Regina, Saskatchewan

INTRODUCTION: Waiting periods for joint replacement surgery have been steadily increasing. Surgeons are primarily responsible for prioritizing patients. This study explored the extent of pain and suffering experienced by patients awaiting surgery and predictors of difficulties functioning. The role of pain and suffering in predicting surgeons' ratings of appropriate waiting times was also examined.

METHOD: In 1999, 446 patients (89.9\% participation) waiting for total hip or knee replacement surgery completed background information (age, sex, education, duration of problem, joint of concern), the Western Ontario and McMaster Osteoarthritis Index (pain, stiffness, functioning difficulties) and the Short-Form-12 (physical and emotional health status). When booking surgery, surgeons rated what they believed would be an appropriate waiting period (i.e., < one month, 1-3, 3-6, or 6-12 months).

RESULTS: Patients experienced moderate pain, stiffness and difficulties with physical functioning while waiting. Physical and emotional health status were significantly lower than norms from similar aged healthy individuals. Regression analysis showed that difficulties with functioning was explained by pain, followed by stiffness, age, and hip pain. Regression also showed that surgeons gave higher priority ratings to males, elderly, and patients with poorer physical and emotional health.

DISCUSSION: Patients waiting for joint surgery are undoubtedly burdened by pain, and likely require support while waiting. Surgeons prioritize patients, but not necessarily based on pain, which is the most important determinant of physical functioning. Consideration of pain in prioritization of patients should be explored. 
P-39

\section{PAIN AND MORPHINE CONSUMPTION AFTER RADICAL PROSTATECTOMY ARE REDUCED BY PERIOPERATIVE AMANTADINE}

\section{[L'ADMINISTRATION D'AMANTADINE PER-OPÉROIRE DIMINUE LA DOULEUR ET LA CONSOMMATION DE MORPHINE SUITE À UNE PROSTATECTOMIE RADICALE]}

Joel Katz, Dirk G Snijedlaar

Acute Pain Research Unit, Department of Anesthesia, Toronto

General Hospital, University Health Network, Toronto, Ontario

INTRODUCTION: Amantadine is used primarily for the treatment of Parkinson's disease and as an antiviral agent although evidence suggests that amantadine is also low affinity noncompetitive NMDA receptor antagonist.

AIM: To evaluate the morphine-sparing and analgesic effects of oral amantadine given perioperatively to patients undergoing radical prostatectomy.

METHODS: 24 patients were randomly assigned to one of two groups in a double-blinded manner. Group 1 received amantadine capsules (po) $200 \mathrm{mg}$ the evening before surgery, $200 \mathrm{mg}$ one hour before surgery, and $100 \mathrm{mg} 8 \mathrm{~h}, 20 \mathrm{~h}$ and $32 \mathrm{~h}$ after surgery. Group 2 received placebo capsules (po) at the same times as group 1. All patients received a standard general anesthetic. Epidural anesthesia was not used. Pain was assessed using a $10 \mathrm{~cm}$ visual analogue scale at rest (VAS-R) and after movement (VAS-M). Secondary mechanical hyperalgesia (SMH) was assessed by pressure applied bilaterally to the wound dressing. PCA-morphine consumption was recorded for $48 \mathrm{~h}$. Data are presented as mean $\pm \mathrm{sd}$. $\mathrm{P}<0.05$ is considered statistically significant.

RESULTS: 21 patients completed the study. Group 1 (51.4 \pm $24.0 \mathrm{mg})$ consumed $32 \%$ less morphine than group $2(75.3 \pm$ $38.9 \mathrm{mg})$ by day $2(\mathrm{p}<0.05)$. Mean VAS-R across all assessments was significantly lower for group $1(2.5 \pm 1.4 \mathrm{~cm})$ than group 2 $(3.7 \pm 1.3 \mathrm{~cm})$. SMH was significantly less intense on day 2 in group $1(2.4 \pm 1.2 \mathrm{~cm})$ than group $2(4.3 \pm 1.8 \mathrm{~cm})$.

CONCLUSIONS: The reduced morphine consumption and less intense pain and hyperalgesia associated with the perioperative use of amantadine may be explained by the NMDA receptor blocking properties of amanatadine.

Support: CIHR grant \#MT-12052 and NIH grant \#NS-35480

\section{P-40}

A RANDOMIZED, DOUBLE-BLIND COMPARISON OF RECTAL INDOMETHACIN VS PLACEBO FOR PAIN AFTER RADICAL PROSTATECTOMY

[ÉTUDE RANDOMISÉE À DOUBLE INSU COMPARANT L'EFFET DE L'INDOMÉTHACINE RECTALE VS UN PLACEBO SUR LA DOULEUR ASSOCIÉE À UNE PROSTATECTOMIE RADICALE]

Joel Katz, Adarose Ardiel Wowk, Jane Beattie, Roger Schmid Acute Pain Research Unit, Department of Anaesthesia, Toronto General Hospital, University Health Network, Toronto, Ontario

INTRODUCTION: Recent studies have combined different classes of analgesic agents in an attempt to reduce postoperative opioid consumption and pain. This has not been adequately examined after radical prostatectomy (RP).

AIMS: To evaluate the PCA morphine-sparing and analgesic effects of rectal indomethacin versus placebo administered before and for 3 days after RP.

METHODS: Thirty patients undergoing RP were randomly assigned indomethacin $(100 \mathrm{mg})$ or placebo suppositories $\mathrm{q} 12 \mathrm{~h}$ beginning 60 minutes before general anesthesia (GA). After surgery, patients were given PCA morphine for 3 days. Adverse effects and satisfaction with pain control were assessed daily. Pain was assessed at rest (R) and movement (M) using a VAS. Data are mean $\pm \mathrm{sd}$.

RESULTS: There were no differences in demographics, intraoperative variables or adverse effects. Mean VAS-R, VAS-M and cumulative PCA morphine were significantly lower in the indomethacin group (Table). Mean satisfaction scores were significantly greater for the indomethacin $(9.7 \pm 0.4 \mathrm{~cm})$ vs the placebo group $(8.9 \pm 1.1 \mathrm{~cm})$.

\begin{tabular}{|c|c|c|c|c|}
\hline \multirow[b]{2}{*}{$\begin{array}{l}\text { Postop } \\
\text { day }\end{array}$} & \multicolumn{2}{|c|}{ Indomethacin } & \multicolumn{2}{|c|}{ Placebo } \\
\hline & VAS-M (cm) & Cum PCA (mg) & VAS-M (cm) & Cum PCA (mg) \\
\hline 1 & $2.5 \pm 1.5^{*}$ & $23.7 \pm 22.8$ & $4.6 \pm 2.5$ & $35.7 \pm 24.8$ \\
\hline 2 & $1.5 \pm 1.8^{*}$ & $28.3 \pm 26.5+$ & $3.9 \pm 2.1$ & $47.5 \pm 33.2$ \\
\hline 3 & $1.0 \pm 1.5^{*}$ & $32.8 \pm 31.9 \dagger$ & $2.4 \pm 1.7$ & $54.8 \pm 39.3$ \\
\hline
\end{tabular}

${ }^{*} p<0.02$, Mann-Whitney, indomethacin vs placebo; $+p<0.05$, onetailed t-test, indomethacin vs placebo

CONCLUSIONS: Rectal indomethacin reduced pain and PCA consumption for 3 days compared to placebo. Adverse effects were comparable.

$\mathrm{P}-41$

LOW-DOSE IV KETAMINE DOES NOT PRE-EMPT PAIN AFTER RADICAL PROSTATECTOMY

[UNE ANALGÉSIE PRÉVENTIVE IMPLIQUANT L'UTILISATION DE KÉTAMINE À FAIBLE DOSE NE DIMINUE PAS LA DOULEUR ASSOCIÉE À UNE PROSTATECTOMIE RADICALE]

Joel Katz, Roger Schmid, Terence J Coderre, Adarose Ardiel Wowk

Acute Pain Research Unit, Department of Anaesthesia, Toronto General Hospital, University Health Network, Toronto, Ontario

INTRODUCTION: Various agents have been administered before surgery in an effort to prevent central sensitization. Ketamine is a good candidate for a pre-emptive approach because of its NMDA channel blocking properties.

AIM: To evaluate the morphine-sparing and analgesic effects of pre-emptive low-dose iv ketamine versus saline in a randomized, double-blind, placebo-controlled trial.

METHODS: Patients scheduled for radical prostatectomy were randomly assigned to one of 3 groups (Pre, Post, Control). Patients received an iv bolus (ketamine or saline) $15 \mathrm{~min}$ before incision followed by a continuous iv infusion (ketamine or saline). After $80 \mathrm{~min}$ patients received a second iv bolus (ketamine or saline) fol- 
lowed by a second continuous iv infusion (ketamine or saline) for $80 \mathrm{~min}$ (Table).

\begin{tabular}{lcccccc} 
& & First & & & Second & \\
Group & Drug & Bolus & Infusion & Drug & Bolus & Infusion \\
\hline Pre & ketamine & $0.2 \mathrm{mg} / \mathrm{kg}$ & $2.5 \mathrm{mg} / \mathrm{kg} / \mathrm{min}$ & saline & $0.2 \mathrm{ml} / \mathrm{kg}$ & $2.5 \mathrm{ml} / \mathrm{kg} / \mathrm{min}$ \\
Post & saline & $0.2 \mathrm{ml} / \mathrm{kg}$ & $2.5 \mathrm{ml} / \mathrm{kg} / \mathrm{min}$ & ketamine & $0.2 \mathrm{mg} / \mathrm{kg}$ & $2.5 \mathrm{mg} / \mathrm{kg} / \mathrm{min}$ \\
Control & saline & $0.2 \mathrm{ml} / \mathrm{kg}$ & $2.5 \mathrm{ml} / \mathrm{kg} / \mathrm{min}$ & saline & $0.2 \mathrm{ml} / \mathrm{kg}$ & $2.5 \mathrm{ml} / \mathrm{kg} / \mathrm{min}$
\end{tabular}

All patients received general anesthesia with fentanyl. Patients used iv PCA morphine for 3 days. Pain was assessed by VAS at rest and after movement. Secondary mechanical hyperalgesia (SMH) was measured with Von Frey filaments. Data are mean $\pm \mathrm{sd}$.

RESULTS: 143 patients completed the study (Pre: $n=47$; Post: $\mathrm{n}=50$; Control: $\mathrm{n}=46$ ). Preliminary analysis of Day 3 cumulative morphine showed that consumption was lower in Pre $(92.3 \pm$ $45.9 \mathrm{mg})$ than in Post $(107.2 \pm 58.4 \mathrm{mg})$ and Control $(103.6 \pm$ $50.4 \mathrm{mg})(\mathrm{p}=0.08)$. VAS-Rest, VAS-Movement and SMH did not differ among the groups.

CONCLUSIONS: Preemptive ketamine failed to show a clinically significant opioid sparing effect and did not reduce pain or hyperalgesia after radical prostatectomy.

Supported by CIHR grants \#MT-12052, \#MCT-38144, \#MOP-37845 and NIH grant \#NS-35480

\section{$\mathrm{P}-42$}

PRE-EMPTIVE EPIDURAL LIDOCAINE AND FENTANYL REDUCE MORPHINE CONSUMPTION AND HYPERALGESIA AFTER ABDOMINAL GYNECOLOGICAL SURGERY

\section{[UNE ANALGÉSIE PRÉVENTIVE ÉPIDURALE AVEC LIDOCAÏNE ET FENTANYL RÉDUIT LA CONSOMMATION DE MORPHINE ET L'HYPERALGÉSIE APRÈS UNE CHIRURGIE GYNÉCOLOGIQUE ABDOMINALE]}

Joel Katz, Roger Schmid, Jane Beattie, Adarose Ardiel Wowk, Lorenzo Cohen

Acute Pain Research Unit, Department of Anaesthesia, Toronto General Hospital, University Health Network, Toronto, Ontario

INTRODUCTION: The controversy over pre-emptive epidural analgesia has flourished partly because studies use incomplete designs (preincisional vs. postincisional treatment) without a standard treatment group that receives general anesthesia (GA) only.

AIM: To evaluate the pre-emptive analgesic effects of epidural analgesia in a 3-group randomized, double-blind trial.

METHODS: 59 patients scheduled for abdominal gynecological surgery were randomly assigned one of three treatments. PRE received epidural lidocaine plus fentanyl before incision. Forty min after incision PRE received epidural saline. POST received epidural saline before incision. Forty min after incision POST received epidural lidocaine plus fentanyl. SHAM received injections of saline $20 \mathrm{~min}$ before and $40 \mathrm{~min}$ after incision. All patients received GA. Patients used iv PCA morphine for 2 days. Pain was assessed by VAS at rest (R) and after movement (M). Secondary mechanical hyperalgesia (SMH) was measured in log mg using Von Frey filaments. Data are mean $\pm \mathrm{sd}$. $\mathrm{P}<0.05$ is statistically significant.

RESULTS: 46 patients completed the study (PRE $n=16$; POST $\mathrm{n}=14$; SHAM $\mathrm{n}=16$ ). Day 1 morphine ( $\mathrm{mg}$ ) was significantly lower in the PRE $(53 \pm 24)$ versus POST $(72 \pm 46)$ and SHAM $(69 \pm 28)$ groups. Day $1 \mathrm{SMH}$ was significantly less intense for the PRE $(6.51 \pm 0.51)$ and POST $(6.46 \pm 0.49)$ versus SHAM $(5.77 \pm 0.95)$ groups. Day 2 VAS-M was significantly less intense in the PRE (3.4 \pm 2.2$)$ versus SHAM (5.0 \pm 2.6$)$ group.

CONCLUSIONS: Patients were more comfortable after surgery if they received pre-emptive epidural analgesia versus postincisonal epidural analgesia or a sham epidural (GA only).

Supported by CIHR grant \#MT-12052 and NIH grant \#NS-35480

P-43

\section{AGE AS A PREDICTOR OF PCA OPIOID CONSUMPTION FOLLOWING SURGERY \\ [PRÉDICTION D'APRÈS L'ÂGE DE LA CONSOMMATION D'OPIACÉS EN MODE D'ANALGÉSIE CONTRÔLÉE PAR LE PATIENT À LA SUITE D'UNE CHIRURGIE]}

Denise H Hosey, Lucia Gagliese, Vincent Chan, Joel Katz Kinesiology and Health Science, York University, Acute Pain Research Unit, Department of Anaesthesia, University Health Network, Toronto, Ontario

BACKGROUND: An age-related decrease in the amount of opioid self-administered following surgery has been consistently reported. In fact, it has suggested that the amount administered could be predicted using the formula 100-age (Pain 64:357). The present study tests the adequacy of this formula.

SUBJECTS: 188 general surgery patients receiving opioids via patient controlled analgesia. Age ranged from 18 to 83 years (average age $=53 \pm 16 \mathrm{y}$ ).

METHODS: Total opioids (in morphine equivalents) self-administered in the first 24 hours postoperatively was recorded. A regression analysis was performed to determine the relationship between amount self-administered and age.

RESULTS: The regression equation for the prediction of opioid dose by age was dose $(\mathrm{mg})=110.17-1.1$ (age) $\left(\mathrm{R}^{2}=0.25\right.$, $\mathrm{p} \leq 0.0001)$. Paired t-tests of the difference between observed and predicted values were not significant. Tests for differences between the two prediction formulas revealed that the slope and intercept of the two lines did not differ.

DISCUSSION: This analysis reinforces the finding that age is an accurate predictor of self-administered morphine post-operatively. It suggests that the formula dose $=100$ - age can be used with a good deal of reliability when predicting opioid self-administration following surgery.

Supported by CIHR grants \#MCT-38144, \#MOP-37845 and NIH grant \#NS-35480 
P-44

\section{THE MEASUREMENT OF POSTOPERATIVE PAIN ACROSS THE ADULT LIFE SPAN: IDENTIFYING AGE-APPROPRIATE INSTRUMENTS}

\section{[L'ÉVALUATION DE LA DOULEUR POST-OPÉRATOIRE À DIFFÉRENTES ÉPOQUES DE LA VIE ADULTE : IDENTIFICATION DES INSTRUMENTS APPROPRIÉS SELON L'ÂGE]}

Lucia Gagliese, Adarose Wowk, Vincent Chan, Joel Katz Kinesiology and Health Science, York University \& Acute Pain, Research Unit, Department of Anaesthesia, University Health Network, Toronto, Ontario

This study was designed to identify the most appropriate postoperative pain assessment tools across the adult life span.

SUBJECTS: Young (YG, n=148, 18-44 y.o.), middle-aged (MG, $\mathrm{n}=151,45-60$ y.o.) and elderly (EG, $\mathrm{n}=156,61-86$ y.o.) general surgery patients.

METHODS: Patients completed the Visual Analog Scale (horizontal (VAS-H) and vertical (VAS-V)), Numeric Rating Scale (NRS), Present Pain Index (PPI) and McGill Pain Questionnaire (MPQ) 24h postoperatively. Scale completion order was counterbalanced using a Latin Square design.

RESULTS: YG had higher scores on every scale than both MG and EG ( $\mathrm{p} \leq$ 0.04-0.0001) which did not differ from each other. There were no age differences in scale correlations. Scores were converted to percentages to allow cross-scale comparison of intensity estimates. An age group by scale interaction was found $(\mathrm{p} \leq 0.0001)$. In YG, PPI was lower than VAS-H, VAS-V and NRS $(\mathrm{p} \leq 0.0001)$. There were no cross-scale differences in MG and EG. Error rate was highest and increased with age on the VAS-H (YG: 12.7\%, MG: 18.9\%; EG: 24.1\%; $\leq \leq 0.05$ ). MPQ subscale correlations and reliability estimates did not differ among the groups. YG chose more words than MG $(\mathrm{p} \leq 0.0001)$ and EG $(\mathrm{p} \leq 0.0001)$ which did not differ from each other. Although the same categories of descriptors were chosen the most frequently by each group, age differences in the adjectives endorsed were evident.

CONCLUSIONS: The MPQ, NRS, and VAS-V appear to be reliable across the adult life span. There may be limitations in the PPI for young patients and the VAS-H for the elderly.

Supported by CIHR grants \#MCT-38144, \#MOP-37845 and NIH grant \#NS-35480

\section{P-45}

\section{THE UTILITY OF FACIAL ACTIONS IN ASSESSING POST-OPERATIVE PAIN IN SENIORS}

\section{[UTILITÉ DES RÉACTIONS FACIALES POUR ÉVALUER LA DOULEUR POST-OPÉRATOIRE CHEZ LES PERSONNES ÂGÉES]}

Thomas Hadjistavropoulos, Diane LaChapelle, Sheryl Green, Gordon JG Asmundson

Department of Psychology, University of Regina, Regina,

Saskatchewan

INTRODUCTION: Hadjistavropoulos et al. (2000) examined measures of pain among seniors who were experiencing move- ment-related exacerbations of musculoskeletal pain and obtained clear support for the utility of the behavioural coding of painrelated body movements (e.g., bracing, guarding). Support for the utility of the Facial Action Coding System (FACS; Ekman \& Friesen, 1975), that involves the objective coding of facial reactions, was not as strong. The findings concerning FACS could have been an artifact of methodological aspects of the study. Specifically, the duration of the facial reactions was not taken into account and the patients suffered from a variety of painful conditions. Thus, the physical activities involved in the study could have been painful for some patients but not for others. The present study corrected the aforementioned concerns. That is, the duration of facial reactions was taken into account and all patients suffered from the same painful condition.

METHOD: Participants were 82 post-surgical (knee replacement) inpatients (average age $73.1 ; 65.9 \%$ male). Cognitive status was assessed using the Modified Mini Mental Status Examination. Under physiotherapist's supervision, the patients performed structured activities (i.e., reclining, standing, knee bends). Facial reactions were coded using FACS.

RESULTS: This study yielded clearer support for the use of the FACS among seniors. Facial reactions varied as a function of the degree to which the various activities were strenuous and were not related to level of cognitive functioning.

CONCLUSIONS: The results support the utility of FACS in the assessment of musculoskeletal pain among seniors undergoing rehabilitation following knee surgery.

P-46

DEMENTIA AS A BARRIER TO PAIN IDENTIFICATION AMONG ELDERLY COMPLEX CONTINUING CARE PATIENTS

\section{[LA DÉMENCE : UNE BARRIÈRE À L'ÉVALUATION DE LA DOULEUR CHEZ LES PERSONNES ÂGÉES QUI REQUIÈRENT DES SOINS CONTINUS COMPLEXES]}

Paddi O'Hara, Katharine Paddock

Research Services, SCO Health Service, Ottawa, Ontario

INTRODUCTION: While there is growing evidence to indicate that pain is a major problem among institutionalized elderly, and the presence of dementia may impair the measurement of pain in this population, there are no definitive data to suggest that dementing patients do not perceive pain in the same way as their nondementing counterparts. The relationship between pain and dementia in a complex continuing care setting is assessed.

METHODS: Information from the Minimum Data Set, Version 2.0 was reviewed for 512 complex continuing care patients (average age: 69.8 years, $\mathrm{SD}=17.1$ ) of the SCO Health Service during one 3-month time period in 2000.

RESULTS: The sample consisted of $126(24.6 \%)$ patients with dementia, and $386(75.4 \%)$ patients without dementia. While the groups did not differ in terms of diagnoses (e.g. stroke, arthritis, fractures, diabetes, osteoporosis, pressure ulcers) a higher proportion of the dementing group was classified as having "no pain" $(65.1 \%)$ than the non-dementing group $(51.6 \%)$. Even when pain was acknowledged, a higher proportion of the dementing group 
was labeled as having "mild" pain $(31.8 \%)$ than the non-dementing group (25.7\%). Logistic regression analysis revealed that lack of speech clarity and the presence of dementia were significant predictors of patients being identified as not having pain.

IMPLICATIONS: Inability to communicate pain because of dementia and/or speech problems may result in the under-recognition of pain in the institutionalized elderly. Further research is needed to examine the way in which physical and cognitive barriers may prevent the identification of pain in this population.

\section{P-47}

\section{AGE DIFFERENCES AND SIMILARITIES AMONG PATIENTS TREATED IN A MULTIDISCIPLINARY CHRONIC PAIN CENTRE}

\section{[DIFFÉRENCES ET SIMILITUDES CHEZ DES PATIENTS DE DIVERS GROUPES D'ÂGE TRAITÉS DANS UNE CLINIQUE MULTIDISCIPLINAIRE DE DOULEUR CHRONIQUE]}

Lucia Gagliese, Ronald Melzack

Kinesiology and Health Science, York University \& Acute Pain Research Unit, Department of Anaesthesia, University Health Network, Toronto, Ontario

As the population ages, the characteristics of elderly chronic pain patients must be identified. This study measured age differences and similarities among patients of various ages.

SUBJECTS: 496 patients treated at the McGill-Montreal General Hospital Pain Centre were divided into four groups: Young ( $\mathrm{n}=185 ; 18-44$ y.o.), Middle-Aged ( $\mathrm{n}=187 ; 45-64$ y.o.), YoungElderly ( $n=78 ; 65-74$ y.o.) and Elderly ( $n=46 ; 75-93$ y.o.).

METHODS: The following measures were completed at initial consultation: McGill Pain Questionnaire (MPQ), Numeric Rating Scale (NRS) of highest, lowest and usual pain intensity, pain drawing, Hospital Anxiety and Depression Scale (HADS) and sleep disturbance.

RESULTS: Younger patients were more likely to report pain onset following an accident whereas older patients were more likely to report spontaneous, illness, or surgery related onset ( $p \leq 0.0001)$. The proportion of patients in each group receiving opioids was not different but young patients were less likely to receive analgesics ( $\mathrm{p} \leq 0.03$ ). Age was correlated with number of health care providers consulted $(\mathrm{r}=-0.15, \mathrm{p} \leq 0.001)$ and sleep disturbance $(\mathrm{r}=$ $0.14, p \leq 0.002$ ) but was not related to pain duration, drawing, or HADS. Increasing age was associated with lower MPQ sensory $(r$ $=-0.3, \mathrm{p} \leq 0.0001)$, affective $(\mathrm{r}=-0.2, \mathrm{p} \leq 0.0001)$ and miscellaneous $(\mathrm{r}=-0.2, \mathrm{p} \leq 0.0001)$ scores but was not related to NRS or MPQ evaluative scores.

CONCLUSIONS: There may be age differences in the onset and qualities of chronic pain. Age differences in treatment are complex with younger patients less likely to receive analgesics and older patients consulting fewer specialists despite comparable pain duration, intensity, and psychological impact. These patterns require further investigation.
P-48

A BIOPSYCHOSOCIAL MODEL OF CHRONIC PAIN: ASSESSING THE ROLE OF BELIEFS, COPING, AND SOCIAL SUPPORT IN ADJUSTMENT

\section{[UN MODÈLE BIO-PSYCHO-SOCIAL DE LA DOULEUR CHRONIQUE : ÉVALUATION DES CROYANCES, DES STRATÉGIES D'ADAPTATION ET DU SOUTIEN SOCIAL DANS LE PROCESSUS D'AJUSTEMENT]}

Sophie Beugnot

Department of Psychology, University of Windsor, Windsor, Ontario

INTRODUCTION: Chronic pain patients show wide individual differences in their risk of developing depression and physical disability. These are not solely accounted for by differences in pain intensity. The cognitive-behavioral model of chronic pain (Turk, 1987) has stimulated much research on how pain beliefs and coping influence adjustment to chronic pain. Incorporating the role of social support to this model of chronic pain may be useful in better understanding the mechanisms involved in adjustment. The current study therefore assessed the role of pain beliefs, coping, and social support in predicting depression and physical adjustment. METHOD: Ninety-three chronic pain patients (44 females, 49 males) participated in this study. Participants completed a battery of self-report questionnaires assessing pain locus of control, passive and active coping, emotional and instrumental social support, depression, and physical disability.

RESULTS: Path analyses revealed that Internal LOC and emotional social support predicted greater active coping whereas Powerful Others LOC and instrumental social support predicted more passive coping. Passive coping, in turn, predicted greater depression and poorer physical adjustment. Finally, emotional social support was a significant predictor of less physical disability above the effects of beliefs and coping.

DISCUSSION: Results support the usefulness of a biopsychosocial model of chronic pain which takes into account the role of social support in the prediction of physical adjustment. Both forms of social support had an impact on adjustment either directly or through passive coping.

P-49
AN INTERDISCIPLINARY INTERVENTION FOR THE TREATMENT OF CHRONIC BENIGN PAIN: PROGRAM DESCRIPTION AND OUTCOME

\section{[UNE APPROCHE D'INTERVENTION INTERDISCIPLINAIRE DANS LE SOULAGEMENT DE LA DOULEUR CHRONIQUE NON-CANCÉREUSE : DESCRIPTION DU PROGRAMME ET RÉSULTATS]}

Sarah Barton Samoluk, Doug Cane, Patti Card,

Eileen MacKinnon, Denise Titus

Pain Management Unit, Queen Elizabeth II Health Sciences Centre, Halifax, Nova Scotia

INTRODUCTION: Many patients with chronic pain suffer from emotional distress, physical de-conditioning, poor posture, and other habits that aggravate pain. Successfully managing ongoing 
pain requires learning a new approach to living and maintaining health. This is best achieved when patients are guided to identify and change those beliefs and behaviours that may be ineffective and even maladaptive. An interdisciplinary program provides for consistent delivery of new information from several perspectives to assist with change and mastery. This poster describes one such program.

METHOD: Clients attend a 12-day program for 3-1/2 hours a day. Members of three disciplines, psychology, physiotherapy, and occupational therapy, are present throughout the program. The educational components of each profession are presented. Clients complete a questionnaire package at the beginning and end of the program. Measures of affect, pain attitudes and beliefs, and coping strategies are presented to evaluate outcome.

RESULTS: Multivariate analyses of variance are reported. Consistent with expectations, measures of affect reveal significant improvements over time. Further analyses reveal that, over time, clients more strongly endorse the use of adaptive versus passive coping strategies. As expected, there is no significant change in pain severity, but clients report an increased ability to control their pain and their lives. Preliminary follow-up analyses at 6 months suggest that many of these changes are maintained.

DISCUSSION: Further analyses are needed to assess whether these improvements are maintained over time via follow-up at 6and 12-months. However, outcome evaluation suggests that even brief interdisciplinary treatment can provide patients with increased control despite continued severe pain.

\section{P-50}

\section{TREATMENT OF CHRONIC PAIN IN PRIMARY CARE: IS SHARED CARE ENOUGH?}

\section{[TRAITEMENT DE LA DOULEUR CHRONIQUE DANS UN CONTEXTE DE SOINS DE PREMIÈRE LIGNE : UN MODĖLE DE SOINS PARTAGÉS EST-IL SUFFISANT?]}

\section{Melanie M Langford, Donald Bakal, Philip Eaton Department of Psychology, University of Saskatchewan, Saskatoon, Saskatchewan}

INTRODUCTION: In 1998 Family Medicine and Mental Health Services within the Calgary Regional Health Association initiated a demonstration study of integrated health care. The Health Transition Fund and Alberta Health and Wellness funded the project. The project was designed to deliver mental health services in a shared care arrangement with family physicians in their offices.

METHOD: An evaluation protocol was part of the demonstration study. The Short Form-36 (SF-36) was used to assess perceived health status following treatment. A research assistant as part of a larger interview administered the questionnaire following the shared care intervention(s). The SF-36 measures eight health concepts and also allows for the derivation of an aggregate Physical Health Score and an aggregate Mental Health Score. Post treatment SF-36 data were available from 30 pain patients and from 95 patients with more traditional mental health complaints (depression, anxiety, marital difficulties). Also available were the number of visits each patient made to the ER during the study period. The majority of pain patients were suffering from fibromyalgia and chronic headache pain. The primary shared care intervention consisted of counseling combined with medication.

RESULTS: The post-treatment SF-36 subscale scores were compared for the pain patients and the mental health patients. The pain patients had significantly poorer scores on 6 of 8 subscales $(p<.01)$. A separate analysis was performed to determine if the pain patients made greater use of ER services. A t-test revealed that the pain group visited the ER more frequently following the treatment than the mental health patients $(\mathrm{p}<.02)$.

IMPLICATIONS: Patients with chronic pain and fibromyalgia do not respond as well as mental health patients to treatments within a shared care framework. Pain patients likely require a comprehensive interdisciplinary intervention outside of the shared care setting.

P-51

THE ANALGESIC ACTION OF INTRAVENOUS ADENOSINE IN ALLEVIATING SPONTANEOUS PAIN, ALLODYNIA AND HYPERALGESIA IN FOUR DIAGNOSTIC CATEGORIES OF NEUROPATHIC PAIN

\section{[L'ACTION ANALGÉSIQUE DE L'ADÉNOSINE INTRAVEINEUSE SUR LA DOULEUR SPONTANÉE, L'ALLODYNIE ET L'HYPERALGÉSIE DANS QUATRE TYPES DE DOULEURS NEUROPATHIQUES]}

\author{
AJ Clark, ME Lynch, J Sawynok \\ Pain Management Unit, Queen Elizabeth II Health Sciences \\ Centre, Halifax, Nova Scotia
}

INTRODUCTION: There is considerable data indicating that adenosine analogs produce analgesic actions in nociceptive paradigms and can alleviate manifestations of neuropathic pain in nerve injury models in rodents. In humans, preliminary work supports an analgesic effect for adenosine in postoperative and neuropathic pain. The present study is a preliminary report on the open trial component of an enriched enrollment design examining the analgesic, antiallodynic and antihyperalgesic effects of intravenous adenosine.

METHODS: Adenosine was administered intravenously in a low dose concentration of $50 \mu \mathrm{g} / \mathrm{kg} / \mathrm{min}$ given over 60 minutes. Subjects from 4 different diagnostic groups were examined: post herpetic neuralgia, diabetic neuropathy, neuropathic orofacial pain and post surgical/post traumatic neuropathic pain. Patients were assessed by VAS for pain intensity, SF-MPQ, and sensory testing of tactile allodynia, and pinprick hyperalgesia.

RESULTS: To date 48 patients have received intravenous infusions of adenosine. Results indicated that $69 \%$ of patients note a greater than $30 \%$ reduction in spontaneous pain, $58 \%$ note a greater than $30 \%$ reduction in dynamic tactile allodynia and $48 \%$ note a greater than $30 \%$ reduction in hyperalgesia.

DISCUSSION AND CONCLUSIONS: The results of this study support previous reports that indicate intravenous adenosine can alleviate spontaneous pain and sensory abnormalities in neuropathic pain. This preliminary data supports our previous prediction that $60 \%$ of subjects would be adenosine "responders" who would be eligible for phase two (the double blind placebo controlled component) of this enriched enrollment designed study. 
P-52

TOPICAL TREATMENT OF NEUROPATHIC PAIN A DOUBLE BLIND PLACEBO CONTROLLED PILOT STUDY EXAMINING THE EFFICACY OF TOPICAL AMITRIPTYLINE, KETAMINE AND A COMBINATION IN THE TREATMENT OF NEUROPATHIC PAIN

\section{[TRAITEMENT TOPIQUE DE LA DOULEUR NEUROPATHIQUE: ÉTUDE PRÉLIMINAIRE CONTRÔLÉE, À DOUBLE- INSU, PORTANT SUR L'EFFICACITÉ DE L'AMITRIPTYLINE TOPIQUE, DE LA KÉTAMINE TOPIQUE ET D'UNE COMBINAISON AMITRIPTYLINE- KÉTAMINE AFIN DE SOULAGER LA DOULEUR NEUROPATHIQUE]}

ME Lynch, L Gammell, AJ Clark, J Sawynok Pain Management Unit, Queen Elizabeth II Health Sciences Centre, Halifax, Nova Scotia

INTRODUCTION: Chronic pain is a neural response to tissue injury where both central and peripheral mechanisms contribute to the generation of spontaneous pain, allodynia and hyperalgesia. This study examines the analgesic action of topical amitriptyline, ketamine and a combination in the treatment of neuropathic pain. METHODS: Subjects included 21 volunteers with chronic neuropathic pain, exhibiting allodynia or hyperalgesia. Topical preparations consisted of $1 \%$ amitriptyline $(10 \mathrm{mg} / \mathrm{ml}), 0.5 \%$ ketamine $(5 \mathrm{mg} / \mathrm{ml})$ or a combination of both and a placebo vehicle. In Phase 1: Subjects used each of the topical preparations ( $\mathrm{q} 6 \mathrm{~h} \times 48 \mathrm{hrs})$ in a double blind, crossover fashion, with a washout between treatments. Measures of spontaneous pain included VAS for pain intensity and pain relief, SF-MPQ, and a Likert Scale for Global Efficacy. In Phase 2: Eleven clinical responders continued to use the cream for a further 7 days, daily pain levels were recorded and blood levels were done at the end of 7 days.

RESULTS: Phase 1 data revealed that approximately $50 \%$ of subjects who reported a baseline level of pain $5 / 10$ or greater reported a $30 \%$ or greater reduction in spontaneous pain to all topical preparations, there was no statistically significant difference from placebo $(p<.05)$ after 2 days of treatment, in 11 subjects who chose to continue into Phase 2, there was a statistically significant time effect with subjects reporting significantly greater analgesia by days 6 and 7 according to measures of pain and relief. There was no detectable systemic absorption of amitriptyline (measured to $<50 \mathrm{nmol} / \mathrm{L}$ ), ketamine levels are pending.

DISCUSSION: The current trial suggests that topical amitriptyline and ketamine may be analgesic with chronic dosing. Subjects reported increasing levels of analgesia over the 7 day treatment period. This is consistent with 2 recently published random controlled trials examining the analgesic effect of topical doxepin (McCleane $2000 \mathrm{a} \& \mathrm{~b}$ ) where it took 10 days of dosing to achieve a statistically significant analgesic effect.
P-53

CHRONIC NEUROPATHIC PAIN IN SPINAL CORD INJURY: THE PATIENT'S PERSPECTIVE

\section{[LA DOULEUR NEUROPATHIQUE CHRONIQUE SECONDAIRE À UNE LÉSION DE LA MOËLLE ÉPINIÈRE : LE POINT DE VUE DU PATIENT]}

Penelope Henwood, Jacqueline Ellis

The Rehabilitation Centre, Ottawa, Ontario

INTRODUCTION: Chronic neuropathic pain in spinal cord injury (SCI) is recognized as severely compromising adjustment after injury and quality of life. Studies report that chronic neuropathic pain in SCI is associated with great emotional distress over and above that of the SCI itself. Currently little is known about the SCI person's perception of the impact of chronic neuropathic pain. No studies have examined this problem from the patient's perspective. The purpose of this study is to examine the impact of chronic neuropathic pain through the experience of SCI individuals considering physical, cognitive, affective, behavioral, and socio-environmental domains.

METHODS: Three focus groups were conducted that included twenty-four SCI outpatients at The Rehabilitation Centre in Ottawa, Ontario. Participants were selected to maximize variation in terms of type of SCI, Frankel classification, years since onset of SCI, age, gender and socioeconomic status. Sessions were audiotaped and tapes were transcribed. Qualitative analysis of data involved a constant comparison approach in which categories and themes were identified.

RESULTS: Many complex themes emerged including: 1) nature of pain; 2) coping; 3) medication failure; 4) pain impact.

DISCUSSION: Learning to live with pain without medication was identified by most participants as essential. Effective but temporary pain relief strategies included swimming in warm water, massage increased activity and distraction. Further research is warranted to determine those coping strategies that facilitate adjustment to chronic neuropathic pain in SCI.

P-54

HIGH DOSING METHADONE: A POSSIBLE RELATIONSHIP TO SERIOUS CARDIAC ARRYTHMIAS

[POSOLOGIE ÉLEVÉE DE MÉTHADONE: UN LIEN POSSIBLE AVEC DES ARYTHMIES CARDIAQUES MALIGNES]

Helen Hays

Edmonton, Alberta

INTRODUCTION: Methadone is a synthetic opioid well-known for its use in addiction medicine. In recent years it has been used in higher doses to treat chronic intractable pain although its unique pharmacokinetic qualities limit its use to experienced practitioners. Methadone has been considered to be relatively safe and not associated with unexpected adverse effects. However, we report the occurrence of serious cardiac arrythmias in at least 5 women who were taking methadone, in doses ranging from $270 \mathrm{mg}-660 \mathrm{mg}$ in divided doses per day. 
METHODS: These patients, ages 33-55, with chronic pain, were prescribed methadone, after trials of alternate opioids failed to provide pain control. All patients had been on stable doses of methadone, for at least 3 months before the occurrence of cardiac arrythmias.

RESULTS: None of the patients had a history of cardiac illness, and were well except for their chronic pain syndrome. All patients recovered following prolonged hospitalization for syncope and implantation of either cardioverter/defibrillator or an AICD for atrial pacing. Arrythmias recorded included ventricular bigeminy and a prolonged QT interval as well as episodes of torsade de pointes.

DISCUSSION: Methadone's popularity has been partly related to its antineuropathic effects by blocking the N-methyl-D-aspartate receptor (NMDA), in addition to its agonist action at the mu receptor. This newly reported possible association of high dosing of methadone and life threatening cardiac arrythmias requires further research. Cardiologists believe these patients have a genetic predisposition for this cardiac event, and associated hypokalemia and hypomagnesemia. It will be important to develop guidelines for follow-up care when prescribing methadone in high doses, including informed consent.

P-55

\section{EFFECTS OF MEDICATION INTAKE ON ASPECTS OF CHRONIC PAIN SYNDROME}

\section{[L'IMPACT DE LA PRISE DE MÉDICAMENTS SUR CERTAINS ASPECTS DU SYNDROME DE DOULEUR CHRONIQUE]}

\section{Zal Saper, Leslie R Peterson}

PACE program; Rehabilitation Centre, Vancouver, British Columbia

Operant theory of chronic pain postulates that operant reinforcers play a role in chronic pain syndrome (CPS). Operant reinforcers can include medication and solicitousness of others. Thus, operant theory predicts positive correlations between medication use and aspects of CPS such as pain, disability and depression, as well as between solicitousness and aspects of CPS. Opponent process theory, on the other hand, predicts positive correlations between aspect of CPS and medication, but would not predict correlations between aspects of CPS and solicitous behaviour. Proponents of narcotic analgesia for chronic pain suggest correlations between CPS and medication should be negative.

METHOD: Using information gathered during 53 consecutive assessments, relationships between Multidimensional Pain Inventory (MPI; Kerns, Turk, \& Rudy, 1985) pain and solicitousness scales, the Beck Depression Inventory-2nd edition, and the Medication Quantification Scale (MQS; Steedman et al., 1992) were examined. Subjects were divided into those scoring above and below the mean on MQS and solicitousness. MANOVAs were conducted to control for familywise error. One-way ANOVAs were then used to examine relationships between the two independent factors (MQS and solicitousness) and aspects of CPS (pain, depression, and disability).

RESULTS: A MANOVA for the effects of MQS was significant at alpha $=.05$, while a MANOVA for solicitousness was not significant. One-way ANOVAs were significant for the effects of medication (MQS) on pain, disability, and depression.
DISCUSSION: The results support opponent process theory and do not support operant theory. They also suggest that medication use is generally detrimental in this population.

P-56

\section{CANNABIS USE FOR CHRONIC PAIN: 5 CASE REPORTS}

\section{[L'UTILISATION DU CANNABIS DANS LA DOULEUR CHRONIQUE : PRÉSENTATION DE CINQ CAS]}

Mark A Ware, Ann Gamsa, Anneli Vainio, Jan Persson Department of Anaesthesia, McGill University, Montreal, Quebec

BACKGROUND: Interest in the therapeutic potential of cannabinoids is increasing. Chronic pain syndromes are one of the most common reasons for therapeutic cannabis use. Little is known about the patterns and prevalence of cannabis use for chronic pain. METHODS: 5 chronic pain patients who freely volunteered therapeutic cannabis use were interviewed. Patients were asked about the type of cannabis used, the mode of administration, the amount and frequency of use, and the main beneficial and adverse effects experienced. Informed consent and ethics review was obtained.

RESULTS: 4 patients smoked herbal cannabis from the flowering heads of the plant, in the form of joints. Dose size and frequency ranged from two puffs at night to one joint five times daily. 4 patients used cannabis daily, and duration of use ranged from 3 months to over three years. The main symptoms for which improvement was noted were pain and ability to relax (4 patients); sleep, mood and appetite ( 3 patients). Drowsiness was the most common side effect (4 patients) but in all cases this was considered beneficial.

INTERPRETATION: Given the limitations of this small selfselected sample, these results must be interpreted with caution. Larger prospective cross-sectional studies are required to explore these findings. The dose size of smoked cannabis is important when advising about the risks of long-term use. Therapeutic cannabis users appear to obtain relief from symptoms including but not limited to pain. Caregivers should communicate with chronic pain patients about cannabis use to improve our understanding of this controversial therapeutic agent.

P-57

EVALUATION OF THE SUPPORTIVE CARE IN ONCOLOGY PARTNERSHIPS IN EDUCATION (S.C.O.P.E.) PILOT PROJECT: THE PAIN AND SYMPTOM MANAGEMENT MODULE

\section{[PROGRAMME ÉDUCATIF EN PARTENARIAT SUR LES SOINS DE SUPPORT EN ONCOLOGIE (PROJET- PILOTE): ÉVALUATION DU MODULE "CONTRÔLE DE LA DOULEUR ET DES SYMPTÔMES"]}

Christine Zaza, Pamela Maki-Carolli, Dwight Moulin Centre for Behavioural Research and Program Evaluation, University of Waterloo, Waterloo, Ontario

INTRODUCTION: The Supportive Care in Oncology Partnerships in Education (S.C.O.P.E.) program is a communitybased on-site extended learning program through which self- 
directed professional education is provided by staff at the London Regional Cancer Centre. The overall goal is to enhance supportive care for people living with cancer and their families in Southwestern Ontario by educating health professionals, providers, and volunteers in the community who participate as Fellows in the program. The S.C.O.P.E. program includes several learning modules and was pilot tested with the Pain and Symptom Management module. This paper describes the evaluation of the S.C.O.P.E. pilot project.

METHODS: The structure and process evaluation was based on surveys of the participating nine Faculty and four Fellows, and the S.C.O.P.E. Co-Ordinator. The outcome evaluation was based on short-term outcomes measured by pre- and post-tests, and Fellows' Action Plans that listed the Fellows' professional goals.

RESULTS: The overall rating of the S.C.O.P.E. pilot was 4.7, and 4.2, by Fellows, and Faculty, respectively ( $5=$ Excellent). Participants rated all components of the pilot highly ( $\geq 4$ out of 5 ). According to the Fellows, S.C.O.P.E.'s major strengths included the individualized curriculum, flexibility of scheduling, and networking. Faculty considered their participation to be rewarding and professionally gratifying. The demand on Faculty's time was mentioned as a concern. Evaluation of available short-term outcomes indicates that Fellows improved their knowledge and attained their goals.

DISCUSSION: The results of the S.C.O.P.E. pilot evaluation were positive, and indicate that the Fellows learned the information they set out to learn. Strengths and limitations will be discussed.
KETAMINE IN PALLIATIVE CARE: DEVELOPMENT AND REVIEW OF PROTOCOL FOR KETAMINE USE

\section{[LA KÉTAMINE DANS LE CONTEXTE DES SOINS PALLIATIFS: DÉVELOPPEMENT ET RÉVISION D'UN PROTOCOLE PORTANT SUR L'UTILISATION DE CE PRODUIT]}

Edward Fitzgibbon, Raymond Viola, Cori Schroder, John Seely, Roberte Leger

University of Ottawa Institute of Palliative Care, Ottawa, Ontario

INTRODUCTION: Ketamine was initially developed as a dissociative anaesthetic. Further study revealed that it is also a potent non competitive N-methyl D-Aspartate [NMDA] receptor antagonist. There has been growing interest and success in the use of sub dissociative or low doses of Ketamine in the management of difficult pain scenarios and in particular neuropathic pain. Ketamine can be associated with some disturbing side effects, especially psychomimetic side effects. This has discouraged many centres from using what can be a very effective agent. Our challenge was to design a protocol for the use of low dose Ketamine as a co-analgesic in a palliative care population maximizing its' analgesic effect and minimizing it's potentially disruptive side effects.

METHOD: A review of the literature regarding the use of low dose ketamine was carried out. Following this a series of meetings involving medical, nursing, and pharmacy staff were held to discuss the issues and reach a consensus on the content of the protocol. Finally the protocol was approved and implemented by the Ottawa Regional Palliative Care Centre [ORPCC]. In this poster the key issues in the development of the protocol will be discussed. The protocol will be presented along with three cases which illustrate its use, both parenterally and the conversion to oral use.

FUTURE CONSIDERATIONS: Our experience with using Ketamine as a coanalgesic has been generally favourable. In the future we will do a formal evaluation of its use by the ORPCC.

\section{Author Index}

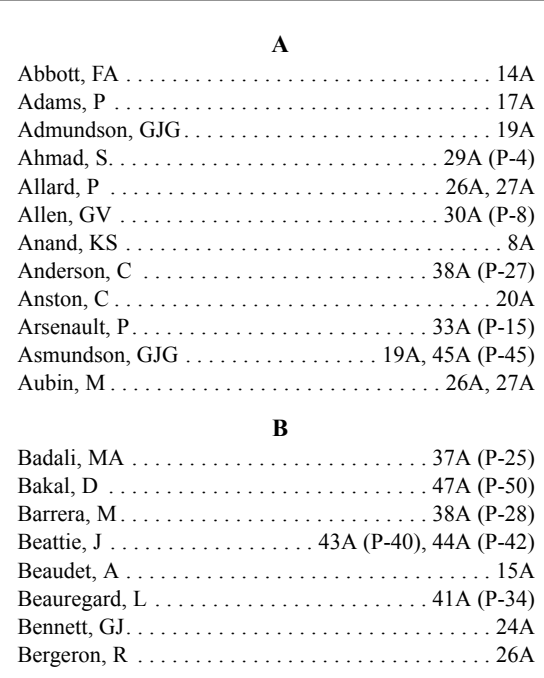

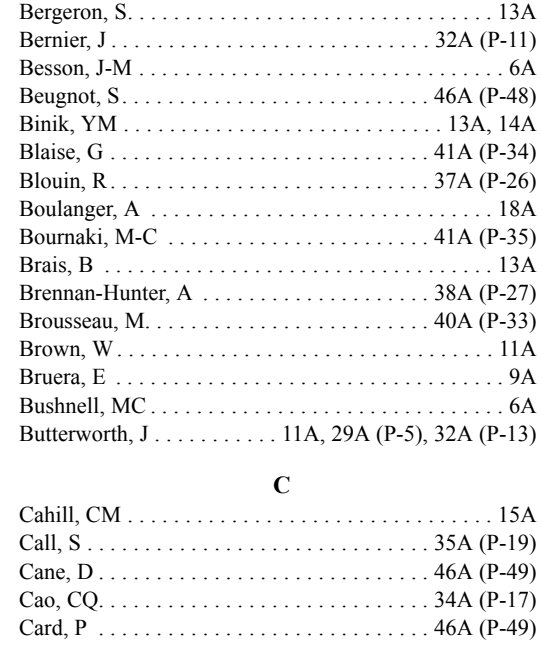

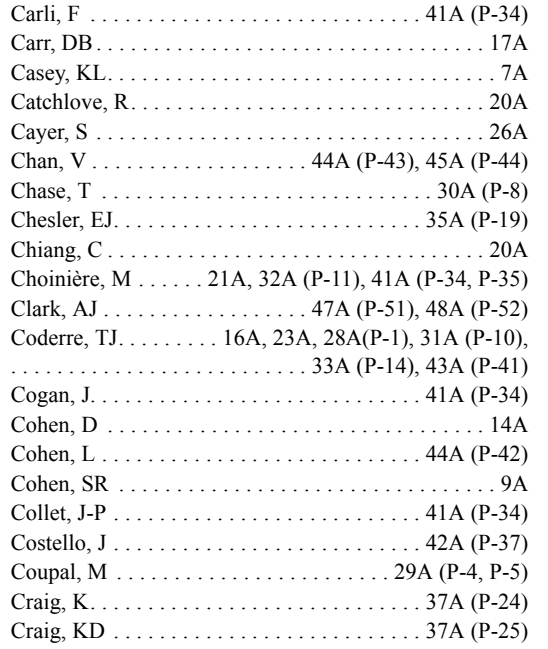




\begin{tabular}{|c|c|c|}
\hline D & 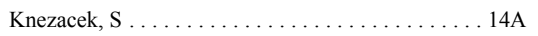 & $\mathbf{R}$ \\
\hline$\ldots \ldots \ldots \ldots 33 \mathrm{~A}(\mathrm{P}-16)$ & 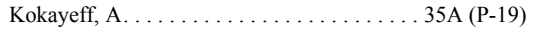 & Ragsdale, D \\
\hline$\ldots \ldots \ldots \ldots 42 \mathrm{~A}(\mathrm{P}-37)$ & 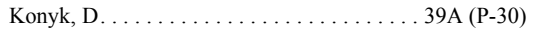 & Rankin, AL . \\
\hline Davies, KD. . . & $\ldots \ldots \ldots 37 \mathrm{~A}(\mathrm{P}-24)$ & Reid, AR .. \\
\hline$\ldots \ldots \ldots \ldots \ldots, 7 \mathrm{~A}$ & ...... 39A (P-29) & $\ldots .42 \mathrm{~A}(\mathrm{P}-37)$ \\
\hline$\ldots 32 \mathrm{~A}(\mathrm{P}-11)$ & $\ldots \ldots \ldots \ldots \ldots+35 \mathrm{~A}(\mathrm{P}-20)$ & Reissing, E . \\
\hline$\ldots \ldots \ldots \ldots \ldots 11 \mathrm{~A}$ & & Richman, S. . \\
\hline$\ldots \ldots \ldots \ldots \ldots \ldots 11 \mathrm{~A}$ & $\mathbf{L}$ & . $33 \mathrm{~A}(\mathrm{P}-14)$ \\
\hline$\ldots \ldots 38 \mathrm{~A}(\mathrm{P}-28)$ & Labarre, M....... 11A, 29A (P-4, P-5), 32A (P-13) & $.11 \mathrm{~A}, 29 \mathrm{~A}(\mathrm{P}-5)$ \\
\hline 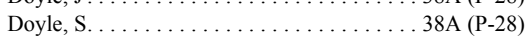 & Labrecque, J . . . . . . . . . . . & ... 41A (P-34) \\
\hline Dray, A $\ldots \ldots \ldots \ldots \ldots$ 15A, 29A (P-5), 32A (P-12), & LaChapelle, D.. & $\ldots \ldots \ldots 28 \mathrm{~A}-2)$ \\
\hline (P-17, P-18) & $\ldots \ldots \ldots \ldots 47 \mathrm{~A}(\mathrm{P}-50)$ & ……3 37A (P-26) \\
\hline . & $\ldots \ldots \ldots 12 \mathrm{~A}, 35 \mathrm{~A}(\mathrm{P}-19)$ & $\ldots 41 \mathrm{~A}(\mathrm{P}-34)$ \\
\hline Ducharme, J . & $\ldots \ldots \ldots \ldots+40 \mathrm{~A}(\mathrm{P}-33)$ & . 18A, 39A (P-30) \\
\hline 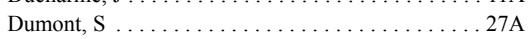 & Lavoie, J-L... & $\ldots . .31$ A (P-9) \\
\hline \multirow{2}{*}{$\ldots \ldots \ldots \ldots \ldots, \ldots \mathrm{A}$} & $\ldots \ldots 32 \mathrm{~A}(\mathrm{P}-12)$ & \multirow[t]{2}{*}{ Kuan, 11 . } \\
\hline & $\ldots \ldots 38 \mathrm{~A}(\mathrm{P}-27)$ & \\
\hline $\mathbf{E}$ & LeFort, SM.... & $\ldots 29 \mathrm{~A}(\mathrm{P}-5)$ \\
\hline$\ldots \ldots$ 47A (P-50) & $\ldots \ldots \ldots \ldots \ldots \ldots \ldots+\ldots,(\mathrm{P}-58)$ & Samoluk, SB \\
\hline …37A (P-26), 48A (P-53) & … & Saper, Z.... \\
\hline 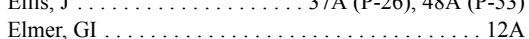 & Lemaire, S... & . 24A, 29A (P-3), 30A (P-8), \\
\hline Esplen, MJ ............ & $\ldots 29 \mathrm{~A}(\mathrm{P}-3)$ & ... 47A (P-51), 48A (P-52) \\
\hline Esser, MI ... & $\ldots \ldots \ldots \ldots \ldots 39 \mathrm{~A}(\mathrm{P}-29)$ & $\ldots \ldots \ldots 33 \mathrm{~A}(\mathrm{P}-14)$ \\
\hline ESSEL, 1 VII & $\ldots \ldots \ldots \ldots 24 \mathrm{~A}, 30 \mathrm{~A}(\mathrm{P}-6)$ & $\ldots \ldots \ldots 11 \mathrm{~A}, 29 \mathrm{~A}(\mathrm{P}-4)$, \\
\hline $\mathbf{F}$ & $\ldots . .47 \mathrm{~A}(\mathrm{P}-51), 48 \mathrm{~A}(\mathrm{P}-52)$ & 43A (P-40, P-41), 44A (P-42), \\
\hline$\ldots \ldots \ldots \ldots 41 \mathrm{~A}(\mathrm{P}-35)$ & & 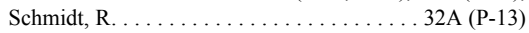 \\
\hline …......26A, 27A & M & Schroder, $\mathrm{C} \ldots \ldots \ldots \ldots \ldots \ldots \ldots \ldots \ldots \ldots \ldots \ldots \ldots \ldots$ \\
\hline \multirow{2}{*}{ 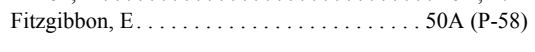 } & MacKinnon, E.. & $\ldots 35 \mathrm{~A}(\mathrm{P}-19)$ \\
\hline & MacMaster, L .. & .......11A \\
\hline \multirow{2}{*}{$\begin{array}{l}\text { G } \\
\ldots 44 \mathrm{~A}(\mathrm{P}-43), 45 \mathrm{~A}(\mathrm{P}-44),\end{array}$} & 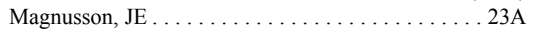 & $\ldots 50 \mathrm{~A}(\mathrm{P}-58)$ \\
\hline & $\ldots \ldots \ldots \ldots 22 \mathrm{~A}, 23 \mathrm{~A}$ & $\ldots \ldots 16 \mathrm{~A}$ \\
\hline ... & Maki-Carolli, P . & $\ldots 35 \mathrm{~A}(\mathrm{P}-21)$ \\
\hline .......26A & $\ldots \ldots \ldots \ldots \ldots 40 \mathrm{~A}(\mathrm{P}-33)$ & ......2. $21 \mathrm{~A}$ \\
\hline$\ldots \ldots \ldots \ldots 48 \mathrm{~A}(\mathrm{P}-52)$ & $\ldots \ldots \ldots \ldots 33 \mathrm{~A}(\mathrm{P}-15)$ & Snijedlaar, DG. . \\
\hline$\ldots \ldots \ldots \ldots \ldots 49 \mathrm{~A}(\mathrm{P}-56)$ & $\ldots \ldots .34 \mathrm{~A}(\mathrm{P}-18)$ & Snutch, TP ..... \\
\hline$\ldots \ldots \ldots \ldots 33 \mathrm{~A}(\mathrm{P}-15)$ & $\ldots \ldots \ldots \ldots 40 \mathrm{~A}(\mathrm{P}-33)$ & $\ldots 28 \mathrm{~A}(\mathrm{P}-1)$ \\
\hline$\ldots \ldots \ldots \ldots \ldots 11 \mathrm{~A}$ & $\ldots \ldots \ldots \ldots \ldots 37 \mathrm{~A}(\mathrm{P}-26)$ & $\ldots 39 \mathrm{~A}(\mathrm{P}-29)$ \\
\hline Gibbins, SA $\ldots \ldots \ldots \ldots \ldots \ldots \ldots \ldots \ldots$ (P-22) & $\ldots \ldots \ldots \ldots \ldots \ldots 17 \mathrm{~A}$ & $\ldots . .40 \mathrm{~A}(\mathrm{P}-32)$ \\
\hline Gilbert, DG. ... & 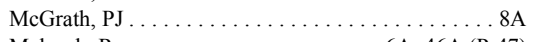 & $36 \mathrm{~A}(\mathrm{P}-22, \mathrm{P}-23), 42 \mathrm{~A}(\mathrm{P}-36, \mathrm{P}-37)$ \\
\hline$\ldots \ldots \ldots \ldots \ldots 13 \mathrm{~A}$ & Melzack, $R \ldots \ldots \ldots \ldots \ldots \ldots$ 6A, 46A (P-47) & …............. $8 \mathrm{~A}$ \\
\hline$\ldots \ldots \ldots \ldots \ldots 40 \mathrm{~A}(\mathrm{P}-32)$ & Menard, $\mathrm{D} \ldots \ldots \ldots \ldots \ldots \ldots \ldots \ldots \ldots \ldots \ldots \ldots$ & Stewart, N .... \\
\hline 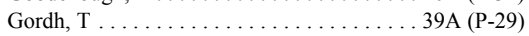 & $\ldots \ldots \ldots \ldots \ldots \ldots 32 \mathrm{~A}(\mathrm{P}-12)$ & 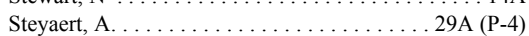 \\
\hline$\ldots \ldots \ldots+25 \mathrm{~A}$ & $\ldots \ldots+\cdots 21 \mathrm{~A}$ & St-Onge, $\mathrm{S} \ldots \ldots \ldots \ldots \ldots \ldots \ldots$ 11A, 29A (P-5) \\
\hline Gosselin, $\mathrm{M} \ldots \ldots \ldots \ldots \ldots \ldots \ldots \ldots 29 \mathrm{~A}(\mathrm{P}-4)$ & $\ldots \ldots \ldots \ldots \ldots+12 \mathrm{~A}$ & Sullivan, MJL. . \\
\hline \multirow[t]{2}{*}{ Green, $\mathrm{S} \ldots \ldots \ldots \ldots \ldots \ldots \ldots \ldots \ldots \ldots \ldots \ldots \ldots$ 45A (P-45) } & Middleton, J..... & Summer, $\mathrm{G} \ldots \ldots . . .$. \\
\hline & $\ldots \ldots \ldots \ldots \ldots \ldots 35 \mathrm{~A}(\mathrm{P}-19)$ & \multirow[t]{2}{*}{ 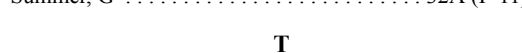 } \\
\hline $\mathbf{H}$ & … & \\
\hline$\ldots \ldots .39 \mathrm{~A}(\mathrm{P}-31)$ & Morinville, $\mathrm{A} \ldots \ldots \ldots \ldots \ldots \ldots \ldots \ldots \ldots \ldots \ldots$ & $\ldots \ldots \ldots \ldots 35 \mathrm{~A}(\mathrm{P}-21)$ \\
\hline Hadjistavropoulos, HD . & Moulin, D $\ldots \ldots \ldots \ldots \ldots \ldots \ldots \ldots \ldots$ 49A (P-57) & $\ldots \ldots .35 \mathrm{~A}(\mathrm{P}-21)$ \\
\hline Hadjistavropoulos, T . . & Moulin, DE. $\ldots \ldots \ldots \ldots \ldots \ldots \ldots \ldots \ldots \ldots \ldots \ldots$ & $\ldots \ldots \ldots \ldots 11 \mathrm{~A}$ \\
\hline$\ldots \ldots \ldots \ldots \ldots 10 \mathrm{~A}$ & & $\ldots .39 \mathrm{~A}(\mathrm{P}-30)$ \\
\hline ... W. 15A, 48A (P-54) & $\mathbf{N}$ & Thomas, MR. . . \\
\hline Hefferan, MP................... 30A (P-6) & Naeini, RS $\ldots \ldots \ldots \ldots \ldots \ldots \ldots \ldots \ldots \ldots \ldots \ldots,(\mathrm{P}-2)$ & $\ldots$. . 46A (P-49) \\
\hline Henning, $K \ldots \ldots \ldots \ldots \ldots \ldots \ldots \ldots .36$. $(\mathrm{P}-23)$ & $\ldots \ldots \ldots \ldots \ldots \ldots \ldots+36 \mathrm{~A}(\mathrm{P}-23)$ & $\ldots \ldots \ldots 34(\mathrm{P}-18)$ \\
\hline Henriques, SM. . . . . . . . . . . . . . . . 38A (P-28) & 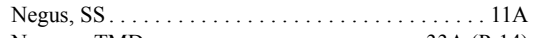 & (............. \\
\hline Henry, JL $\ldots \ldots \ldots \ldots 15 \mathrm{~A}, 28 \mathrm{~A}(\mathrm{P}-2), 33 \mathrm{~A}$ (P-16), & Nguyen, TMD $\ldots \ldots \ldots \ldots \ldots \ldots \ldots \ldots \ldots \ldots \ldots \ldots \ldots+33 \mathrm{~A}(\mathrm{P}-14)$ & 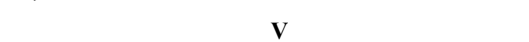 \\
\hline Henwood, P................... 48A (P-53) & 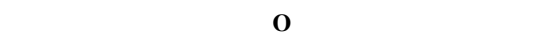 & $\ldots \ldots \ldots \ldots 49 \mathrm{~A}(\mathrm{P}-56)$ \\
\hline Héon, $\mathrm{H} \ldots \ldots \ldots \ldots \ldots \ldots \ldots \ldots \ldots \ldots \ldots \ldots \ldots \ldots$ & $\ldots \ldots \ldots \ldots \ldots 15 \mathrm{~A}$ & $\begin{array}{l}\ldots \ldots \ldots \ldots \ldots 40 \mathrm{~A}(\mathrm{P}-32) \\
\ldots \ldots \ldots \ldots \ldots \ldots\end{array}$ \\
\hline Heughan, CE $\ldots \ldots \ldots \ldots \ldots \ldots \ldots \ldots \ldots \ldots$ 30A (P-8) & (P-46) & $\begin{array}{l}y^{2} \\
\ldots \ldots \ldots \ldots 41 \mathrm{~A}(\mathrm{P}-34)\end{array}$ \\
\hline$\ldots \ldots \ldots \ldots 40 \mathrm{~A}(\mathrm{P}-32)$ & $\ldots \ldots \ldots \ldots \ldots 30 \mathrm{P}-6)$ & Vézina, L . . . . . \\
\hline$\ldots \ldots \ldots \ldots 36 \mathrm{~A}(\mathrm{P}-22)$ & O'Rielly, DD .................... 30A (P-7) & (P-58) \\
\hline (... & 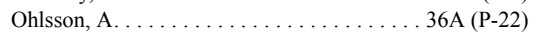 & 39A (P-31), 40A (P-32) \\
\hline Hong, $Y \ldots \ldots \ldots \ldots \ldots \ldots \ldots \ldots \ldots \ldots \ldots \ldots \ldots \ldots(\mathrm{P}-17)$ & 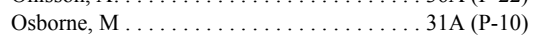 & \\
\hline Hosey, DH. . . . $\ldots \ldots \ldots \ldots \ldots \ldots . . . \ldots 44 \mathrm{~A}(\mathrm{P}-43)$ & & $\mathbf{W}$ \\
\hline$\ldots \ldots \ldots \ldots \ldots \ldots 15 \mathrm{~A}$ & $\mathbf{P}$ & $\ldots \ldots 29 \mathrm{~A}(\mathrm{P}-4)$ \\
\hline & $\ldots \ldots \ldots \ldots \ldots+45 \mathrm{~A}(\mathrm{P}-46)$ & $\ldots \ldots .35 \mathrm{~A}(\mathrm{P}-20)$ \\
\hline I & (.2. & $\ldots$. 11A, 29A (P-4, P-5) \\
\hline$\ldots \ldots \ldots \ldots 14 \mathrm{~A}$ & Parent, $R \ldots \ldots \ldots \ldots \ldots \ldots \ldots 2 \mathrm{~A}, 27 \mathrm{~A}$ & $\ldots \ldots \ldots 37 \mathrm{~A}(\mathrm{P}-24)$ \\
\hline & 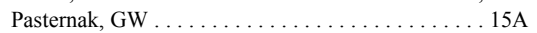 & … 49A (P-56) \\
\hline $\mathbf{J}$ & 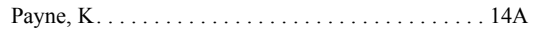 & $\ldots \ldots \ldots 42 \mathrm{~A}(\mathrm{P}-36, \mathrm{P}-37)$ \\
\hline$\ldots \ldots \ldots . \ldots 36 \mathrm{~A}(\mathrm{P}-23)$ & Payne, $R \ldots \ldots \ldots \ldots \ldots \ldots \ldots \ldots \ldots$ & ...... 11A, 29A (P-5) \\
\hline - & Payza, K . . . . . . & $\ldots \ldots 29 \mathrm{~A}(\mathrm{P}-3)$ \\
\hline … $7 \mathrm{~A}, 35 \mathrm{~A}(\mathrm{P}-20)$ & Pedigas, $\mathrm{K} \ldots \ldots \ldots \ldots \ldots \ldots \ldots \ldots \ldots \ldots \ldots \ldots \ldots$ & 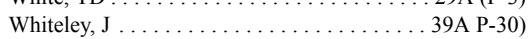 \\
\hline ... 11A, 29A (P-5) & Perkins, M . . . . . . . 10A, 11A, 34A (P-17, P-18), & ......... $35 \mathrm{~A}(\mathrm{P}-19)$ \\
\hline … & $\ldots \ldots \ldots \ldots+\ldots 49 \mathrm{~A}(\mathrm{P}-56)$ & …... 43A (P-40, P-41), \\
\hline & Peterson, LR $\ldots \ldots \ldots \ldots \ldots \ldots \ldots \ldots$ 49A (P-55) & $\ldots 44 \mathrm{~A}(\mathrm{P}-42), 45 \mathrm{~A}(\mathrm{P}-44)$, \\
\hline $\mathbf{K}$ & Petryshen, $\mathrm{P} \ldots \ldots \ldots \ldots \ldots \ldots \ldots \ldots$ 36A (P-23) & \\
\hline$\ldots \ldots \ldots \ldots+40 \mathrm{~A}(\mathrm{P}-33)$ & $\ldots \ldots \ldots \ldots \ldots \ldots 37 \mathrm{~A}(\mathrm{P}-25)$ & 111 \\
\hline Katz, J . . . . . . . 20A, 35A (P-21), 42A (P-37), & .... 36A (P-22) & $\ldots \ldots \ldots \ldots \ldots 11 \mathrm{~A}$ \\
\hline 43A (P-39, P-40, P-41), 44A (P-42, P-43), & 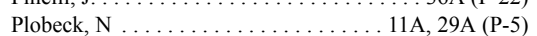 & $\ldots \ldots \ldots 33 \mathrm{~A}(\mathrm{P}-14, \mathrm{P}-16)$ \\
\hline 2. & 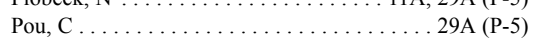 & Yue, S-Y.......... \\
\hline 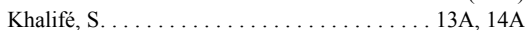 & $\ldots .31 \mathrm{~A}(\mathrm{P}-9)$ & $\mathbf{Z}$ \\
\hline Kieffer, BL... & 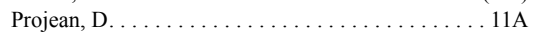 & $\ldots \ldots \ldots \ldots 49 \mathrm{~A}(\mathrm{P}-57)$ \\
\hline$\ldots 35 \mathrm{~A}(\mathrm{P}-21)$ & 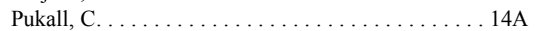 & $\ldots \ldots \ldots \ldots 29 A(\mathrm{P}-5)$ \\
\hline
\end{tabular}




\section{ERRATUM}

In the Spring 2001 supplement to Pain Research \& Management, the abstracts for Speakers 2 and 3 in the Concurrent Special Research Symposia \#1 - Basic research: Ion channels (Pain Res Manage 2001;6[Suppl A]:16A-17A) - were transposed. The abstract attributed to Speaker 2, David Ragsdale, entitled "Structure and molecular pharmacology of the voltage-gated sodium channel, an important target for analgesic agents", is actually the abstract for Speaker 3, Terrance P Snutch, entitled "A new class of N-type calcium channel blockers as pain therapeutics”. Likewise, the abstract attributed to Speaker 3 is actually the abstract for Speaker 2 . 


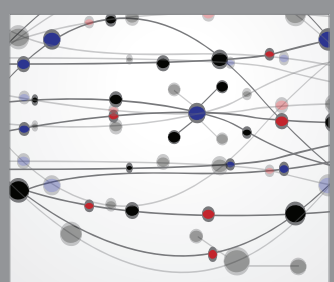

The Scientific World Journal
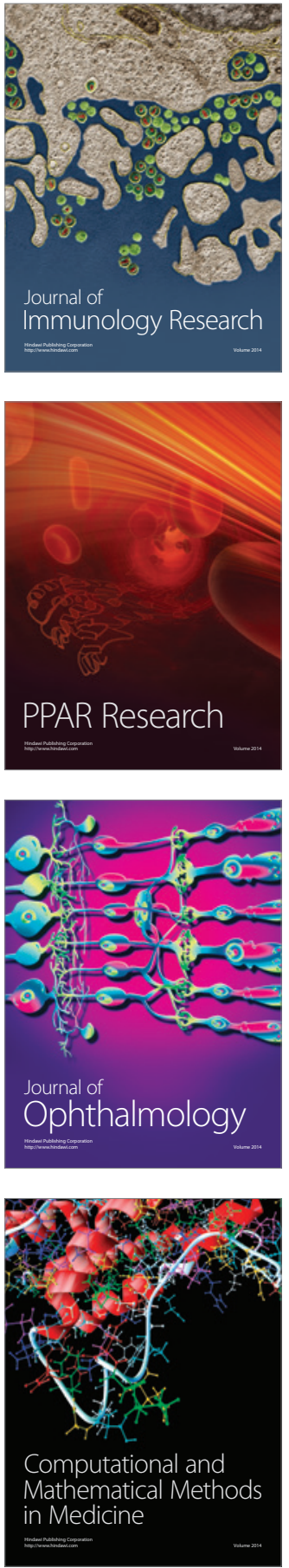

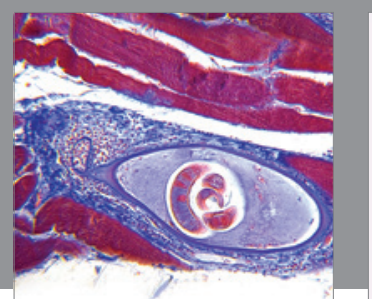

Gastroenterology Research and Practice

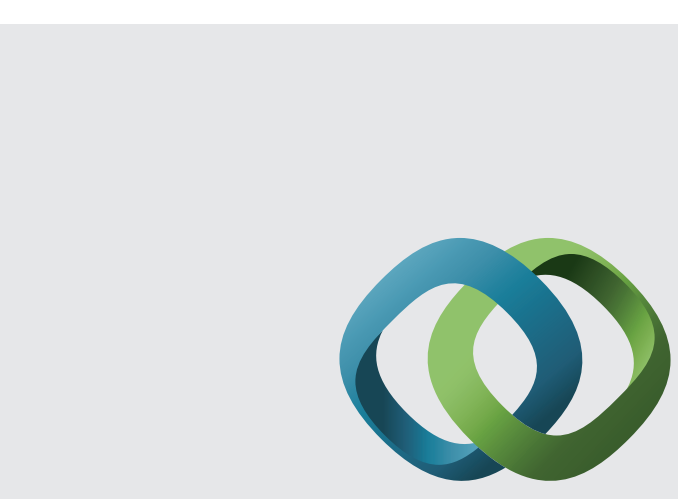

\section{Hindawi}

Submit your manuscripts at

http://www.hindawi.com
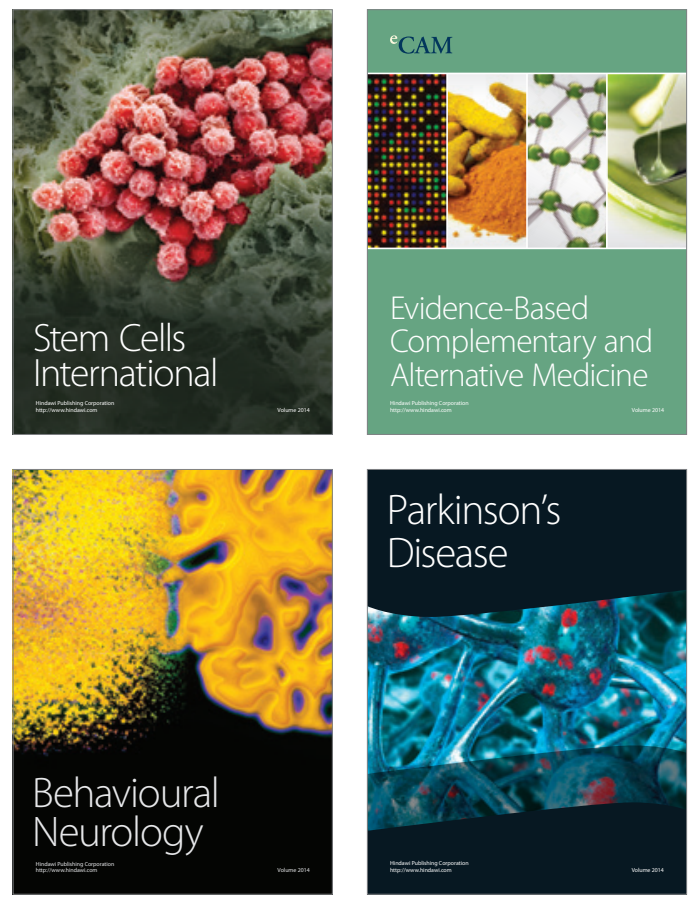
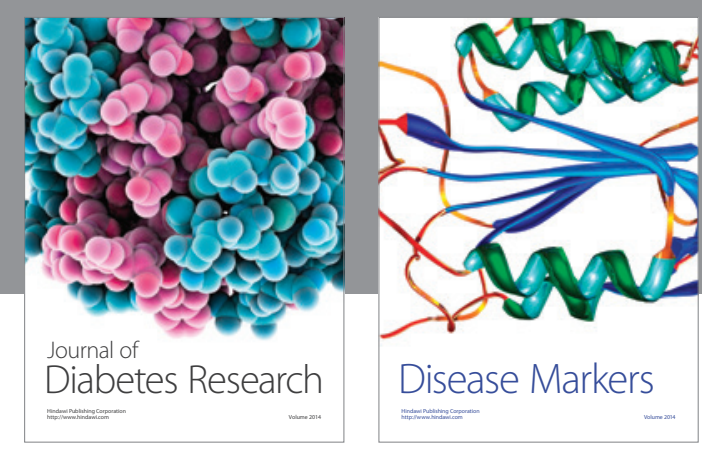

Disease Markers
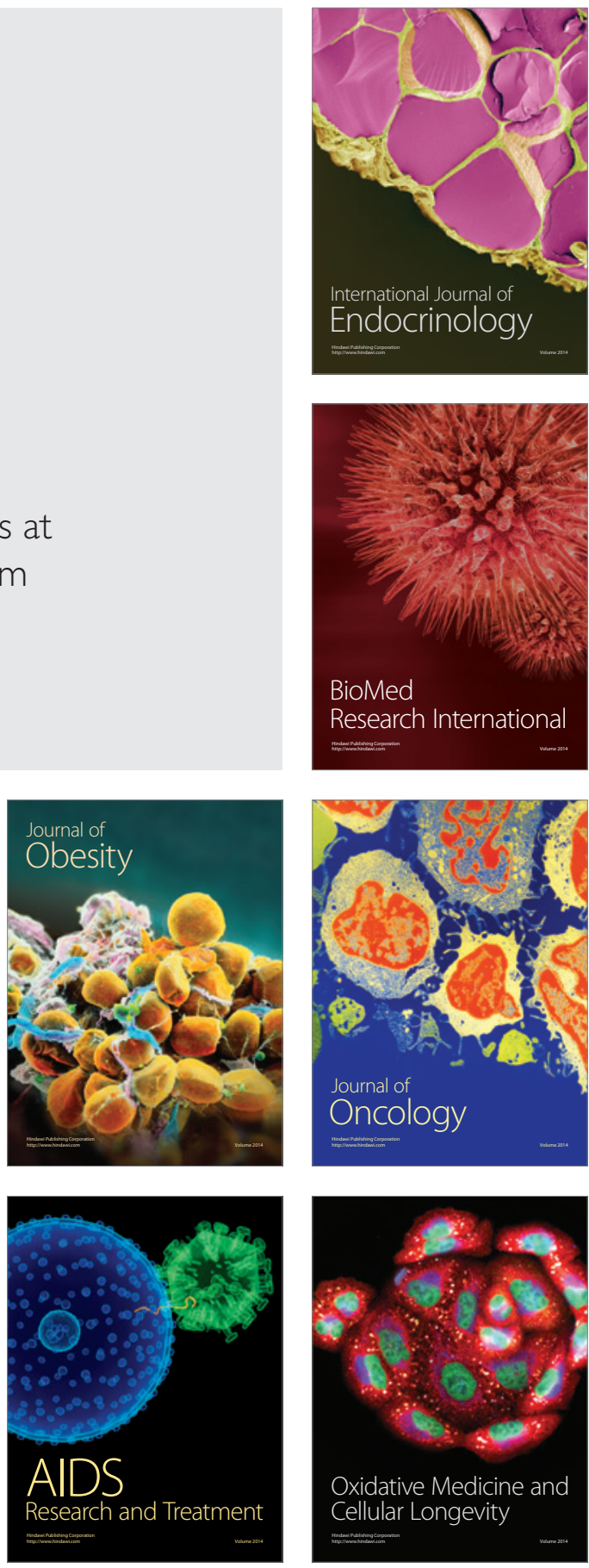